UNIVERSIDADE DE SÃO PAULO

INSTITUTO DE ASTRONOMIA, GEOFÍSICA E CIÊNCIAS

ATMOSFÉRICAS

DEPARTAMENTO DE CIÊNCIAS ATMOSFÉRICAS

Humberto Martins Ramos

PROJEÇÕES CLIMÁTICAS REGIONAIS

EM ALTA RESOLUÇÃO: TENDÊNCIAS NO VENTO

E POTENCIAL EÓLICO DO NORDESTE DO BRASIL 

Humberto Martins Ramos

\title{
PROJEÇÕES CLIMÁTICAS REGIONAIS EM ALTA RESOLUÇÃO: TENDÊNCIAS NO VENTO E POTENCIAL EÓLICO DO NORDESTE DO BRASIL
}

\begin{abstract}
Dissertação apresentada ao
Departamento de Ciências

Atmosféricas do Instituto de

Astronomia, Geofísica e Ciências

Atmosféricas da Universidade de São

Paulo como requisito parcial para obtenção do título de Mestre em Ciências.
\end{abstract}

Área de Concentração: Meteorologia Orientadora: Prof ${ }^{a}$ Dr ${ }^{a}$ Rosmeri Porfírio da Rocha.

Versão Corrigida. 0 original encontra-se disponível na Unidade. 
Dedico este trabalho a todos que o lerem. 


\section{AGRADECIMENTOS}

À minha orientadora, Prof. ${ }^{a}$ Dr. ${ }^{a}$ Rosmeri Porfírio da Rocha, pela parceria, apoio e confiança ao longo deste projeto.

Ao Conselho Nacional de Desenvolvimento Científico e Tecnológico (CNPq), sob o processo 133424/2020-0 pelo apoio financeiro concedido.

Aos professores e demais funcionários do Instituto de Astronomia, Geofísica e Ciências Atmosféricas (IAG), por partilharem do seu tempo e conhecimento.

Aos meus amigos e familiares que fizeram parte desta jornada - Muito obrigado. 



\section{RESUMO}

Este estudo avaliou o impacto das mudanças climáticas nos ventos e no potencial eólico no Nordeste (NEB) do Brasil a fim de fornecer subsídios para o panejamento energético no futuro. Para isso, foi utilizado um conjunto de projeções climáticas em alta resolução espacial ( $25 \mathrm{~km}$ de espaçamento de grade) realizadas com o Regional Climate Model version 4 (RegCM4) como parte do CORDEX-CORE. Essas projeções foram forçadas por três modelos globais do CMIP5 (Coupled Model Intercomparison Project phase 5) no cenário RCP8.5. A análise concentrou-se em três períodos: 19852014 (clima presente), 2031-2060 (futuro próximo) e 2070-2099 (futuro distante). Para o clima presente, avaliou-se o desempenho das simulações através de comparações com a reanálise ERA-Interim. Em geral, as simulações reproduzem intensidade dos ventos a $100 \mathrm{~m}$ de altura na parte central da América do Sul similar à reanálise, mas simulam ventos mais intensos na porção leste do Brasil (especialmente na região sudeste, bias superior à $3 \mathrm{~ms}^{-1}$ ), e na Argentina e na cordilheira Andina. O RegCM4 também simula ventos mais fortes na extremidade oeste do NEB. Para os períodos futuros, as projeções indicam um aumento na magnitude dos ventos e na densidade de potência do vento (Wind Power Density, WPD) em diversos locais do Brasil. No NEB, projeta-se aumento de velocidade ao longo de todo ano nos subdomínios costeiros (leste e norte), sendo mais intenso e estatisticamente significativo no outono (março-maio) do futuro distante. Nesta estação, poderá ocorrer uma amplificação na WPD de $35,34 \%$ no norte do Ceará, $28,20 \%$ no norte do Piauí-Maranhão e $22,84 \%$ no leste do NEB. Para a estação seca (junho-novembro), projeta-se aumento de velocidade menor, mas ainda assim, estatisticamente significativo. Tais resultados indicam, do ponto de vista eólico, que a relação de complementaridade hídrico-eólica seguirá viável no futuro. A análise da variabilidade dos ventos, com base no modelo probabilístico de Weibull, indica que os ventos deverão tornar-se mais constantes (variáveis) no leste e norte do NEB (interior da Bahia), dado o aumento (redução) no parâmetro de forma. Por fim, as estimativas do potencial eólico do NEB, considerando um aerogerador de $2 \mathrm{MW}$ de potência, projetam um aumento na Produção Anual de Energia (Annual Energy Production, AEP) e no Fator de Capacidade (Capacity Factor, $\mathrm{CF}$ ) em todo o NEB. Este cenário seria extremamente otimista para o setor eólico, pois aponta que as mudanças climáticas afetarão positivamente a geração de energia eólica no NEB. 
Palavras-chave: Ventos. Energia eólica. Projeções climáticas. RegCM4. Nordeste do Brasil. 


\begin{abstract}
This study evaluated the impact of climate change on the winds and the wind energy potential of the northeast (NEB) of Brazil, in order to support energy management in the future. For this, a set of high-resolution regional climate projections $(25 \mathrm{~km}$ grid spacing) from the CORDEX-CORE initiative was used. The projections were carried out with the Regional Climate Model version 4 (RegCM4) and forced by three CMIP5 (Coupled Model Intercomparison Project phase 5) Global Circulation Models (GCMs) in the RCP8.5 scenario. The analysis focused on three periods: 1985-2014 (present climate), 2031-2060 (near future) and 2070-2099 (far future). In the present climate, the performance of the simulations was evaluated through comparison with the ERAInterim reanalysis. In general, the simulations realistically reproduce the wind intensity at $100 \mathrm{~m}$ height in central South America but simulate stronger winds in eastern Brazil (especially in the southeast region, with 3,0 $\mathrm{ms}^{-1}$ bias), Argentina and the Andes Mountains. RegCM4 also simulates stronger winds over western NEB. For future climate, the projections indicate an increase in wind magnitude and Wind Power Density (WPD) in several parts of Brazil. For NEB, the increase in wind magnitude is projected throughout the whole year in coastal (east and north) subdomains. This increase is greater and statistically significant during austral autumn (march-may) in the far future period. In this season, the projections indicate a WPD amplification of $35,34 \%$ in north of Ceará, $28,20 \%$ in north of Piauí-Maranhão, and 22,84\% in east of the NEB. For the dry period (June-November) the increase in WPD is small but still statistically significant. From the wind energy point of view, the projections are indicating that the hydro-wind complementarity relationship will remain possible in the future climate. Wind variability analyses based on the Weibull probabilistic model projects more constant (variable) winds in east and north of the NEB (interior of Bahia), given the increase (reduction) in the shape parameter. Finally, the projections of wind energy potential, estimated for the $2 \mathrm{MW}$ Enercon wind turbine, indicate an increase in the Annual Energy Production (AEP) and Capacity Factor (CF) throughout NEB. This scenario is extremely optimistic for the wind energy industry, as it points out that climate change will positively affect the generation of wind energy in NEB.
\end{abstract}

Key words: Winds. Wind energy. Climate projections. RegCM4. Northeast of Brazil. 



\section{LISTA DE FIGURAS}

Figura 1 - Representação esquemática da circulação geral da atmosfera. Entre o equador e os polos destacam-se três células de circulação (Hadley, Ferrel e Polar) originadas pelo aquecimento diferencial da superfície e pela rotação da Terra. Dentre os regimes de ventos resultantes estão: ventos alísios (trade winds) de nordeste e sudeste, confluentes na região tropical; ventos de oeste (westerlies) em latitudes médias; jato subtropical (subtropical jet stream) e jato polar (polar jet stream). Fonte: Adaptado de (WUEBBLES; FAHEY; HIBBARD, 2017).

Figura 2 - Principais sistemas meteorológicos atuantes no clima da AS: Zona de Convergência Intertropical (Intertropical Convergence Zone, ZCIT); Zona de Convergência do Atlântico Sul (South Atlantic Convergence Zone, ZCAS); Jato de Baixos Níveis da América do Sul (South American Low-Level Jet, SALLJ); Baixa do Chaco (Chaco Low, CL); Complexo Convectivo de Mesoescala (Mesoscale Convective System, MCS). Linhas vermelhas representam a circulação de verão (DJF) e azuis de inverno (JJA). Fonte: (CAl et al., 2020). .29

Figura 3 - Matriz elétrica brasileira em 2019. Inclui a oferta de energia de todas as fontes destinadas a fins elétricos. Fonte: Adaptado de (EPE, 2020).

Figura 4 - Evolução da capacidade instalada (MW) da energia eólica no Brasil ao longo dos anos. Fonte: Adaptado de ABEEÓLICA (2020).

Figura 5 - Produção mensal de energia produzida por uma usina eólica hipotética de 3 GW de potência instalada no Nordeste do Brasil (esquerda). Afluência natural no reservatório da usina de sobradinho durante o período de 1931 a 1992 (direita). Fonte: Adaptado de Amarante et al. 2000.

Figura 6 - Representação esquemática das principais mudanças no clima da AS previstas por diversos estudos para o final do século XXI (2070 a 2100). Fonte: Adaptado de Ambrizzi et al. (2019). 39 
Figura 7 - Esquerda: Domínio utilizado nas simulações climáticas sugerido pelo CORDEX para a AS (Fonte: Adaptado de (SINES et al., 2018)). Direita: Subdomínios analisados no NEB (C1, C2, C3 e C4) semelhantes à Brito (2018). 44

Figura 8 - Distribuições de probabilidade de Weibull em diferentes regimes de ventos. Esquerda: variações de $k$ para $c=1$; direita: variações de c para $k=2$. Fonte: Adaptado de Silva (2003). 49

Figura 9 - Climatologia sazonal do vento a $100 \mathrm{~m}$ de altura $(m s-1)$ para o período presente (1985 a 2014), representados pela reanálise ERA-Interim (coluna esquerda), RegEns (coluna central) e diferença RegEns menos ERAI (coluna direita). 56

Figura 10 - Bias sazonal do vento a $100 \mathrm{~m}$ ( $m s-1)$ no período presente (1985 a 2014) das simulações: RegHAD (esquerda), RegMPI (centro) e RegESM (direita). 57

Figura 11 - Painel superior: Ciclo anual da magnitude do vento a $100 \mathrm{~m}$ de altura ( $\mathrm{ms}-$ 1) para os quatro subdomínios do NEB simulado pelas simulações individuais (RegHAD, RegMPI e RegESM), ensemble (RegEns), simulação controle (RegEI) e reanálise (ERAl). Painel inferior: Diagrama de Taylor das séries temporais utilizadas no painel superior. 58

Figura 12 - Séries temporais de magnitude do vento a $100 \mathrm{~m}$ de altura $(m s-1)$ do RegEns para as quatro sub-regiões analisadas no NEB (C1, C2, C3 e C4) no período presente (1985 a 2014). O painel superior a) contém as séries temporais antes aplicação do bias correction, e o painel b) após. 61

Figura 13 - Boxplot das séries temporais de magnitude do vento a $100 \mathrm{~m}$ do RegEns para os quatro subdomínios analisados no NEB (C1, C2, C3 e C4) no período presente (1985 a 2014). 62

Figura 14 - Tendências (futuro menos presente) sazonais da magnitude do vento (ms - 1) a $100 \mathrm{~m}$ de altura. Na coluna da esquerda são apresentadas as tendências no futuro próximo (2031-2060) e a da direita as tendências no futuro distante (20702099) 65 
Figura 15 - Idem a Figura 14, mas para a WPD. Neste caso, são tendências relativas expressas em porcentagem (\%).

Figura 16 - Idem a Figura 15, mas para o domínio NEB. ( Neste domínio a escala percentual varia de -50 a $50 \%$ ).

Figura 17 - Tendências mensais relativas (\%) de WPD nos quatro subdomínios (C1, C2, C3 e C4) do NEB para o futuro próximo (coluna esquerda) e futuro distante (coluna direita). O triângulo preto indica os meses em que a mudança é estaticamente significativa ao nível de $95 \%$. As caixas horizontais exibem a tendência projetada para o período seco, realçado pelo sombreado cinza. .70

Figura 18 - Séries temporais da velocidade do vento $(m s-1)$ a $100 \mathrm{~m}$ de altura da projeção climática no RCP8.5 do ensemble do RegCM4 para o período seco (vermelho) e outono (azul). A reta representa o ajuste linear das séries temporais..72

Figura 19 - Séries temporais (1985 a 2099) de anomalias da velocidade do vento a $100 \mathrm{~m}$ (sem tendência e sem a média anual) no período seco das projeções do RegCM4 ensemble. Em cada caixa, a linha horizontal tracejada superior (inferior) representa o limiar do percentil $90 \%$ (10\%). Os pontos vermelhos (azuis) indicam os anos em que a anomalia de velocidade do vento esteve acima (abaixo) deste limiar.

Figura 20 - Idem a Figura 19, mas para o outono. .73

Figura 21 - Distribuição de probabilidade dos valores mensais de velocidade do vento a $100 \mathrm{~m}$ de altura da ERA-Interim no período 1985 a 2014 para os subdomínios C1, C2, C3 e C4. O ajuste da PDFw às medidas de vento está representado pela curva em vermelho e as estatísticas ( $R^{2}$, parâmetros de forma $k$ e de escala c) do ajuste sumarizados no canto esquerdo superior. .77

Figura 22 - Idem a Figura 21, mas para o RegEns. .77

Figura 23 - Climatologia sazonal do vento a $100 \mathrm{~m}$ de altura para o período presente (1985 a 2014), representados pela reanálise ERA-Interim (coluna esquerda), RegEI (coluna central) e diferença entre RegEI e ERAI (coluna direita). .98 
Figura 24 - Curva de potência do aerogerador E-82 2 MW da ENERCON. Fonte: (SILVEIRA, 2011).

Figura 25 - Distribuição de probabilidade dos valores mensais de velocidade do vento a $100 \mathrm{~m}$ de altura do RegEns para o futuro próximo (2031 a 2060) para os subdomínios $\mathrm{C} 1, \mathrm{C} 2, \mathrm{C} 3$ e C4. O ajuste da PDFw às medidas de vento está representado pela curva em vermelho e as estatísticas ( $R^{2}$, parâmetros de forma $k$ e de escala c) do ajuste sumarizados no canto esquerdo superior. 99

Figura 26 - Idem a Figura 24, mas para o futuro distante. 100 


\section{LISTA DE TABELAS}

Tabela 1 - Média da velocidade do vento $(m s-1)$ a $100 \mathrm{~m}$ de altura durante os meses de outono nos três períodos analisados: presente (1985-2014), futuro próximo (20312060) e futuro distante (2070-2099). Em negrito estão destacados os subdomínios cuja velocidade se aproximará da mínima operável, e o asterisco $\left(^{*}\right)$ indica os locais que sofrerão maior aumento na velocidade em relação ao período presente. .71

Tabela 2 - Número de episódios extremos de vento a 100 m de altura do RegEns para o período presente (1985 a 2014), futuro próximo (Próximo, 2031-2060) e futuro distante (Distante, 2070 a 2099) nos quatro subdomínios do NEB. Extremos positivos estão representados pelo símbolo + e os negativos pelo símbolo .75

Tabela 3 - Semelhante a Tabela 2, mas para o outono. .75

Tabela 4 - Valores de $\mathrm{R}^{2}$ obtidos com a ERAl e o RegEns para os três períodos analisados: presente (1985 a 2014), futuro próximo (Próximo, 2031 a 2060) e futuro distante (Distante, 2071 a 2099). .79

Tabela 5 - Valores dos parâmetros de forma (k) e de escala (c) obtidos da ERA-Interim (ERAI) e com o RegEns nos três períodos analisados: presente (pres), futuro próximo (Próx) e futuro distante (Dist). Valores entre parênteses indicam diferença entre climas futuro e presente do RegEns.

Tabela 6 - Estimativas de AEP e CF, considerando o aerogerador de 2 MW de potência da Enercon, realizadas com o RegCM4 ensemble nos três períodos estudados: presente (1985-2014), futuro próximo (2031-2060) e futuro distante (20702099)

Tabela 7 - Tendência (futuro menos presente) da frequência de ocorrência e amplitude dos eventos extremos de velocidade do vento a $100 \mathrm{~m}$ de altura. Os extremos positivos e negativos representam, respectivamente, os percentis de $90 \%$ e $10 \%$. Simbologia: -, redução; +, aumento; =, semelhante ao presente. 85 



\section{LISTA DE ABREVIATURAS E SIGLAS}

\begin{tabular}{|c|c|}
\hline ABEEólica & Associação Brasileira de Energia Eólica \\
\hline AEP & Annual Energy Production \\
\hline AS & América do Sul \\
\hline ASAN & Alta Subtropical do Atlântico Norte \\
\hline ASAS & Alta Subtropical do Atlântico Sul \\
\hline ASPS & Alta Subtropical do Pacífico Sul \\
\hline $\mathrm{CDF}$ & Cumulative Density Function \\
\hline $\mathrm{CF}$ & Capacity Factor \\
\hline CLM4.5 & Community Land Model 4.5 \\
\hline CMIP5 & Coupled Model Intercomparison Project Phase 5 \\
\hline CCSM4 & Cummunity Climate System Model version 4 \\
\hline CORDEX & Coordinated Regional Climate Downscaling Experiment \\
\hline DOLS & Distúrbios Ondulatórios de Leste \\
\hline ECMWF & European Centre for Medium-Range Weather Forecast \\
\hline ENSO & El Niño-Southern Oscillation \\
\hline ESMs & Earth System Models \\
\hline EstVal & Estudo de validação \\
\hline EstProj & Estudo de projeção \\
\hline GCM & Global Circulation Model \\
\hline GRADM & Gradiente Meridional do Atlântico \\
\hline \multicolumn{2}{|c|}{ HADGEM2-ES Hadley Centre Global Enviroment Model version 2} \\
\hline ICTP & International Centre for Theoretical Physics \\
\hline INMET & Instituo Nacional de Meteorologia \\
\hline IOD & Indian Ocean Dipole \\
\hline LI & Linhas de Instabilidades \\
\hline
\end{tabular}


MJO Madden-Julian Oscillation

MLM Maximum Likelihood Method

MM4 Mesoscale Model version 4

MPI-ESM-MR Max Planck Institute Earth Sytem Model

NARCCAP North American Regional Climate Change Assessment Program

NCAR National Center for Atmospheric Research

NorESM-1 Norwegian Earth System Model 1

NEB Nordeste

PDFw Função Densidade de Probabilidade de Weibull

PROINFA Programa de Incentivo às fontes Alternativas de Energia Elétrica

RAMS Regional Atmospheric Modeling System

RCA4 Rossby Centre regional atmospheric model

RCP Representative Concentration Pathways

RegCM4 Regional Climate Model version 4

SAM Southern Annular Mode

SE Sudeste

SRES Special Report on Emissions Scenarios

TSM Temperatura da Superfície do Mar

VCAN Vórtice Ciclônico de Altos Níveis

WMO World Meteorological Organization

WPD Wind Power Density

WRF Weather Research and Forecasting Model

ZCAS Zona de Convergência do Atlântico Sul

ZCIT Zona de Convergência Intertropical 



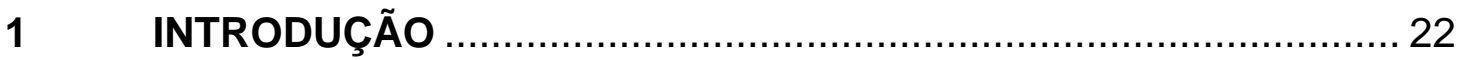

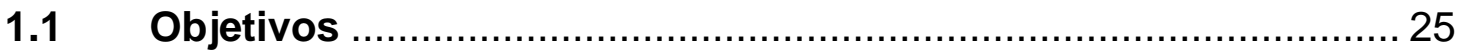

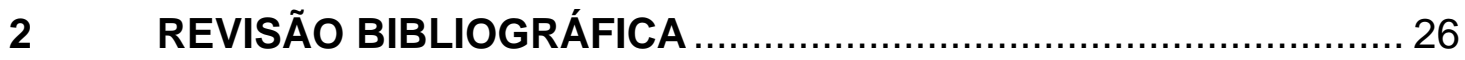

2.1 Padrões gerais de circulação da atmosfera ………..................... 26

2.2 Os ventos no Nordeste do Brasil ............................................. 27

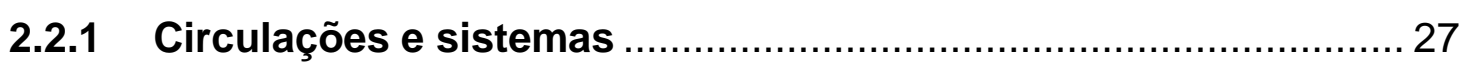

2.2.2 Variabilidade de baixa frequência ............................................. 30

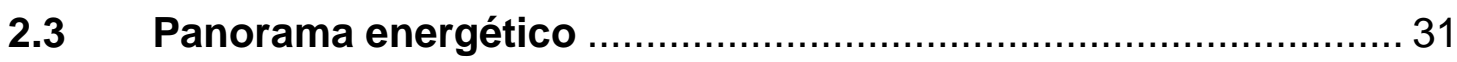

2.3.1 Matriz energética mundial e brasileira .......................................... 31

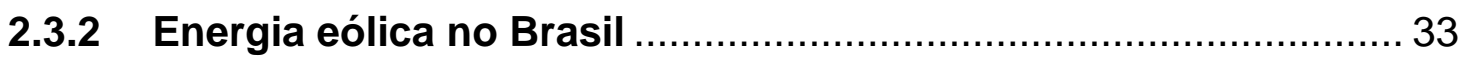

2.3.3 Potencial eólico no NEB: estimativas e técnicas estatísticas ..... 34

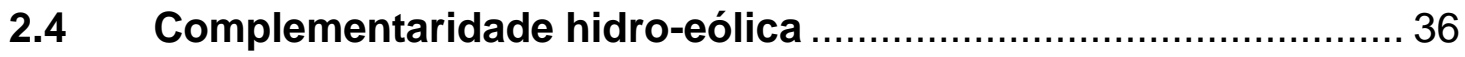

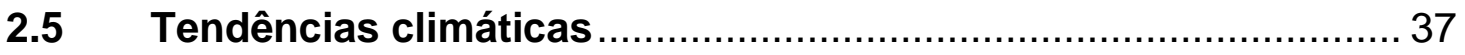

2.5.1 Projeções climáticas para a América do Sul ................................ 38

2.5.2 Projeções climáticas de ventos e WPD ...................................... 40

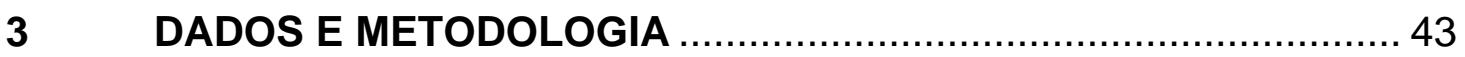

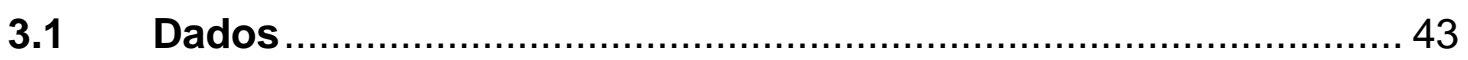

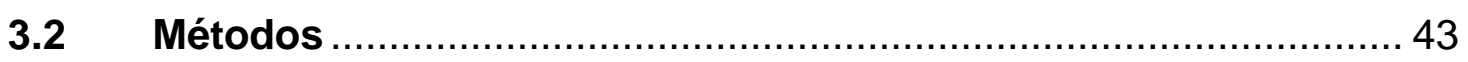

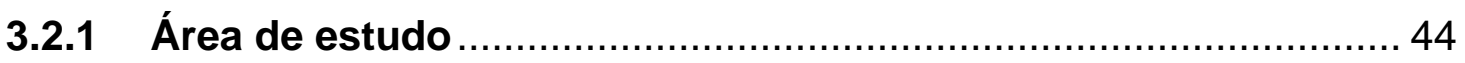

3.2.2 Descrição do modelo RegCM4 …............................................... 45

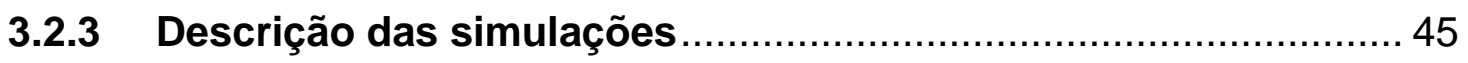

3.2.4 Extrapolação vertical: vento a $100 \mathrm{~m}$............................................. 47

3.3 Função densidade de probabilidade de Weibull ........................... 48

3.3.1 Métodos de ajuste e parâmetros da distribuição .......................... 48

3.4 Produção anual de energia e fator de capacidade .........................50 
3.5 Análise das projeções climáticas regionais .51

3.5.1 Estudo de validação: EstVal........................................................

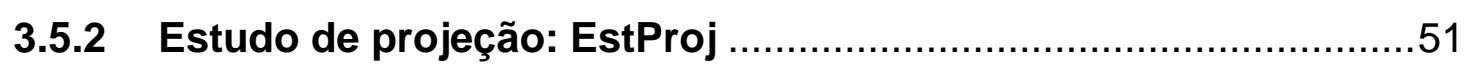

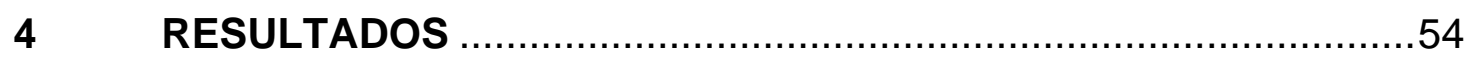

4.1 Validação das simulações no clima presente................................54

4.1.1 Bias Correction (Correção de viés) …………...............................

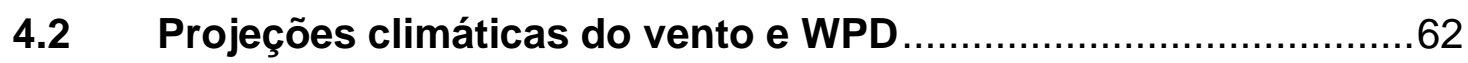

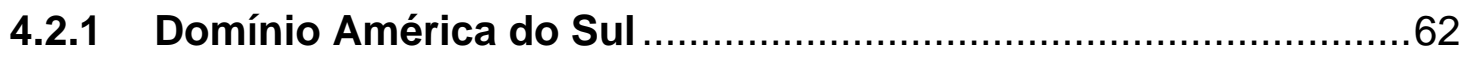

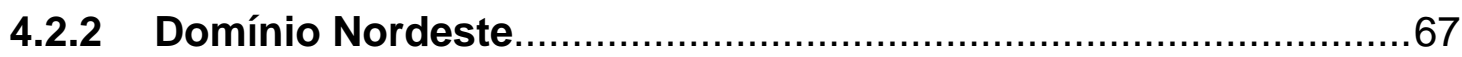

4.2.3 Complementaridade hídrico-eólica no NEB ...................................69

4.3 Tendências e extremos de vento no NEB ……..........................72

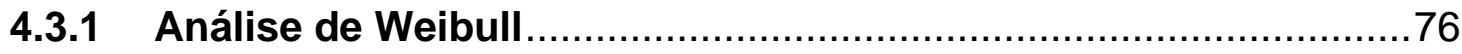

4.4 Estimativas do potencial eólico do NEB: AEP e CF .....................81

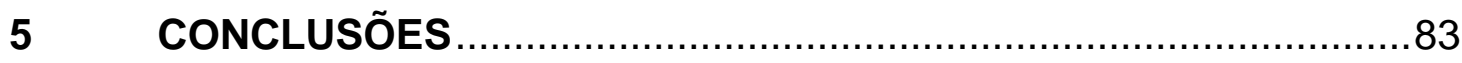

6 PERSPECTIVAS E TRABALHOS FUTUROS ...............................8

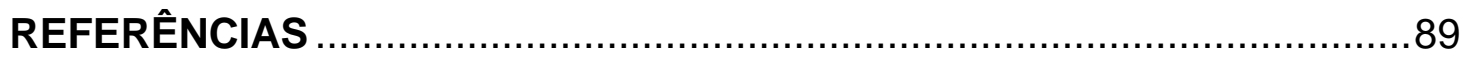

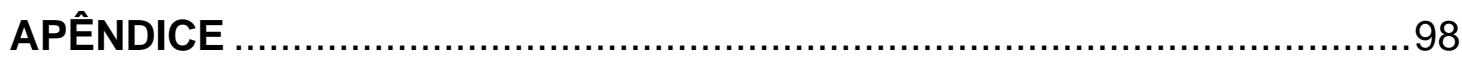

Apêndice A - Lista de figuras complementares aos resultados..............98 




\section{INTRODUÇÃO}

No decorrer de sua história, os humanos têm explorado diversas fontes de energia. Inicialmente, a energia era utilizada para a execução de tarefas simples, como irrigação agrícola e moagem de grãos. Com o passar do tempo, em virtude do aumento populacional, a demanda energética aumentou exponencialmente, o que impulsionou a descoberta de novas fontes. A maior disponibilidade de energia permitiu a automatização em larga escala dos meios de produção, construção de ferrovias e transporte de matéria prima, diminuindo a dependência do ecossistema local. Contudo, a exploração desenfreada dos recursos naturais do Planeta veio acompanhada de um forte impacto ambiental, e se converteu em um dos grandes impasses para o desenvolvimento da sociedade moderna (ARTAXO, 2020; IPCC, 2014).

Atualmente, a principal pauta relaciona-se à emissão de gases de efeito estufa. Isto acontece, pois grande parte da energia consumida mundialmente vem da queima de combustíveis fósseis (IEA, 2018). Durante este processo, quantidades enormes de $\mathrm{CO}_{2}, \mathrm{CH}_{4}$ e $\mathrm{N}_{2} \mathrm{O}$ são liberadas na atmosfera, contribuindo para amplificação do efeito estufa, cujos impactos incluem: aumento da temperatura média do Planeta, aumento dos níveis dos oceanos e desequilíbrio ecossistêmico (IPCC, 2014).

Todavia, apesar da primazia das fontes não renováveis de energia, tem-se notado que as renováveis, como a solar e eólica, vem conquistando cada vez mais espaço na matriz energética mundial. A maior participação das fontes renováveis de energia garante maior oferta energética ao mesmo tempo que reduz a emissão de poluentes na atmosfera. Segundo os dados da International Energy Agency, desde os anos 2000 as fontes renováveis apresentam a maior taxa de crescimento, superando inclusive o carvão e o petróleo. Para os próximos anos as projeções apontam para um crescimento ainda maior, revelando um cenário otimista em termos de sustentabilidade e redução dos impactos ambientais (IEA, 2020).

No Brasil, por exemplo, as energias renováveis já respondem por mais de $80 \%$ de toda energia produzida para fins elétricos, o que faz do país um dos líderes em geração de energia limpa. Desse total, aproximadamente $65 \%$ é produzido nas usinas hidroelétricas, como a de Itaipu (EPE, 2020). Contudo, por mais que não emitam gases estufa na atmosfera, as hidroelétricas, em seu processo de construção, acarretam uma série de problemas para o ecossistema local e para as comunidades 
que vivem próximo às represas (GIONGO; MENDES; SANTOS, 2015; KOIFMAN, 2001). Além disso, a forte dependência hídrica pode ocasionar instabilidades no fornecimento e distribuição de energia em períodos de seca prolongada, como as de 2014 e 2015 (COELHO et al., 2016; MARENGO; ALVEZ, 2015) resultando no aumento da tarifa de energia elétrica.

Por outro lado, outra fonte de energia renovável que se solidificou no país nas últimas duas décadas foi a eólica. Embora a exploração da energia dos ventos tenha ocorrido tardiamente no Brasil, o setor expandiu-se rapidamente a partir dos anos 2000 por meio de programas de incentivo do governo, como o PROINFA (Programa de Incentivo às fontes Alternativas de Energia Elétrica). Hoje, a fonte eólica é a segunda com maior representatividade na matriz elétrica nacional, totalizando quase 10\%. De acordo com a Associação Brasileira de Energia Eólica (ABEEólica), a capacidade instalada no país ultrapassou os 16 GW em 2020. Ao todo, são 637 parques eólicos instalados, sendo a grande maioria (523) na região Nordeste (NEB).

A fonte de energia eólica, apesar de ser inesgotável e não emitir gases estufa na atmosfera, é susceptível de gerar efeitos socioambientais negativos. Dentre os principais malefícios no uso desta fonte, estão a poluição visual e sonora e mortandade de diversas espécies de aves. No Nordeste do Brasil (NEB), o estudo de Sales Costa et al. (2019) mostrou que largas áreas de vegetação foram afetadas durante a instalação de usinas eólicas no litoral do Ceará, principalmente devido aos processos de terraplanagem, compactação e achatamento do solos. Já Hofstaetter (2016) revelou as drásticas consequências na saúde mental (stress, insônia e depressão) das comunidades próximas às usinas eólicas no Rio Grande do Norte em decorrência do intenso ruído sonoro dos aerogeradores.

O NEB, de fato, tem sido um dos locais mais atrativos para investimentos no setor de energia eólica. A razão para isso é a predominância de ventos de qualidade. Devido sua proximidade com o equador, os ventos alísios sopram com velocidades elevadas na região ao longo de todo o ano. No primeiro semestre, especialmente durante o outono, os ventos costumam ser mais fracos, podendo ficar abaixo do ideal operável $\left(6 \mathrm{~ms}^{-1}\right)$ em alguns dias. Mas, no inverno e na primavera, época conhecida como "safra dos ventos", a velocidade média mensal supera os $10 \mathrm{~ms}^{-1}$ em diversos locais do NEB (SANTOS; SANTOS E SILVA, 2013). E, justamente neste período, a demanda energética no país dispara, em função da menor atividade nas hidrelétricas - devido a redução das chuvas. Desse modo, a participação eólica desempenha papel 
fundamental na estabilização da oferta sazonal de energia, que é equilibrada graças ao caráter complementar de ambas as fontes (ARAUJO; MARINHO, 2019).

Entretanto, o regime de ventos no NEB depende ainda de diversos fenômenos climáticos que atuam direta (Zona de Convergência Intertropical, ZCIT; Zona de Convergência do Atlântico Sul, ZCAS; Distúrbios Ondulatórios de Leste, DOLS; Vórtice Ciclônico de Altos Níveis, VCAN) e remotamente (EI Niño-Southern Oscillation, ENSO; Madden-Julian Oscillation, MJO) na região (BRITO, 2018; CAVALCANTI, 2016; GRIMM; TEDESCHI, 2009). Por controlar a magnitude e direção dos ventos, estes fenômenos são extremamente importantes do ponto de vista eólico, e suas previsibilidades são cruciais no planejamento energético.

Outro aspecto importante, mas menos explorado pela literatura, envolve a influência das mudanças climáticas na geração de energia eólica. Na América do Sul (AS), a maior parte dos estudos que abordam tendências futuras do clima regional avaliam, principalmente, alterações nos campos de precipitação e temperatura conforme revisado em Ambrizzi et al. (2019). Por outro lado, pouquíssimos estudos atentam para as mudanças no comportamento do vento próximo à superfície em cenários futuros. Os raros trabalhos existentes (LUCENA et al., 2010; PEREIRA et al., 2013; REBOITA; AMARO; DE SOUZA, 2018) carecem de uma metodologia mais robusta e uma caracterização mais precisa da variabilidade dos ventos nos diferentes cenários futuros.

Neste sentido, este estudo propõe complementar algumas destas lacunas, descritos na seção 1.2. Os demais assuntos abordados estão estruturados da seguinte forma: o capítulo 2 apresenta uma revisão bibliográfica dos principais estudos e conceitos na área de energia eólica e projeções climáticas; o capítulo 3 descreve a base de dados, hipóteses e metodologia; o capítulo 4 apresenta os principais resultados; capítulo 5 resume e apresenta as principais conclusões da pesquisa; o capítulo 6 lista algumas sugestões para trabalhos futuros. 


\subsection{Objetivos}

Este estudo tem como objetivo principal avaliar tendências climáticas de longo período (130 anos) em cenários futuros do vento em baixos níveis (100 m) e seus impactos na geração de energia eólica no Nordeste do Brasil. Para isso, são analisadas projeções climáticas regionais em alta resolução espacial (25 km) forçadas com modelos globais do CMIP5 (Coupled Model Intercomparison Project Phase 5) no RCP8.5 (representative concetration pathways). Dentre os objetivos específicos, estão:

- Validar as simulações de magnitude do vento a $100 \mathrm{~m}$ de altura no clima presente (1985-2014) por meio de comparações com dados de reanálise;

- Caracterizar mudanças na magnitude do vento a 100 m e suas implicações para a complementaridade hídrico-eólica;

- Estimar o potencial eólico do NEB no futuro.

- Analisar a frequência e amplitude futura de episódios de magnitude do vento a 100 m extremos. 


\section{REVISÃO BIBLIOGRÁFICA}

\subsection{Padrões gerais de circulação da atmosfera}

Os ventos, junto com as correntes oceânicas, são os principais mecanismos de manutenção energética do planeta Terra, responsáveis por redistribuir os excessos de calor, energia e massa ao redor do planeta (REBOITA et al., 2010). Os ventos, geralmente, realizam este transporte de maneira mais rápida e eficiente, se comparado às correntes oceânicas. Entretanto, as variações espaço-temporais deste transporte dependem da complexa interação multiescala dos diversos componentes do sistema terrestre (CAVALCANTI, 2016).

Em escala global, por exemplo, os ventos são modulados pelo gradiente meridional de temperatura entre o equador e os pólos e pela rotação da terra. A interação desses elementos dá origem às células de circulação global: Hadley, Ferrell e Polar (PEIXOTO; OORT, 1992). Dentre os principais regimes de ventos associados, destacam-se os ventos alísios (NE e SE) em baixos níveis da atmosfera equatorial, e os ventos de oeste em latitudes médias (Figura 1). Em altos níveis da troposfera predominam ventos de oeste nos extratrópicos e de leste nos trópicos.

Em escala regional, outros elementos como a orografia e diferentes tipos de cobertura de superfície passam a ser preponderantes na intensidade e direção dos ventos. As brisas marítima e de vale-montanha são exemplos de fenômenos de escala regional e surgem devido ao aquecimento diferencial entre superfícies com características distintas (WALLACE; HOBBS, 2006).

$\mathrm{Na} A S$, devido a sua grande extensão territorial, os padrões de circulação frequentemente mesclam características locais, regionais e globais. Dentre os principais regimes de ventos atuantes destacam-se as Altas Subtropicais do Atlântico Sul (ASAS) e Pacífico Sul (ASPS), os jatos Polar e Subtropical em altos níveis, o Jato de Baixos Níveis (JBN), além da Baixa do Chaco, a Alta da Bolívia e os vórtices ciclônicos de altos níveis, mais presentes durante o verão (CAVALCANTI, 2016). 


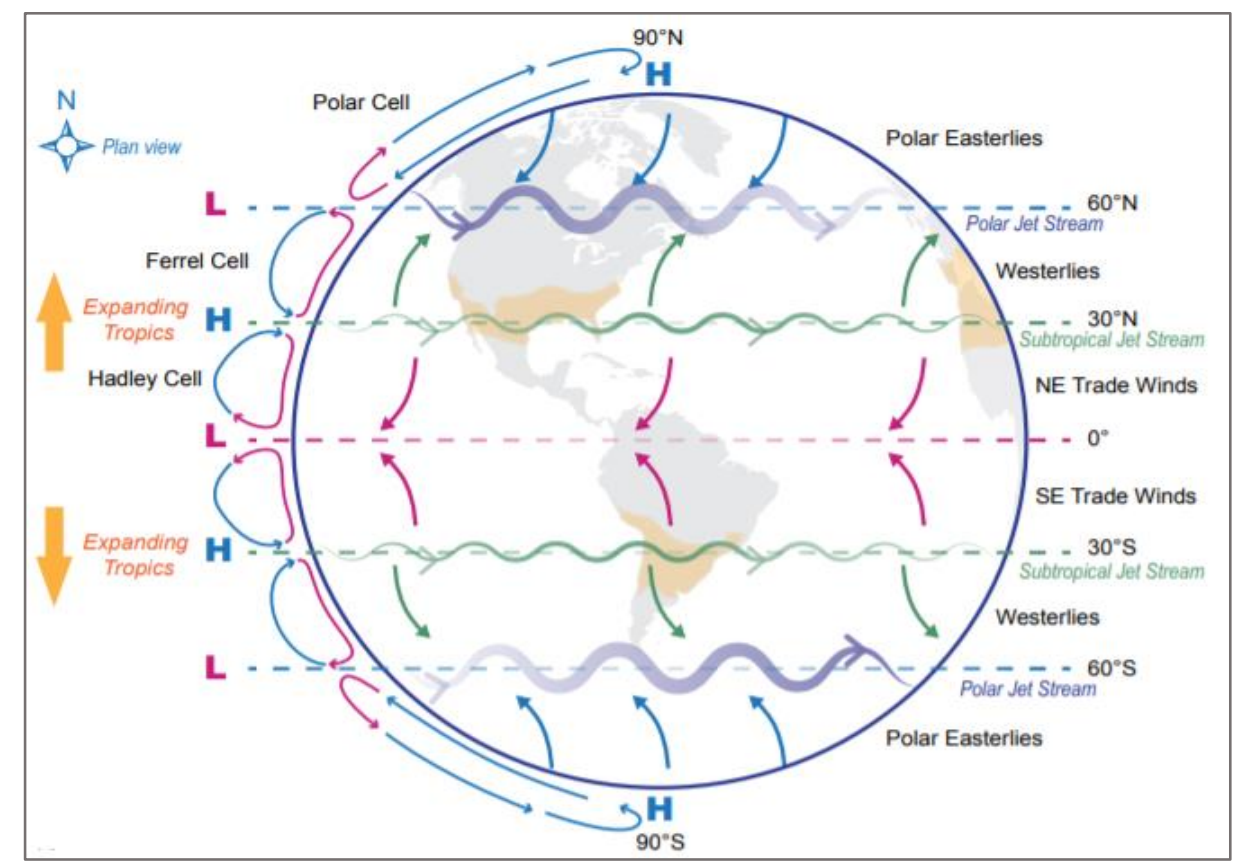

Figura 1 - Representação esquemática da circulação geral da atmosfera. Entre o equador e os polos destacam-se três células de circulação (Hadley, Ferrel e Polar) originadas pelo aquecimento diferencial da superfície e pela rotação da Terra. Dentre os regimes de ventos resultantes estão: ventos alísios (trade winds) de nordeste e sudeste, confluentes na região tropical; ventos de oeste (westerlies) em latitudes médias; jato subtropical (subtropical jet stream) e jato polar (polar jet stream). Fonte: Adaptado de (WUEBBLES; FAHEY; HIBBARD, 2017).

\subsection{Os ventos no Nordeste do Brasil}

\subsubsection{Circulações e sistemas}

O NEB situa-se na região equatorial, entre $48,05^{\circ} \mathrm{W}$ e $35,02^{\circ} \mathrm{W}$ e $18,05^{\circ} \mathrm{S}$ e $1^{\circ} \stackrel{\mathrm{S}}{ }$, com aproximadamente $1.558 .196 \mathrm{~km}^{2}$ de território possui a maior faixa litorânea do Brasil, banhada pelas águas quentes do Oceano Atlântico Tropical. Ao longo do ano, os ventos alísios (de sudeste e nordeste) oriundos da ASAS e ASAN (Alta Subtropical do Atlântico Norte) sopram constantes na região. Desse modo, as decorrentes variações na intensidade e direção dos alísios depende diretamente da variabilidade destes centros anticiclônicos (VAREJÃO-SILVA, 2006).

Durante o inverno austral, por exemplo, a ASAS encontra-se fortalecida e mais próxima do continente Sul-Americano (GARREAUD et al., 2009; REBOITA et al., 2019). Em decorrência disso, os alísios de sudeste (SE) também se fortalecem e atingem o NEB mais intensos. De fato, ao investigar a sazonalidade dos ventos a 10 m de altura no NEB, Santos e Santos e Silva (2013) notaram que a magnitude do vento é maior durante os meses de inverno e primavera, podendo atingir valores 
médios de 11,4 $\mathrm{ms}^{-1}$ nas extremidades norte e nordeste desta região, e também em áreas de relevo pronunciado, como no interior da Bahia. Essa sazonalidade na intensidade dos ventos a $10 \mathrm{~m}$ de altura sobre o NEB também foi identificada em dados da reanálise ERA-20C por Brito (2018).

Outro tipo de circulação presente no NEB são as brisas. A influência deste fenômeno no clima do nordeste foi investigado inicialmente por Kousy (1980). Neste estudo, o autor buscou explicar o ciclo diurno da precipitação no NEB por meio da interação dos alísios com as circulações locais de brisa. Segundo Kousky (1080), os máximos noturnos de precipitação ocorrem devido à intensificação da brisa terrestre que, ao soprar em direção oposta ao escoamento médio (alísios) favorecem a convergência de massa próximo à costa, resultando em maior atividade convectiva noturna.

O mecanismo proposto por Kousky (1980) baseado na atuação conjunta da circulação local com o escoamento médio foi, posteriormente, corroborado por (BARRETO, 2001). Neste trabalho, os autores avaliaram o ciclo diurno dos ventos à superfície $(10 \mathrm{~m})$ no NEB por meio de dados observacionais de 77 estações meteorológicas do Instituto Nacional de Meteorologia (INMET). O estudo mostrou que as variações na intensidade e direção dos ventos ao longo da costa do NEB podem, em partes, serem explicadas pela ação simultânea de ambos os sistemas (brisas e alísios). Durante o dia, por exemplo, os ventos são mais fortes devido à superposição dos escoamentos de brisa marítima com os alísios atuando na mesma direção. Já no período noturno, os ventos enfraquecem devido à mudança na orientação do escoamento, ou seja, a brisa terrestre com ventos do continente para o oceano se opondo aos alísios, conforme proposto por Kousky (1980).

Um estudo do comportamento do vento próximo ao Centro de Lançamento de Alcântara, localizado no estado do Maranhão, mostrou que a variabilidade anual da intensidade dos ventos também está diretamente relacionada à atividade das brisas (ROBALLO; FISCH, 2008). Os autores verificaram que durante a estação chuvosa os ventos variam entre 7,0 e 8,0 $\mathrm{ms}^{-1}$ associados, essencialmente, aos alísios de leste. Enquanto na estação seca, os ventos se mostraram mais intensos, podendo chegar a $15,0 \mathrm{~ms}^{-1}$. Para os autores, isso ocorre em função da superposição dos alísios com a brisa marítima, que é mais intensa nessa época do ano (setembro a novembro) devido ao maior contraste térmico (oceano-continente) em virtude da migração para norte da Zona de Convergência Intertropical (ZCIT). 
A ZCIT é um dos principais sistemas meteorológicos atuantes no clima e na variabilidade do clima do NEB. Este sistema, de escala global, caracteriza-se pela confluência dos ventos alísios na baixa atmosfera e por produzir chuvas torrenciais ao longo de toda faixa equatorial (CAVALCANTI, 2016). No Atlântico Tropical, encontrase, em média, entre 14ํN (de agosto a setembro) e $2^{\circ} \mathrm{S}$ (de março a abril). Ao longo do ano a migração latitudinal deste sistema controla a os totais pluviométricos no NEB, com a estação chuvosa se estabelecendo no norte do NEB quando a ZCIT está mais ao sul, bem como as regiões de confluência dos ventos (CAVALCANTI, 2016).

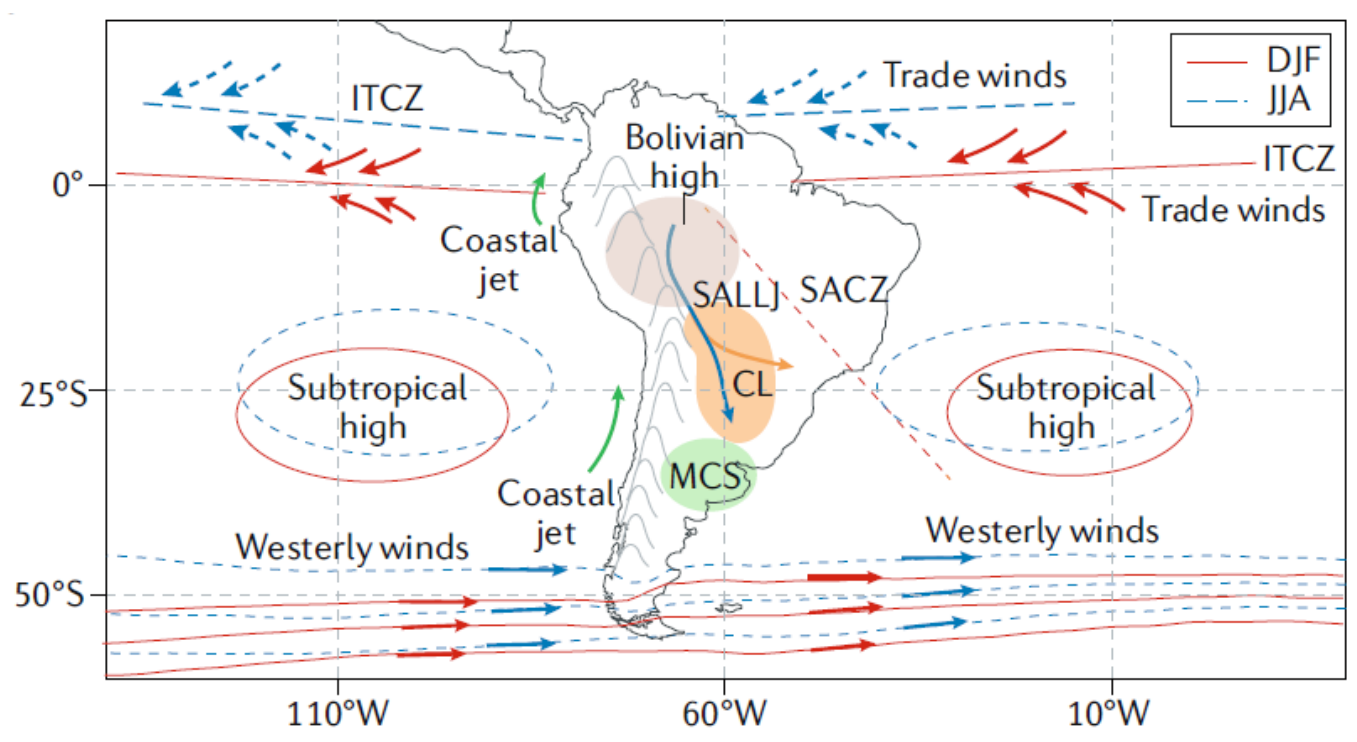

Figura 2 - Principais sistemas meteorológicos atuantes no clima da AS: Zona de Convergência Intertropical (Intertropical Convergence Zone, ZCIT); Zona de Convergência do Atlântico Sul (South Atlantic Convergence Zone, ZCAS); Jato de Baixos Níveis da América do Sul (South American LowLevel Jet, SALLJ); Baixa do Chaco (Chaco Low, CL); Complexo Convectivo de Mesoescala (Mesoscale Convective System, MCS). Linhas vermelhas representam a circulação de verão (DJF) e azuis de inverno (JJA). Fonte: (CAl et al., 2020).

De maneira semelhante à ZCIT, a Zona de Convergência do Atlântico Sul (ZCAS) destaca-se como responsável pelos padrões de precipitação, temperatura e vento na porção sul da região Nordeste. A dinâmica e manutenção deste fenômeno bem como seus impactos na AS tem sido estudado desde a década de setenta De acordo com Cavalcanti et al. (2009), a ZCAS é um sistema de escala sinótica presente no verão austral associado a uma região de nebulosidade que se estende no sentido noroeste-sudeste desde a Amazônia ao sudeste do Brasil e, por vezes, ao Oceano Atlântico Sul subtropical. Durante os meses de novembro a março, a ZCAS contribui com os totais pluviométricos no sul do NEB, especialmente no estado da Bahia (CAVALCANTI, 2016). Um resumo esquemático dos principais sistemas atuantes na 
AS e NEB, conforme mencionado anteriormente, é apresentado na Figura 2 (retirada de Cai et al. 2020).

\subsubsection{Variabilidade de baixa frequência}

Os padrões climatológicos observados na AS e no NEB podem, em partes, ser explicados pelos sistemas meteorológicos descritos anteriormente e sintetizados na figura 2. Contudo, uma parte significativa da variabilidade interanual observada devese à atuação de outros fenômenos, como: ENSO, GRADM (Gradiente Meridional do Atlântico), MJO (CARVALHO; JONES; LIEBMANN, 2004; GRIMM; BARROS; DOYLE, 2000; MOURA; SHUKLA, 1981; TASCHETTO; AMBRIZZI, 2012) entre outros. O ENSO é o modo de variabilidade mais conhecido dentro e fora da comunidade científica em função dos seus impactos na variabilidade climática em nível global (ROPELEWSKI; HALPERT, 1987). Os primeiros estudos a respeito destes fenômenos datam da década de 20 (PHILANDER, 1985).

De acordo com Philander (1985) o ENSO é um fenômeno de acoplamento oceano-atmosfera, de caráter oscilatório quasi-periódico, que se manifesta no Pacífico central e leste associado a anomalias na Temperatura da Superfície do Mar (TSM). Seus impactos na AS podem ser de forma direta ou indireta e dependem da região onde se desenvolvem as anomalias de TSM, além da interação conjunta com outros modos de variabilidade, como o GRADM e SAM (Southern Annular Mode) (ASHOK et al., 2007; GRIMM, 2003; HOSKINS; KAROLY, 1981; MO; HIGGINS, 1998; PEZZI; CAVALCANTI, 2001; VERA; OSMAN, 2018).

Tipicamente, em episódios de anomalias positivas de TSM no pacífico leste equatorial ( $E$ I Niño), partes da Amazônia e do NEB tendem a experimentar períodos de seca. Isso acontece devido ao ramo descendente da célula de Walker que se desloca para estas regiões e então desfavorece a atividade convectiva (CAI et al., 2020; KOUSKY; KAGANO; CAVALCANTI, 1984; UVO et al., 1998). Já no sudeste da AS, a precipitação tende a ficar acima da média em virtude do maior transporte de umidade em baixos níveis através do jato de baixos níveis e da maior divergência de massa em altos níveis (GRIMM; TEDESCHI, 2009). O oposto geralmente é observado na fase negativa de anomalias de TSM da oscilação (La Niña).

Além das chuvas, o ENSO também modula a variabilidade interanual dos alísios no setor do Atlântico Tropical. Em anos de El Niño, anomalias ciclônicas foram 
observadas no Atlântico Norte (NAMIAS, 1972) responsáveis por enfraquecer a ASAN e, consequentemente, os alísios de NE. Em contrapartida, os alísios de SE se mostraram fortalecidos, em resposta à maior atividade anticiclônica da ASAS (VAREJÃO-SILVA, 2006). De fato, diversos estudos confirmaram a intensificação dos ventos no NEB durante episódios de EI Niño (BRITO, 2018; CAVALCANTI et al., 2020; OLIVEIRA; COSTA, 2011). Todavia, alguns autores ressaltam a importância da atuação simultânea de outros modos de variabilidade, como o GRADM.

Em um estudo recente, Brito (2018) utilizou a reanálise centenária ERA-20C para investigar a variabilidade interanual e eventos extremos de vento a $10 \mathrm{~m}$ de altura em quatro regiões do NEB, e sua relação com as anomalias de TSM nas bacias do Atlântico e Pacífico. O autor concentrou-se em analisar somente a estação de outono por ser a de maior influência do ENSO no NEB, e a de maior variância na velocidade do vento. O estudo mostrou que, quando o sinal das oscilações é igual (ENSO+ e GRADM+) há uma intensificação dos ventos no NEB, e que o contrário acontece na fase oposta. Além disso, a ação apenas do GRADM+ (GRADM-) correlacionou-se com extremos positivos (negativos) de vento em toda a extensão do NEB, enquanto o ENSO mostrou-se capaz de produzir extremos significativos somente nos domínios centrais e leste do NEB.

Em um estudo publicado no periódico Nature Review, Cai et al. (2020) realizaram uma revisão sobre a compreensão teórica e observacional do ENSO, bem como seus impactos associados na AS. Além disso, a pesquisa aborda temas relacionados à previsibilidade e projeções climáticas do fenômeno. Para os autores, episódios de El Niño e La Niña intensos devem ocorrer com mais frequência no futuro, e seus impactos, consequentemente, amplificados.

\subsection{Panorama energético}

\subsubsection{Matriz energética mundial e brasileira}

Atualmente, cerca de $70 \%$ de toda energia consumida no mundo resulta da queima de combustíveis fósseis (gás natural, petróleo e carvão) (IEA, 2018). Os motivos desta predominância residem, principalmente, na eficiência energética (pequenas quantidades de matéria prima geram enormes quantidade de energia), conveniência (facilidade de extração e processamento) e estabilidade no mercado 
mundial (pelo menos 150 anos). Entretanto, são várias as consequências relatadas pela literatura advindas do processo de queima e extração destes combustíveis: liberação de gases estufa na atmosfera, derramamento de óleo nos oceanos etc. (IPCC, 2014).

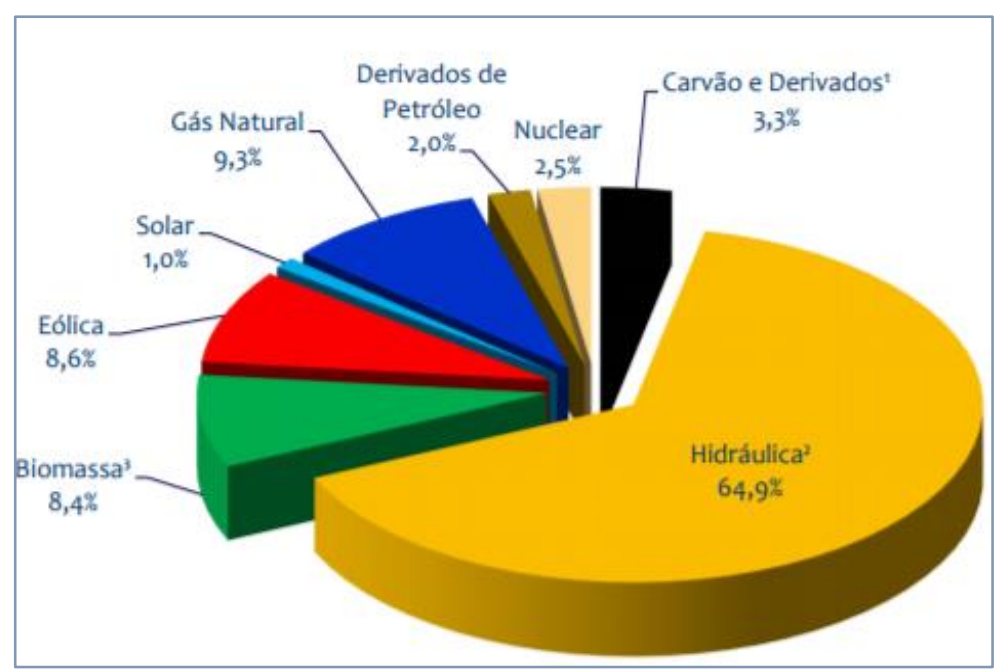

Figura 3 - Matriz elétrica brasileira em 2019. Inclui a oferta de energia de todas as fontes destinadas a fins elétricos. Fonte: Adaptado de (EPE, 2020).

Por outro lado, na contramão do padrão mundial de produção de energia, o Brasil solidificou $83 \%$ de sua matriz elétrica em fontes renováveis (Figura 3), sobretudo hidráulica (64,9\%) (EPE, 2020). As vantagens em possuir uma das matrizes energéticas mais limpas do mundo esbarra em outros desastres ambientais envolvidos na construção de usinas hidrelétricas, como o desmatamento e alagamento de vastas áreas e 0 deslocamento de populações ribeirinhas estabelecidas nas proximidades das represas. As alterações na fauna e flora e no microclima local são permanentes e podem levar à extinção de centenas de espécies vivas. Um outro fator limitante à expansão do setor hidrelétrico está relacionado à irregularidade dos regimes das chuvas. A maioria das grandes hidrelétricas brasileiras situa-se na região sul e sudeste do país, onde a precipitação apresenta forte sazonalidade (AMARANTE et al., 2000). Desse modo, períodos de seca prolongados podem resultar em déficit na produção de eletricidade, indicando então a necessidade de uma matriz energética diversificada. 


\subsubsection{Energia eólica no Brasil}

A energia eólica representa uma fonte de energia inesgotável e de baixo impacto ambiental. No Brasil, entretanto, sua exploração é tardia. A primeira turbina instalada no país ocorreu somente em julho de 1992, na ilha de Fernando de Noronha, 105 anos após a invenção do primeiro aerogerador, por Charles F. Brush, em Cleveland, nos Estados Unidos (CRESESB-CEPEL, 2017). Desde então, o setor expandiu-se rapidamente apoiado nos projetos de incentivo do governo, como o PROINFA. Na última década o país passou de $600 \mathrm{MW}$ de capacidade instalada por fonte eólica para $15 \mathrm{GW}$ em 2019 (Figura 4), assumindo o segundo lugar na matriz elétrica nacional (ABEEÓLICA, 2020).

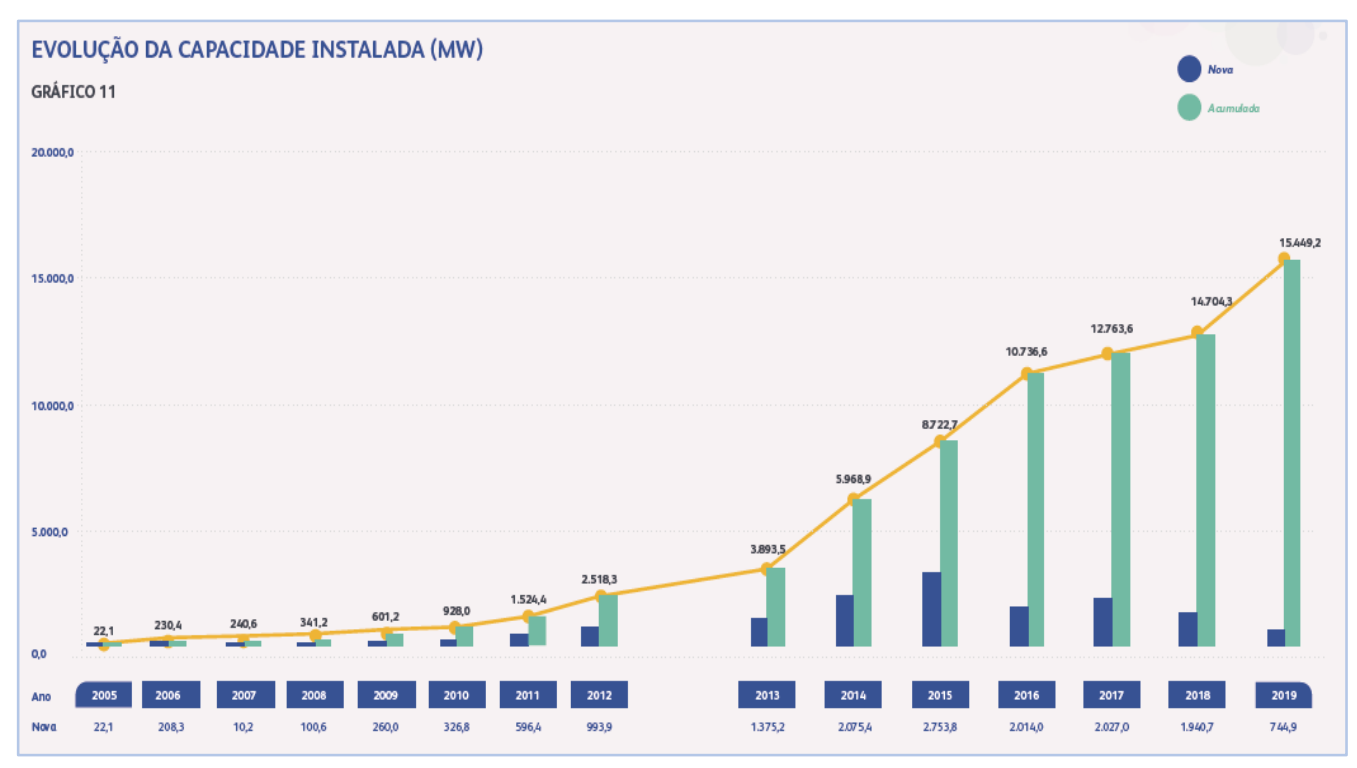

Figura 4 - Evolução da capacidade instalada (MW) da energia eólica no Brasil ao longo dos anos. Fonte: Adaptado de ABEEÓLICA (2020).

No Brasil, as principais áreas favoráveis à exploração eólica encontram-se nas regiões sul e nordeste do país (AMARANTE; BROWER, M., ZACK; SÁ, 2001). O NEB, sobretudo, tem se mostrado um dos locais mais atrativos para a geração de energia eólica. De acordo com o último boletim da ABEEólica, a região concentra mais de $80 \%$ dos parques eólicos instalados em território nacional sendo responsável por $86,7 \%$ de toda energia gerada. Em termos de abastecimento, a fonte eólica foi capaz de suprir a demanda energética de 88,8\% do subsistema Nordeste em 2019 (ABEEÓLICA, 2020), o que comprova a dimensão do potencial eólico brasileiro. 


\subsubsection{Potencial eólico no NEB: estimativas e técnicas estatísticas}

O potencial eólico de uma região pode ser estimado de inúmeras maneiras. Uma das variáveis mais utilizadas e de fácil cálculo é a Wind Power Density (WPD), cuja relação é expressa como (MANWELL; MCGOWAN; ROGERS, 2010):

$$
W P D=\frac{1}{2} \rho v^{3}
$$

onde $\rho$ é a densidade do ar $\left(\mathrm{Kgm}^{-3}\right)$ e $v$ a velocidade do vento $\left(\mathrm{ms}^{-1}\right)$. De acordo com a equação (1) a WPD exibe uma relação cúbica com a velocidade do vento, de tal forma que pequenas variações de $v$ implicam em grandes variações na WPD. Assim, quanto melhor for a representação da velocidade do vento, melhor será a estimativa da WPD.

No NEB, diversos projetos buscaram investigar detalhadamente 0 comportamento dos ventos buscando desvendar os locais ideais para implantação de parques eólicos com máximo aproveitamento energético. Silva et al. (2002), por exemplo, estudaram a variabilidade espacial e temporal da WPD no NEB entre os anos de 1977 a 1981. Para tanto, os autores utilizaram a Função Densidade de Probabilidade de Weibull (PDFw) para representar as medidas do vento a $10 \mathrm{~m}$. A PDFw é um dos modelos probabilísticos mais utilizados em estudos eólicos (ISLAM; SAIDUR; RAHIM, 2011; SEGURO; LAMBERT, 2000; STEVENS, M. J. M. SMULDERS, 1979). No período analisado, foi constatado uma predominância de ventos de leste nas estações meteorológicas analisadas. A análise espacial de WPD revelou que os estados do Rio Grande do Norte, Ceará, Pernambuco e Sergipe detém características ideias para implantação de parques eólicos, com totais horários superiores a $20 \mathrm{Wm}^{-2}$.

Lima et al. (2010) analisaram as variações de vento e WPD em cinco sítios no estado da Paraíba, localizados na costa leste do NEB. O estudo utilizou medidas horárias de vento a $10 \mathrm{~m}$ de altura de 5 estações meteorológicas do INMET. A fim de obter maior representatividade do potencial do vento na altura de operação dos aerogeradores, os autores extrapolaram o vento medido nas estações para os níveis de $50 \mathrm{~m}$ e $110 \mathrm{~m}$ utilizando uma relação logarítmica. Os resultados do estudo mostraram que os ventos são mais fracos durante a estação chuvosa e mais intensos 
no período seco, geralmente entre setembro e outubro. De maneira análoga a Silva et al. (2002), os autores utilizaram o modelo probabilístico de Weibull e estimaram os parâmetros da PDFw por meio do método dos momentos e, a partir do ajuste, a WPD e a AEP. Os valores do parâmetro de forma encontrados no estudo variam entre 1 e 2 e o de escala entre $3 \mathrm{~ms}^{-1}$ e $7 \mathrm{~ms}^{-1}$. Os maiores valores de WPD foram observados nas estações de Campina Grande $\left(142 \mathrm{Wm}^{-2}\right)$ e Patos $\left(126 \mathrm{Wm}^{-2} \mathrm{~W}\right)$. A AEP estimada para estes locais foi de $1248 \mathrm{kWh} \mathrm{m}^{-2} \mathrm{ano}^{-1}$ ano e $1108 \mathrm{kWh} \mathrm{m}^{-2} \mathrm{ano}^{-1}$, o que evidencia uma grande capacidade de produção eólica.

A metodologia de Lima et al. (2010) foi posteriormente empregada em Lima et al. (2011) para avaliar o potencial eólico no município de Jaguaruana, no litoral do Ceará, costa norte do NEB. As estimativas mensais de WPD a $110 \mathrm{~m}$ de altura para o município mostram-se satisfatórias, superiores a $350 \mathrm{Wm}^{-2}$ durante a estação seca. Além disso, os autores estimaram o fator de capacidade considerando a curva de potência de um aerogerador AAER A-2000/84. Os valores encontrados variam de $20 \%$ a $35 \%$.

Oliveira e Costa (2011) avaliaram a influência da variabilidade de baixa frequência na circulação dos ventos no NEB e seus impactos na geração eólica. Para estimar a WPD e energia eólica mensal produzida, os autores utilizaram simulações climáticas regionais conduzidas com o modelo regional RAMS (Regional Atmospheric Modeling System). O estudo concentrou-se em estudar os anos de 1973/74 e 1982/83 por serem anos de La Niña e El Niño, respectivamente. Durante o evento de La Niña, Oliveira e Costa (2011) verificaram um enfraquecimento dos ventos sob a região, devido à prevalência do escoamento de leste-nordeste, que favoreceu o deslocamento da ZCIT para sul. O oposto foi observado no evento de 1982/83 (El Niño e Atlântico Norte mais quente), ou seja, ventos mais intensos e de sudeste. $O$ impacto destes fenômenos na produção de energia eólica foi determinado por meio dos parâmetros da PDFw, WPD e Annual Energy Production (AEP), considerando um aerogerador de 1,5 MW. Em suma, os valores de WPD encontrados Oliveira e Costa (2011) foram maiores ao longo dos anos de 1982/83, especialmente nos meses de agosto e setembro, atingindo valores de $372 \mathrm{Wm}^{-2}$ e $378 \mathrm{Wm}^{-2}$, respectivamente. Nestes meses, o parâmetro de escala da PDFw aproximou-se dos $9 \mathrm{~ms}^{-1}$, e o parâmetro de forma manteve-se acima de 7. Estes valores sugerem ventos constantes com magnitude elevada. Ainda para estes meses, a AEP observada foi de aproximadamente $500 \mathrm{MWh}$. 
Carvalho et al. (2012) investigaram o potencial eólico de três regiões distintas do NEB: Serra, sertão do Ceará e litoral. Para tal, os autores extrapolaram a velocidade do vento em superfície $(10 \mathrm{~m})$ medidos em escala horária para três níveis superiores (50, 80 e $100 \mathrm{~m}$ ). Os resultados mostraram que as três regiões em questão apresentam alto potencial de geração eólica, especialmente a região serrana.

Santana et al. (2015) utilizaram a reanálise ERA-40 para analisar a variabilidade espacial do vento sobre o NEB. A utilização desta reanálise possibilitou uma maior abrangência temporal para o estudo - 1958 a 2001. Os autores concluíram que o emprego da distribuição de Weibull de dois parâmetros demonstrou eficácia em representar a variabilidade observada, sendo superior às demais distribuições aplicadas, e que a porção que compreende a Zona da Mata, no leste do NEB, apresentou valores elevados de magnitude do vento e baixa variabilidade, que são características desejáveis para exploração eólica.

Santos et al. (2016) investigaram os recursos eólicos dos municípios de Paracuru, no estado do Ceará, e Triunfo, em Pernambuco. Para isso, os autores realizaram simulações numéricas com o modelo Weather Research and Forecasting Model (WRF) utilizando dois domínios espaciais com resoluções horizontais de $15 \mathrm{~km}$ e $5 \mathrm{~km}$. Os resultados do estudo mostraram que ambas as localidades possuem condições favoráveis para implantação de parques eólicos, com destaque para a cidade de Triunfo, onde as estimativas de WPD mensal ultrapassaram $400 \mathrm{Wm}^{-2}$..

O estudo de Lira et al. (2017) buscou caracterizar o regime de ventos do estado do Piauí para identificação de possíveis sítios com características favoráveis à produção de energia eólica. Os autores investigaram a direção predominante e intensidade do vento em escala horária e mensal, obtendo para os municípios de Parnaíba e Paulistana mostraram potencial elevado para aproveitamento eólico.

\subsection{Complementaridade hidro-eólica}

Amarante et al. (2000) examinaram a viabilidade da estabilização sazonal da oferta energética do país por meio da atuação complementar das fontes eólica e hidráulica. No NEB, por exemplo, o estudo comparou a geração mensal de energia de uma usina eólica de $3 \mathrm{GW}$ instalada (hipoteticamente) em 5 sítios do litoral cearense, com a vazão média do reservatório da hidrelétrica de Sobradinho, na Bahia. De acordo com os resultados das simulações, a sazonalidade presente em ambas as matrizes 
geradoras é de caráter complementar (Figura 5). Durante os meses que compreendem a estação seca (junho a novembro), a componente eólica pode suprir o déficit na geração hidráulica, de modo a salvaguardar o nível dos reservatórios.
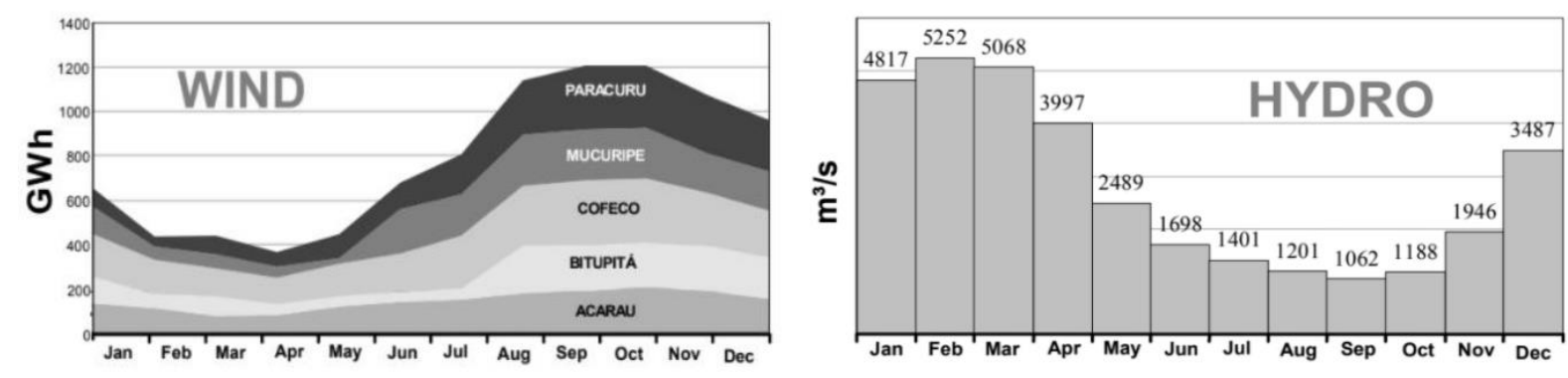

Figura 5 - Produção mensal de energia produzida por uma usina eólica hipotética de 3 GW de potência instalada no Nordeste do Brasil (esquerda). Afluência natural no reservatório da usina de sobradinho durante o período de 1931 a 1992 (direita). Fonte: Adaptado de Amarante et al. 2000.

Um estudo mais recente de Araújo e Marinho (2019) avaliou a complementaridade na produção energética no estado de Pernambuco por meio da combinação das fontes eólica e hidráulica. Ou autores calcularam a geração eólica através da estimativa dos parâmetros da distribuição de Weibull de séries temporais de vento a $10 \mathrm{~m}$ durante o período de 2005 a 2015. As análises mostraram que a produção de energia eólica na região poderia representar uma economia de 9.55\% na vazão do rio São Francisco, responsável pela componente hídrica. Os autores destacam que a água poupada pode ser crucial para a população nordestina, que sofre frequentemente com a escassez de água, especialmente em regiões como o semiárido.

\subsection{Tendências climáticas}

O estudo do clima futuro, bem como do clima passado, pode ser realizado por meio de modelos climáticos. Tais modelos dividem-se em duas classes: globais e regionais. Os modelos globais, ou Modelos de Circulação Global (General Circulation Models, GCMs), geralmente apresentam habilidade em representar o clima e a variabilidade do mesmo em larga escala da atmosfera, porém, devido à menor resolução horizontal, falham em reproduzir certos padrões de escala regional que resultam de contrastes próximo à superfície (separação oceano-continente, brisa valemontanha, brisa marítima, presença de cidades etc. Os modelos climáticos regionais 
(Regional Climate Models, RCMs) são modelos de área limitada, ou seja, são utilizados para estudar o clima e sua variabilidade em regiões específicas do globo.

A resolução horizontal mais refinada utilizada nos RCMs somado aos esquemas de parametrização mais sofisticados, permitem resolver os processos de mesoescala de maneira mais realística (GIORGI; MEARNS, 1999). Os RCMs apresentam, em geral, desempenho superior ao dos GCMs para simular variáveis que sofrem forte influência da heterogeneidade da superfície (chuva, temperatura, vento próximo da superfície etc. Entretanto, simulações climáticas envolvem incertezas que surgem tanto pelo nosso entendimento incompleto dos processos físicos naturais (representados de forma paramétrica nos modelos) quanto pelas dúvidas inerentes sobre o impacto das ações humanas no decorrer das próximas décadas (LLOPART; REBOITA; DA ROCHA, 2020). Portanto, devem ser interpretadas como indicadores e não como verdades definitivas.

\subsubsection{Projeções climáticas para a América do Sul}

$\mathrm{Na}$ AS, diversos estudos utilizaram modelos numéricos para simular as características gerais do clima presente bem como avaliar o impacto das mudanças climáticas no clima futuro. Com relação às projeções, parte destes estudos concentraram-se em avaliar as tendências nos campos de precipitação e temperatura. Utilizando GCMs, por exemplo, Boulanger et al. (2006) reportaram tendências de aumento na temperatura em várias partes da $A S$, como a região tropical $\left(+4^{\circ} \mathrm{C}\right)$ e sul $\left(+2-3^{\circ} \mathrm{C}\right)$ da AS. Além disso, as projeções do estudo indicaram aumento na amplitude do ciclo anual da temperatura no sul e redução no norte da AS.

Vera et al. (2006) utilizaram um conjunto de simulações de diferentes GCMs participantes do IPCC-AR4 (Intergovernamental Panel on Climate Change) para investigar mudanças no campo de precipitação na AS para o final deste século (2070 a 2099). De acordo com Vera (2006), o consenso dos modelos aponta para: 1) aumento da precipitação no sudeste da AS durante o verão; 2) redução da precipitação no inverno em grande parte do continente; 3) redução da precipitação ao longo de todo o ano no sul dos Andes.

Entre os trabalhos com RCMs, destaca-se o de Marengo et al. (2010). Neste estudo, os autores utilizaram três modelos regionais (Eta CCS, RegCM3 e HadRM3P) aninhados ao modelo global Had-AM3P para investigar mudanças no clima da AS no 
final do século XXI, considerando o cenário de altas emissões A2 do IPCC. Dentre as principais mudanças projetadas, estão: redução da precipitação no nordeste do Brasil, centro-leste e sul da Amazônia; aumento da temperatura na região tropical, principalmente no inverno, podendo chegar a $6^{\circ} \mathrm{C}$.

No estudo Reboita et al. (2014) o modelo regional RegCM3 foi novamente utilizado para investigar o clima da AS no futuro, porém, desta vez, aninhado aos modelos globais HadCM3 e ECHAM5 no cenário A1B do IPCC. Como resultado, Reboita et al. (2014) relataram tendência positivas de precipitação no sul da AS e negativas no norte da AS, em concordância com estudos prévios.

Em suma, apesar das diferentes metodologias empregadas e conclusões, notase um consenso dos estudos quanto ao sinal das tendências projetadas em regiões específicas da AS, como: tendências negativas (positivas) de precipitação na porção central-leste da Amazônia e também no NEB (sudeste da $A S$ ), e tendências aquecimento em todo o continente (LLOPART; REBOITA; DA ROCHA, 2020; MARENGO et al., 2010). Ambrizzi et al. (2019) sumarizam estas tendências futuras do clima em um mapa esquemático, mostrado na Figura 6.

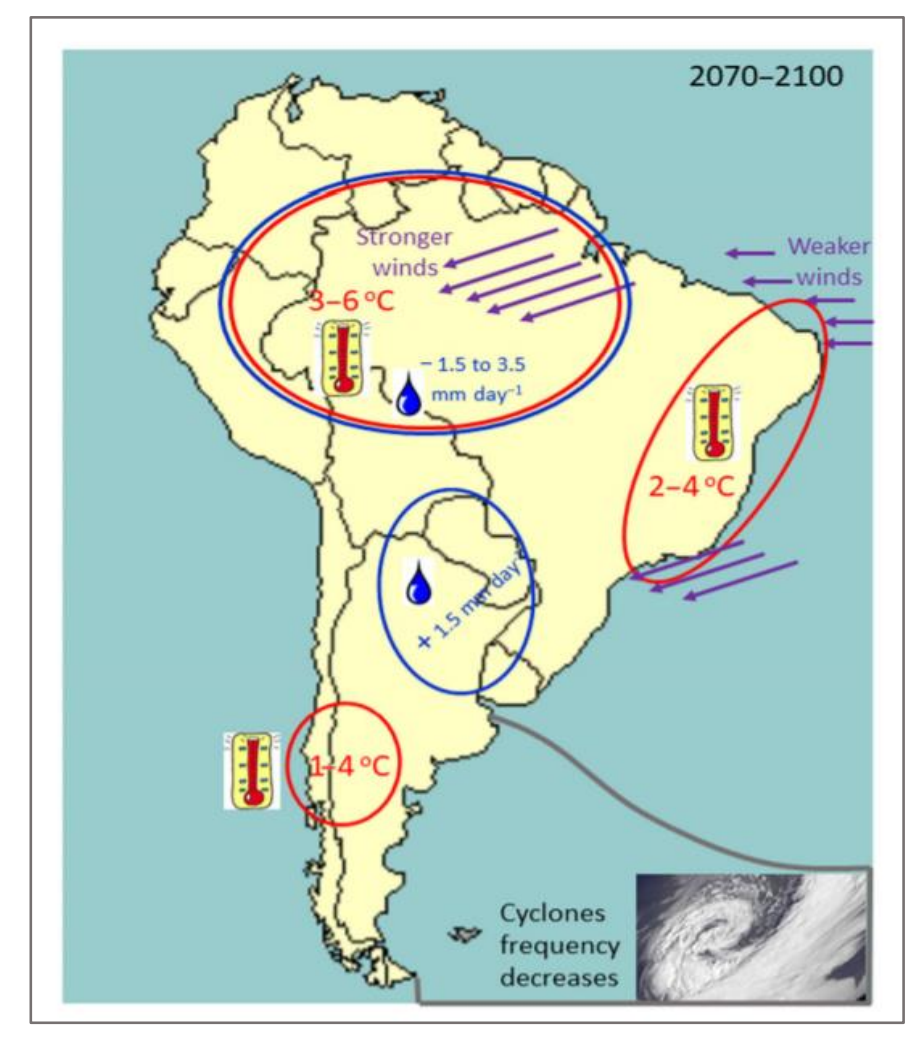

Figura 6 - Representação esquemática das principais mudanças no clima da AS previstas por diversos estudos para o final do século XXI (2070 a 2100). Fonte: Adaptado de Ambrizzi et al. (2019). 


\subsubsection{Projeções climáticas de ventos e WPD}

As projeções climáticas de vento próximo à superfície e WPD foram pouco exploradas até a última década. Porém, a crescente busca por recursos energéticos limpos e sustentáveis tem fomentado pesquisas ao redor do mundo. Na Europa, alguns estudos buscaram avaliar os possíveis impactos das mudanças climáticas nos padrões de vento e WPD ao longo do século XXI (BLOOM; KOTRONI; LAGOUVARDOS, 2008; CARVALHO et al., 2017; HUEGING et al., 2013; TOBIN et al., 2016). Os resultados destes estudos apontam para uma tendência de redução do potencial eólico na região do Mediterrâneo e Atlântico adjacente, e um aumento no Norte da Europa e partes da Turquia.

Em um estudo recente, Davy et al. (2018) investigaram o potencial eólico Europeu em dois cenários representativos de emissão (Representative Concentration Pathways, RCP) do IPCC, RCP4.5 e RCP8.5. As projeções foram realizadas com o modelo regional RCA4 (Rossby Centre regional atmospheric model) que utilizou cinco modelos globais do CMIP5 como condições iniciais e de fronteira. O estudo confirmou as tendências climáticas de trabalhos anteriores: diminuição do potencial eólico em grande parte do continente Europeu e aumento nas extremidades sul e norte do mar Negro, além de uma intensificação no potencial offshore nos mares Báltico e Egeu.

Sawadogo et al. (2020) investigaram as mudanças futuras no potencial eólico e solar no continente Africano por meio de um conjunto de simulações realizadas com o modelo regional RegCM4, como parte da iniciativa do Coordinated Regional Downscaling Experiment (CORDEX) na sua versão CORDEX-CORE (GUTOWSKI et al., 2016). As simulações consideraram dois cenários possíveis de emissão do IPCC, o mais otimista RCP2.6 e pessimista RCP8.5, para dois períodos futuros: 1) de 2021 a 2040; 2) de 2041 a 2060. De acordo com os autores, as condições para a expansão de fontes renováveis no clima futuro mostram-se promissoras no continente Africano. Apesar da redução projetada no potencial solar, espera-se um aumento significativo de até $20 \%$ na WPD na porção central e noroeste da África, especialmente no futuro distante.

Nos Estados Unidos, as projeções futuras de velocidade do vento e WPD indicam condições favoráveis em partes das planícies central e sul, que abrangem os estados do Kansas, Texas e Oklahoma, conforme proposto pelo estudo de Johnson e Erhardt (2016). Neste trabalho, os autores avaliaram quatro modelos regionais do 
projeto NARCCAP (North American Regional Climate Change Assessment Program) sob o cenário de emissão A2 do SRES (Special Report on Emissions Scenarios) para o período futuro, entre 2030 a 2070. Os autores encontraram um forte consenso entre as simulações quanto às mudanças projetadas para a WPD. Com exceção das planícies americanas, projeta-se uma diminuição dos ventos e WPD no restante do país. Tal resultado já havia sido encontrado por Greene et al. (2012).

Conforme discutido anteriormente, estudos sobre projeções climáticas para AS avaliam, principalmente, as alterações futuras de precipitação e temperatura, dado seus impactos mais diretos na sociedade e nos recursos naturais. Alguns destes discutiram mudanças nos padrões de circulação geral da atmosfera, porém, pouquíssimos trabalhos atentaram para os efeitos das mudanças climáticas no comportamento futuro do vento próximo à superfície e seu impacto na produção de energia eólica.

Lucena et al. (2010) realizaram um dos primeiros estudos de projeção climática de ventos para o Brasil buscando examinar a vulnerabilidade da produção eólica no país no clima futuro. As projeções analisadas foram as com o modelo de circulação global HadCM3 do Hadley Centre considerando dois cenários de emissão do SRES: A2 e B2, durante o período de 2070 e 2100 . Para obter uma maior representatividade do potencial eólico, os autores extrapolaram o vento de $10 \mathrm{~m}$ para $50 \mathrm{~m}$ de altura utilizando a lei logarítmica. As estimativas de Lucena et al. (2010) sugerem que o potencial eólico do Brasil será afetado positivamente pelas mudanças climáticas, especialmente no final deste século (2091 a 2100) no cenário A2 (mais pessimista). Um aumento mais significativo (> 20\%) foi projetado pelo HAdCM3 para as regiões norte, nordeste, leste do sudeste e sul do Rio Grande do Sul. Entretanto, os autores salientam que, dadas as incertezas nas simulações dos GCMs e na evolução do clima futuro, as projeções analisadas devem ser vistas como uma possibilidade ao invés de uma fatalidade.

Posteriormente, Pereira et al. (2013) abordaram as tendências no potencial eólico do Brasil por meio de um downscaling dinâmico entre o Modelo Regional Eta do CPTEC (Centro de Previsão de Tempo e Estudos Climáticos) e o global HadCM3, sob o cenário A1B do IPCC. O estudo focou nas regiões sul e nordeste do país por serem os principais núcleos geradores de energia eólica no cenário atual. $A$ maior resolução horizontal utilizada $(40 \mathrm{~km})$ somada a maior abrangência temporal (2010 a 2100) possibilitou aos autores uma melhor caracterização da variabilidade da WPD 
em cenários futuros. Como resultado, Pereira et al. (2013) encontraram um aumento médio na WPD entre $15 \%$ e $30 \%$ em todo NEB, podendo chegar a $100 \%$ no setor norte e nordeste desta região (entre 2070 e 2100). A análise de projeções sazonais revelou que a intensificação da WPD será mais intensa no outono, acima de $60 \% \mathrm{em}$ grande parte do NEB. As projeções para a região sul do Brasil são igualmente otimistas, porém com indicações futuras de aumento da WPD de menor intensidade (de $10 \%$ a $20 \%$ )

Recentemente, Reboita et al. (2018) revisitou as tendências climáticas de vento e WPD para AS por meio de um downscaling dinâmico com o modelo regional RegCM4 do ICTP (International Centre for Theoretical Physics). Os autores empregaram técnicas mais elaboradas buscando reduzir as incertezas nas projeções, como a aplicação de bias correction na velocidade do vento, o uso de um conjunto de vários GCMs, além de considerar as variações de densidade no cálculo de WPD. Ademais, este foi o primeiro estudo de projeção de WPD a considerar os novos cenários RCPs do IPCC. Deve-se ressaltar, ainda, que o conjunto de projeções com o RegCM4 foram realizadas com resolução horizontal de $50 \mathrm{~km}$, ligeiramente menor que a de Pereira et al. (2013). Segundo Reboita et al. (2018), o modelo RegCM demonstrou destreza em representar os padrões espaciais de circulação da AS no clima presente, apesar de superestimar a velocidade do vento no centro-leste do Brasil e na Patagônia. Com relação ao clima futuro, o estudo identificou uma intensificação da velocidade do vento na WPD para o norte da AS, Brasil central e leste (com exceção do verão) e em latitudes. Em contrapartida, regiões como o oeste da Amazônia, partes do Chile, Colômbia e Peru, além de toda a extremidade norte da Patagônia devem experienciar uma redução na magnitude do vento no futuro. Essas mudanças projetadas serão mais intensas no futuro distante (2070 a 2098) do cenário RCP8.5

Os resultados encontrados por Reboita et al. (2018) concordam, em partes, com os estudos prévios de Lucena et al. (2010) e Pereira et al. (2013). O sinal e a distribuição espacial das variações de vento e WPD no clima futuro apresentam similaridades entre os estudos, porém com diferentes intensidades. Segundo Reboita et al. (2018), as divergências entre os resultados estariam associadas ao uso de diferentes cenários e modelos, além das incertezas presentes nas simulações. 


\section{DADOS E METODOLOGIA}

\subsection{Dados}

Medidas de vento em estações meteorológicas são realizadas por anemômetros instalados a $10 \mathrm{~m}$ de altura, conforme sugere a WMO (World Meteorological Organization). Observações diretas a $100 \mathrm{~m}$ são escassas no Brasil, pois requerem instalação de torres e uma infraestrutura robusta de operação e manutenção. Dessa forma, este estudo utilizou dados de vento a $10 \mathrm{~m}$ de altura (posteriormente extrapolados) da reanálise ERA-Interim, produzida pelo ECMWF (European Centre for Medium-Range Weather Forecast) em frequência mensal, com resolução horizontal de $0,75^{\circ} \times 0,75^{\circ}$ de latitude por longitude (DEE et al., 2011). A ERA-Interim foi escolhida por ser o banco de dados oficial de validação dos experimentos CORDEX e CMIP5 (BRANDS et al., 2013; REBOITA; AMARO; DE SOUZA, 2018). Embora poucos estudos tenham comparado medidas de vento da ERA-interim no Brasil com dados observacionais, diversos trabalhos realizados em outras partes do Globo mostraram a destreza desta reanálise em representar a variabilidade climática observada (BROWER et al., 2013; KAISER-WEISS et al., 2015; TABATA et al., 2011).

\subsection{Métodos}

Para avaliar o comportamento do vento na AS nos cenários presente e futuro, bem como realizar estimativas de potencial eólico, foi utilizado um conjunto de simulações climáticas regionais de alta resolução horizontal $(25 \mathrm{~km})$ realizadas com a última versão do modelo climático regional RegCM (GIORGI et al., 2012) como parte do projeto CORDEX-CORE (GUTOWSKI et al., 2016). Parte da metodologia empregada nas análises deriva dos estudos prévios de Reboita et al. (2018) e Brito (2018). A abordagem subdivide-se em duas partes ou estudos: 1) Estudo de validação (EstVal): cujo objetivo é avaliar a qualidade da regionalização no clima presente por meio da comparação do vento a $100 \mathrm{~m}$ de altura nas simulações com a ERA-Interim; 2) Estudo de Projeção (EstProj): Cujo objetivo é mensurar e caracterizar as mudanças de vento e WPD no clima futuro. O detalhamento dos dados e métodos empregados é apresentado nas próximas sessões. 


\subsection{1 Área de estudo}

O domínio espacial das projeções climáticas utilizou o recomendado pelo Coordinated Regional Climate Downscaling Experiment (CORDEX) para a América do Sul (Figura 7, esquerda), semelhante à fase 1 do projeto RegCM Hyper-Matrix (CREMA). Segundo Giorgi (2014) o projeto CREMA tem por finalidade investigar a resposta do RegCM4 à diferentes modelos globais forçantes do CMIP5 (Coupled Model Intercomparison Project Phase 5). Ambos, CMIP e CORDEX, são projetos que objetivam a padronização dos experimentos de modelagem climática, global e regional respectivamente, fornecendo diretrizes que devem ser executadas pelos grupos de pesquisa.
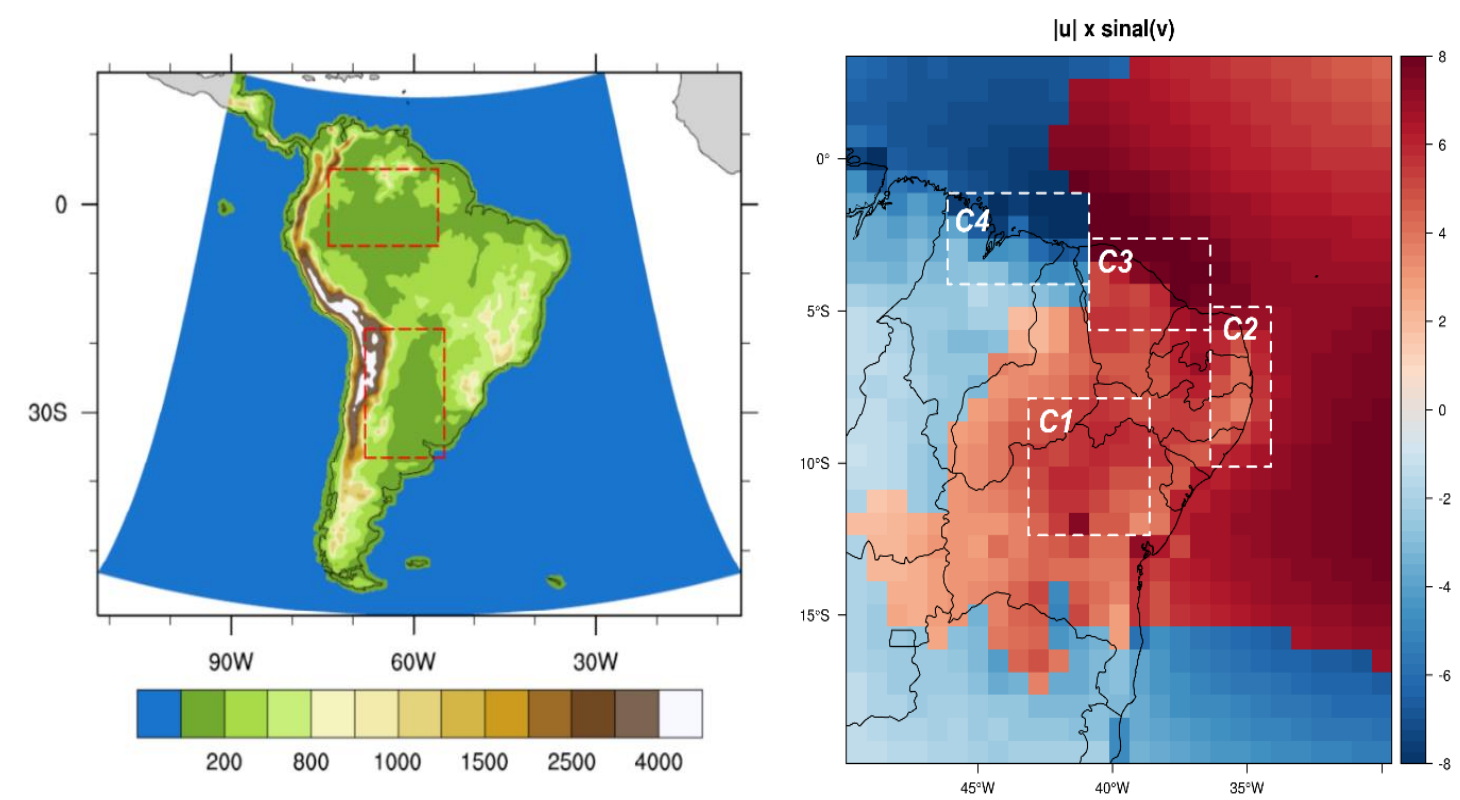

Figura 7 - Esquerda: Domínio utilizado nas simulações climáticas sugerido pelo CORDEX para a AS (Fonte: Adaptado de (SINES et al., 2018)). Direita: Subdomínios analisados no NEB (C1, C2, C3 e C4) semelhantes à Brito (2018).

Neste domínio proposto pelo CORDEX, as fronteiras do modelo estão distantes da área de interesse o que permite ao modelo desenvolver circulações locais resultantes da representação mais realística de fatores fisiográficos (topografia, linha de costa, diferentes coberturas do solo etc.). Neste estudo, o subdomínio de interesse corresponde à porção Nordeste do Brasil. Para avaliar o potencial eólico desta região, foram selecionados quatro subdomínios mostrados na Figura 7 (direita), denominados C1 (interior), C2 (leste), C3 (norte) e C4 (noroeste). A delimitação de cada subdomínio 
seguiu os critérios propostos por Brito (2018), que considerou a distribuição espacial da velocidade e direção do vento e a densidade de parques eólicos instalados no nordeste do Brasil.

\subsubsection{Descrição do modelo RegCM4}

O RegCM é um modelo climático regional que surgiu no NCAR (National Center for Atmospheric Research) em 1989 (GIORGI; MARINUCCI; BATES, 1993) como uma versão aprimorada do Mesoscale Model version 4 (MM4, ANTHES; HSIE; KUO, 1987). Desde então, tem sido usado por diversas instituições de pesquisa em estudos do clima atual e mudanças climáticas (DA ROCHA et al., 2014; GIORGI et al., 2012; GIORGI; MEARNS, 1999; PAL et al., 2007). Atualmente o RegCM4 é mantido e distribuído pelo ICTP e possui código de livre acesso.

Para resolver as equações que governam os movimentos atmosféricos 0 RegCM utiliza o método de diferenças finitas para uma atmosfera compressível, com coordenada vertical sigma-pressão e pode ser executado utilizando núcleo dinâmico hidrostático ou não-hidrostático. A integração no tempo é realizada em área limitada e utiliza um esquema de "split-explicit" (GIORGI et al., 2012; GIORGI; MEARNS, 1999).

Em sua versão mais recente, o RegCM4 trouxe uma série de novas atualizações na física do modelo. Uma das maiores inovações foi a inclusão de um novo esquema de parametrização de superfície, o CLM4.5 (Community Land Model 4.5) (OLESON; LAWRENCE, 2013). O CLM4.5 representa o estado da arte em modelagem de processos de troca superfície-planta-atmosfera, sendo uma evolução em termos de descrição da temperatura e umidade do solo, da vegetação e dos processos hidrológicos.

\subsubsection{Descrição das simulações}

As simulações do RegCM4 utilizadas aqui foram realizadas no contexto do projeto CORDEX-CORE, cujo objetivo principal foi disponibilizar simulações em alta resolução para estudos de mudanças climáticas em diversas regiões do Globo (GUTOWSKI et al., 2016). Para o CORDEX-CORE, no domínio da AS, o RegCM4 foi integrado de 1970 a 2100 com resolução horizontal de 25 km, 23 níveis verticais e 
núcleo dinâmico hidrostático. Com relação ao conjunto de parametrizações empregadas nas simulações com o RegCM4, destacam-se os esquemas de Tiedtke (TIEDTKE, 1989) e Kain-Fritsch (KAIN; FRITSCH, 1993) para a solução da convecção profunda sobre o continente e oceano, respectivamente. A precipitação na escala de grade foi resolvida com o esquema SUBEX (PAL et al., 2007), e para descrever os processos de interação solo-planta-atmosfera foi utilizado o CLM4.5. Apesar das simulações com o RegCM4 se estenderem por 130 anos, a análise foca em três períodos de 30 anos: 1985 a 2014 (presente); 2031-2060 (futuro próximo); 2070 a 2099 (futuro distante). Tal escolha se deve por este ser o intervalo de tempo mínimo considerado na grande maioria dos estudos de projeção climática e por possibilitar a comparação entre períodos distintos (i.e presente e futuro).

As simulações do RegCM4, obtidas do projeto CORDEX-CORE, estão aninhadas a três Earth System Models (ESMs) do CMIP5, são eles: 1) Hadley Centre Global Enviroment Model version 2 (HADGEM2-ES, JONES et al., 2011) ) com resolução horizontal de $1,5^{\circ} \times 1,5^{\circ}$; 2) Max Planck Institute Earth Sytem Model (MPIESM-MR, GIORGETTA et al., 2013) com resolução horizontal de $\sim 1,9^{\circ} \times 1,9^{\circ}$; 3) Norwegian Earth System Model 1 (NorESM-1, BENTSEN et al., 2012) com $\sim 1,9^{\circ} \mathrm{x}$ $1,9^{\circ}$ de resolução horizontal.

Estudos anteriores de downscaling dinâmico com modelos dinâmicos aninhados nos modelos globais MPI-ESM-MR e HADGEM2-ES para o domínio da AS mostraram que ambos são capazes de reproduzir as condições climáticas observada de grande escala, sendo, portanto, adequados para estudos de mudanças climáticas (DA ROCHA et al., 2014; LLOPART et al., 2014; MARENGO et al., 2012; REBOITA et al., 2018).

O global NorESM-1 foi desenvolvido recentemente, na Noruega, e é principalmente baseado no Cummunity Climate System Model version 4 (CCSM4) do NCAR (BENTSEN et al., 2012). Embora ainda não tenha sido utilizado em simulações climáticas na AS, diversos estudos realizados em outros continentes sugerem uma boa performance deste modelo, principalmente em experimentos de projeção climática e paleoclima (SELAND et al., 2020; ZHANG et al., 2012).

As três simulações com o RegCM4 serão denominadas: RegHAD, RegMPI e RegESM, forçadas pelos globais HADGEM2-ES, MPI-ESM-MR e NorESM-1, respectivamente. A simulação forçada pela reanálise ERA-Interim, ou simulação "controle", RegEl. As projeções climáticas foram executadas considerando o cenário 
de emissões RCP8.5, do CMIP5 IPCC, cujas concentrações de gases de efeito estufa são fornecidas em Van Vuuren et al. (2011). Este cenário futuro é o mais pessimista de todos, uma vez que assume um aumento contínuo de emissão de gases estufa até o final deste século.

\subsubsection{Extrapolação vertical: vento a $100 \mathrm{~m}$}

A altura média de operação dos aerogeradores modernos é entre 80 e 120 metros (EIA, 2017). Dessa forma, é desejável ter estimativas de vento nestas altitudes a fim de averiguar a capacidade eólica de uma região. Assim, antes de calcular a magnitude do vento e WPD, o vento a $10 \mathrm{~m}$ foi extrapolado para $100 \mathrm{~m}$ por meio da lei logarítmica expressa abaixo (MANWELL; MCGOWAN; ROGERS, 2010).

$$
U(Z)=U(Z r) \frac{\ln \left(\frac{Z}{Z o}\right)}{\ln \left(\frac{Z r}{Z o}\right)}
$$

onde $U(Z)$ representa a velocidade do vento na altura desejada, $U(Z r)$ é a velocidade do vento na altura de referência, $Z$ a altura desejada $(100 \mathrm{~m}), Z r$ altura de referência (10 m) e $Z o$ o coeficiente de rugosidade da superfície. Para cada ponto de grade do modelo estimou-se $Z o$ a partir da tabela disponibilizada no manual do RegCM4 (Tabela 3.1) (ELGUINDI et al., 2011). A aproximação logarítmica e uma técnica amplamente usada em estudos de modelagem de vento (ARCHER; JACOBSON, 2005; CARVALHO et al., 2012; LIMA et al., 2011; LIMA; CAVALCANTI; SOUZA, 2010; PIMENTA; ASSIREU, 2015; SILVA et al., 2016). Este processo foi aplicado somente nos dados de reanálise, uma vez que as simulações dispunham do vento a $100 \mathrm{~m}$. Deve-se salientar que, embora a equação 1.2 não leve em consideração variações na estabilidade da atmosfera, ela é bastante apropriada para ser empregada em estudos de escala climática (REBOITA et al., 2018). 


\subsection{Função densidade de probabilidade de Weibull}

\subsubsection{Métodos de ajuste e parâmetros da distribuição}

A PDFw é uma das distribuições mais utilizadas para modelar a variabilidade observada dos ventos (ARAUJO; MARINHO, 2019; JUSTUS; MIKHAIL, 1976). Os parâmetros derivados desta distribuição, denominados c (escala) e k (forma), fornecem informações sobre o valor médio e a dispersão de ocorrência das medidas. Além disso, a PDFw incorpora casos particulares de outras distribuições estatísticas dependendo do valor que $k$ assume. Por exemplo, quando $k=1,0$ a PDFw torna-se uma distribuição exponencial, e quando $k=2,0$, distribuição de Rayleigh (LIMA e FILHO, 2010). A PDFw e sua função cumulativa (Cumulative Density Function, CDF) são expressas segundo as relações abaixo (JUSTUS; MIKHAIL, 1976):

$$
\begin{aligned}
& f(v)=\left(\frac{k}{c}\right)\left(\frac{v}{c}\right)^{k-1} e^{-\left(\frac{v}{c}\right)^{k}} \\
& F(v)=\int_{0}^{v} f(v) d v=1-e^{-\left(\frac{v}{c}\right)^{k}}
\end{aligned}
$$

onde $f(v)$ representa a PDFw, $F(v)$ a CDFw, $c$ o parâmetro de escala, em $m s^{-1}$ e $k$ o fator de forma, adimensional. A interpretação destes parâmetros é ilustrada na Figura 7. Considerando $\mathrm{c}=1,0 \mathrm{~ms}^{-1}$, tem-se que maiores valores $k$ estão associados a distribuições mais simétricas e deslocadas para direita, implicando em ventos mais intensos e constantes. Por outro lado, quando $k=2,0$ nota-se que à medida que $c$ aumenta, a distribuição se achata e a dispersão das medidas também aumenta. Assim, quanto maior c mais variáveis e extremos são os ventos. Como se pode notar, os parâmetros c e k divergem quanto ao seu significado físico e, portanto, devem ser analisados conjuntamente (SILVA, 2003). 

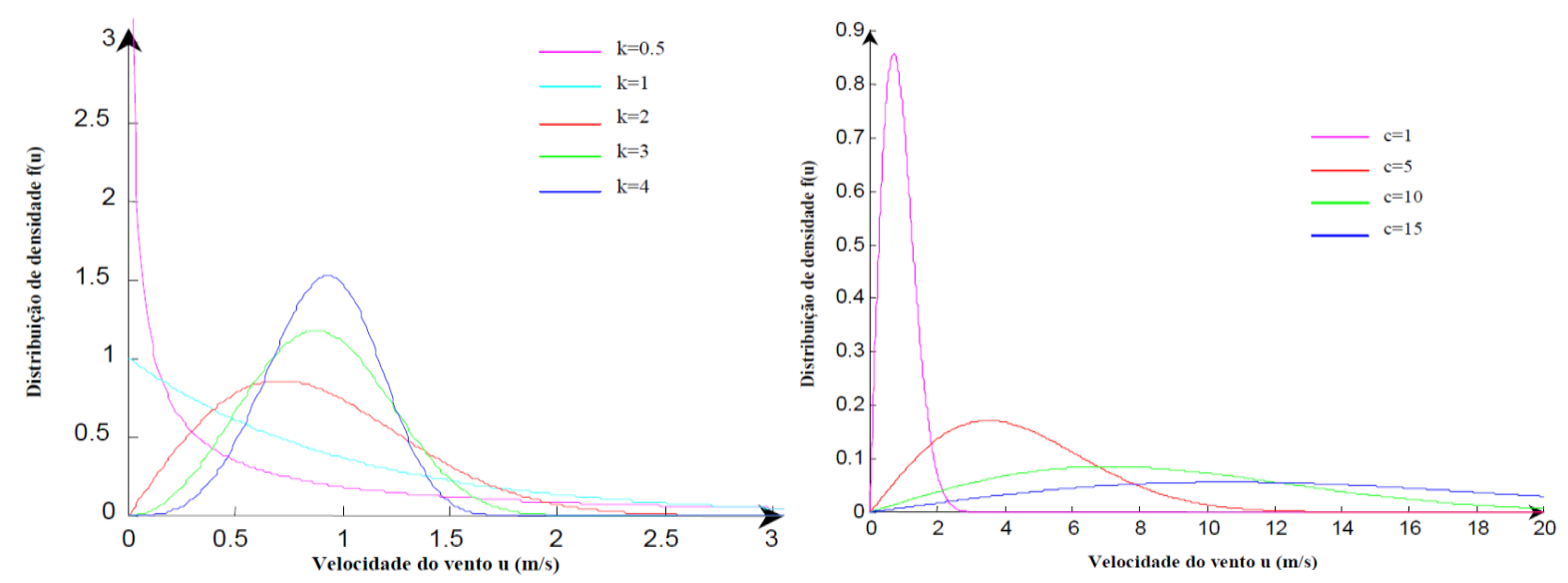

Figura 8 - Distribuições de probabilidade de Weibull em diferentes regimes de ventos. Esquerda: variações de $k$ para $c=1$; direita: variações de c para $k=2$. Fonte: Adaptado de Silva (2003).

Existem inúmeros métodos documentados na literatura para se obter $\mathrm{c} \mathrm{e} \mathrm{k}$ (COSTA ROCHA et al., 2012). Neste estudo, estes foram estimados com o método de máxima verossimilhança (Maximum Likelihood Method, MLM) calculado com o pacote fitdistrplus (DELIGNETTE-MULLER; DUTANG, 2015) do RStudio (TEAM, 2015). O MLM consiste na maximização da função de verossimilhança por meio de métodos interativos (KIDMO et al., 2015), de modo c e k são dados por:

$$
\begin{gathered}
k=\left[\frac{\sum_{i=1}^{n} v_{k}^{i} \ln \left(v_{i}\right)}{\sum_{i=1}^{n} v_{i}^{k}}-\frac{\sum_{i=1}^{n} \ln \left(v_{i}\right)}{n}\right]^{-1} \\
c=\left[\frac{1}{n}\left(\sum_{i=1}^{n} v_{k}^{i}\right)\right]^{\frac{1}{k}}
\end{gathered}
$$

A qualidade do ajuste da PDFw foi aferida através do coeficiente de determinação $\left(R^{2}\right)$. O $R^{2}$ é uma medida que expressa a destreza do modelo probabilístico em representar os dados observados (COSTA ROCHA et al., 2012). Os valores de $R^{2}$ variam entre 0 e 1, sendo que valores próximos a 1 indicam melhor ajuste, enquanto valores próximos a zero indicam pior ajuste. 


\subsection{Produção anual de energia e fator de capacidade}

A produção anual de energia (AEP) e o fator de capacidade (CF) são importantes variáveis que traduzem o potencial eólico de uma região. Ambas são frequentemente utilizadas em atlas eólicos e são calculadas considerando um tipo específico de aerogerador. Neste trabalho, considerou-se um aerogerador de $2 \mathrm{MW}$ comumente utilizado na literatura (modelo ENERCON E82 2MW). A partir da curva de potência deste aerogerador (ver apêndice) e das distribuições de frequências dos intervalos de velocidades da PDFw, a AEP foi calculada como (IEC, 1998):

$$
A E P=8760 \times \sum_{i=1}^{n}\left\{\left[f\left(v_{i}\right)-f\left(v_{i-1}\right)\right] \times\left[\left(\frac{P_{i-1}+P_{i}}{2}\right)\right]\right\}
$$

onde $n$ representa o número de intervalos de frequência de velocidade ou bins, $P_{i}$ a potência associada ao intervalo, e $f\left(v_{i}\right)$ a frequência de ocorrência da PDFw. O fator de capacidade, por outro lado, é uma grandeza adimensional utilizada para medir a produtividade de qualquer dispositivo gerador de energia em um certo período de tempo (geralmente 1 ano) (ELHADJ SIDI et al., 2016). Para o aerogerador em questão, o CF é dado pela razão entre a AEP observada (real) e AEP máxima (hipotética) que pode ser alcançada de acordo com a equação:

$$
C F=\frac{A E P_{\text {real }}}{A E P_{\max }} \times 100
$$

Frequentemente, o CF é utilizado como um índice de desempenho, expresso em termos percentuais. Segundo o atlas eólico nacional, as estimativas de CF sobre o NEB variam de 10 a 35\%, sendo que valores acima de $20 \%$ já são considerados razoáveis para geração eólica. Entretanto, valores mensais no NEB podem atingir os 70\%, superando inclusive diversos sítios na Europa (ABEEÓLICA, 2020). 


\subsection{Análise das projeções climáticas regionais}

\subsubsection{Estudo de validação: EstVal}

O EstVal consistiu em avaliar o desempenho das simulações climáticas no período presente (1985 a 2014). Para isso, foram calculados os biases (ou vieses) sazonais comparando as simulações com a reanálise ERA-Interim no domínio da AS. Isto foi calculado para cada simulação individual e para a média das três simulações (ensemble). O bias é uma medida simples e de fácil cálculo, porém incapaz de inferir a real acurácia do modelo (HALLAK; FILHO, 2011). Dessa forma, foram elaborados diagramas de Taylor para os quatro subdomínios no NEB. O diagrama de Taylor, por sua vez, combina uma série de índices estatísticos, como a raiz quadrada do erro médio quadrático (Root Mean Square Error, RMSE), coeficiente de correlação e desvio padrão (TAYLOR, 2001), que fornecem mais informações sobre a robustez dos valores modelados. Por fim, antes de analisar as projeções futuras, aplicou-se um bias correction às simulações de maneira semelhante à Reboita et al. (2018).

Como pequenos erros na velocidade do vento acarretam grandes erros na WPD, uma vez que esta depende da velocidade do vento ao cubo (Equação 1), utilizou-se uma metodologia simples de bias correction (ou correção de vieses) com base no trabalho de Reboita et al. (2018). Esta técnica consiste em subtrair de cada simulação o seu respectivo "erro", calculado como a diferença entre modelo e reanálise. A partir das séries corrigidas, calcula-se então o ensemble das simulações. Esta metodologia de bias correction foi aplicada tanto nas simulações do clima presente quanto no futuro.

\subsubsection{Estudo de projeção: EstProj}

O EstProj buscou mensurar e caracterizar as mudanças na velocidade do vento e WPD no clima futuro. Para tanto, foram calculadas as diferenças sazonais e mensais entre o futuro e o presente para a magnitude do vento e WPD. As diferenças relativas (ou tendências relativas) foram calculadas como: 


$$
\text { Tend }=\left(\frac{\text { Futuro }- \text { Presente }}{\text { Presente }}\right) \times 100
$$

Deve-se ressaltar que no cálculo da WPD a densidade do ar $(\rho)$ foi calculada segundo a relação proposta por Custódio (2009):

$$
\rho \cong \frac{353,4\left(1-\frac{Z}{45271}\right)^{5,2624}}{273,15+T}
$$

onde $\rho$ representa a densidade do ar $\left(\mathrm{Kgm}^{-3}\right), T$ representa a temperatura do ar $\left({ }^{\circ} \mathrm{C}\right)$ e $Z$ a altura de interesse $(100 \mathrm{~m})$. A temperatura em 100 metros foi obtida a partir da temperatura a 2 metros considerando um lapse rate adiabático seco, onde a cada 100 $m$ de altitude a temperatura decresce $1^{\circ} \mathrm{C}$ (WALLACE; HOBBS, 2006).

A partir das médias mensais de WPD, calculou-se a tendência total para o outono e período seco (junho a novembro, AMARANTE et al. 2000) dos quatro subdomínios do NEB (Figura 7, direita) com intuito de investigar possíveis impactos para a complementaridade hidro-eólica. Em seguida, para cada mês do ano foram realizados os testes t de Student, para verificar se as mudanças projetadas no clima futuro resultam da variabilidade natural do clima ou não. O teste foi conduzido assumindo o intervalo de confiança de 95\% e distribuição bicaudal (WILKS, 2011), ou seja:

$$
t=\frac{\mu_{1}-\mu_{2}}{\sqrt{\frac{\sigma_{1}^{2}}{n_{1}}+\frac{\sigma_{2}^{2}}{n_{2}}}}
$$

onde $\mu$ representa a média, $\sigma$ o desvio padrão e $n$ o número de elementos da série temporal. Os subíndices 1 e 2 referem-se aos períodos presente e futuro, respectivamente. Ainda para cada subdomínio analisado foram calculadas e comparadas as PDFws da magnitude do vento e os parâmetros derivados (c e k), a AEP e o CF. Por último, através de séries temporais com valores médios mensais de velocidade do vento, analisou-se a tendência de longo período (1985 a 2099) e a ocorrência de episódios extremos. Esta análise de extremos foi empregada nas séries 
de magnitude do vento média para o período seco (junho a novembro) e chuvoso (março a maio) do NEB. A justificativa para a estação chuvosa ou de outono austral, deve-se a dois motivos principais apresentados por Brito (2018): 1) maior variabilidade interanual da velocidade do vento; 2) maior influência do ENSO. Por outro lado, Brito (2018) também mostra que a velocidade do vento apresenta baixa variabilidade interanual fora do período chuvoso, que inclui os meses de junho a novembro que se denominou período seco. Dessa forma, a finalidade desta análise é identificar possíveis futuros aumentos ou diminuições no número de eventos extremos de velocidade do vento em duas estações do ano contrastantes no NEB. 


\section{RESULTADOS}

Este capítulo está subdividido em quatro sessões. Na primeira sessão são apresentados os resultados de validação das simulações no clima presente, referente ao estudo EstVal. Nas seções seguintes são apresentados os resultados do estudo EstProj. A seção 2 contém as projeções climáticas de vento e WPD. A sessão 3 analisa tendências e extremos de magnitude do vento no NEB, além da análise estatística do modelo probabilístico Weibull. A sessão quatro exibe as estimativas do potencial eólico do NEB.

\subsection{Validação das simulações no clima presente}

A Figura 9 mostra a climatologia sazonal do vento a $100 \mathrm{~m}$ para o período presente (1985 a 2014) referente à reanálise ERAI (coluna esquerda), RegEns (ensemble das simulações) (coluna do meio) e a diferença RegEns e ERAI, ou bias (coluna direita). Sobre o Atlântico Sul, o padrão de ventos mais intensos nos extratrópicos, que decrescem de magnitude nos subtrópicos e voltam a se intensificar na região tropical presente na reanálise ERAl é reproduzido pelo ensemble do RegCM4. Como padrão geral, destacam-se diferenças positivas persistentes ao longo do ano na região Sudeste do Brasil, especialmente no estado de Minas Gerais e sobre o Oceano Atlântico desde a costa do Espírito Santo até o Paraná. Durante o outono e inverno, a superestimativa atinge valores pontuais de até $3 \mathrm{~ms}^{-1}$, expandindo-se para a região Centro-Oeste do Brasil. Ainda nestas estações, são notadas superestimativas, porém de menor intensidade $\left(\sim 1 \mathrm{~ms}^{-1}\right)$ em todo território argentino. Na primavera, um erro de destaque, também verificado por Reboita et al. (2018) ocorre no leste do NEB, englobando todo o estado do Piauí. Nesta região, o RegEns simula ventos muito mais intensos que a reanálise ERAI. Deve-se também destacar os altos valores de biases positivos ao longo de toda cordilheira Andina. No noroeste da AS e partes da Amazônia, em contrapartida, o modelo tende a subestimar a velocidade do vento em relação à reanálise ERAI, especialmente no verão $\left(<2 m s^{-1}\right)$, e outono $(<$ $1,5 \mathrm{~ms}^{-1}$ ). Nas demais áreas continentais, sobretudo no leste da Amazônia e partes da Argentina (na primavera e verão), o RegEns é capaz de simular a magnitude do vento muito próximo à da ERAI. Sobre o oceano Atlântico, o RegCM4 apresenta bom desempenho nas estações de inverno e primavera (Figura 9). No entanto, no verão e 
outono o RegCM4 tende a superestimar as velocidades da reanálise ERAI próximo das latitudes de $30^{\circ} \mathrm{S}$ e $50^{\circ} \mathrm{S}$. Além disso, as diferenças positivas em $50^{\circ} \mathrm{S}$ abrangem também a extremidade sul do continente sul-americano, na Patagônia da Argentina. Ainda sobre o Atlântico, próximo à região equatorial, notam-se diferenças negativas que se estendem até o norte do NEB durante as estações de verão e inverno. As simulações de magnitude do vento no Pacífico apresentam bom desempenho. Nesta região, pode-se evidenciar uma tendência geral de pequena subestimativa da velocidade do vento, ligeiramente diferente de Reboita et al. (2018). Todavia, os valores de biases não ultrapassam $-1 \mathrm{~ms}^{-1}$, com exceção da costa do Peru no outono. Os padrões espaciais de bias encontrados neste estudo assemelham-se aos de Reboita et al. (2018). Entretanto, nas simulações de Reboita et al. (2018) as diferenças são maiores e mais abrangentes em alguns locais, como o Brasil central e norte da Argentina. Tal diferença pode ser atribuída aos diferentes modelos globais forçantes (Geophysical Fluid Dynamics Laboratory model, DUNE et al., 2012), bem como a menor resolução horizontal $(50 \mathrm{~km})$.

A fim de verificar as características de cada simulação em individual (RegHAD, RegMPI e RegESM) a Figura 10 apresenta o bias sazonal para cada simulação. Apesar da singularidade de cada simulação existem áreas de consenso quanto ao sinal do bias. Durante o primeiro semestre do ano (DJF e MAM) as 3 simulações mostram maior dificuldade em representar a magnitude observada dos ventos, especialmente o RegMPI e RegESM. Sobre o Atlântico, ambas reproduzem um padrão de dipolo, com bias negativo (até $-3 \mathrm{~ms}^{-1}$ ) próximo ao equador e positivo (até $>3 \mathrm{~ms}^{-1}$ ) a sul de $10^{\circ} \mathrm{S}$. No segundo semestre do ano (JJA e SON) as simulações capturam melhor a intensidade dos ventos da ERAI, com destaque para o RegMPI e RegESM. No Pacífico, as simulações discordam entre si. Ao longo de todo ano, o RegHAD subestima a magnitude do vento, enquanto o RegMPI e RegHAD simulam padrões semelhantes ao Atlântico, mas com biases menores. Sobre o continente, diferenças negativas de velocidade são notadas na região Amazônica e estão presentes nas 3 simulações durante todo $o$ ano. A área de subestimativas engloba também o NEB, e perduram do verão ao outono no RegMPI. Já no RegESM, a subestimativa ocupa mais a porção norte do NEB. No RegHAD os valores de bias são menores (entre $-1 \mathrm{~ms}^{-1}$ e $1 \mathrm{~ms}^{-1}$ ) e mais heterogêneos do que no RegMPI e RegESM. Na primavera, destaca-se novamente a porção centro-leste do NEB com valores de biases positivos $\left(3 \mathrm{~ms}^{-1}\right)$ nas três simulações, sendo mais intenso no RegHAD. No 
Brasil central e sudeste os 3 modelos tendem a superestimar a velocidade do vento da ERAI em todas as estações do ano, principalmente o RegESM no outono e inverno.
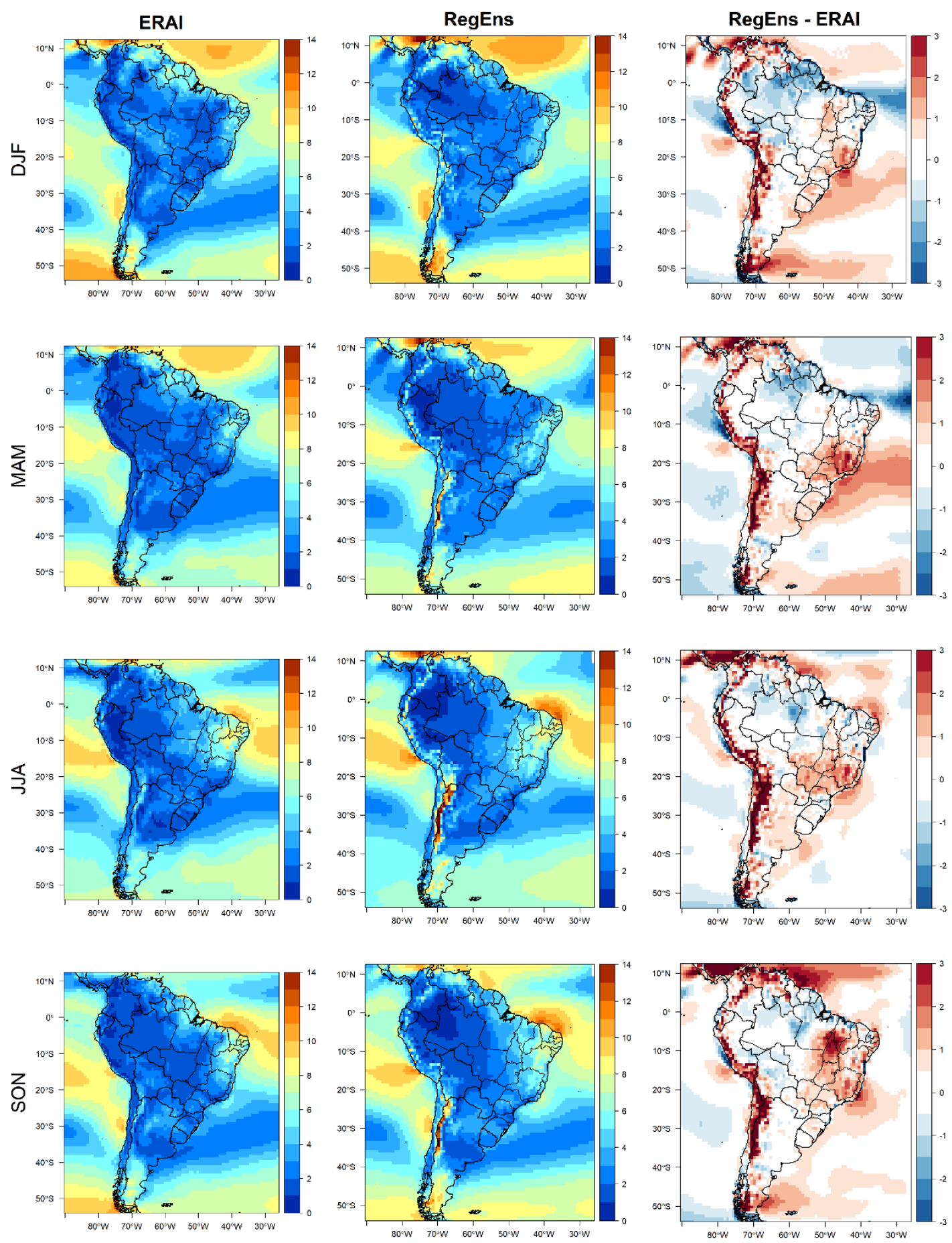

Figura 9 - Climatologia sazonal do vento a $100 \mathrm{~m}$ de altura $\left(m s^{-1}\right)$ para o período presente (1985 a 2014), representados pela reanálise ERA-Interim (coluna esquerda), RegEns (coluna central) e diferença RegEns menos ERAI (coluna direita). 

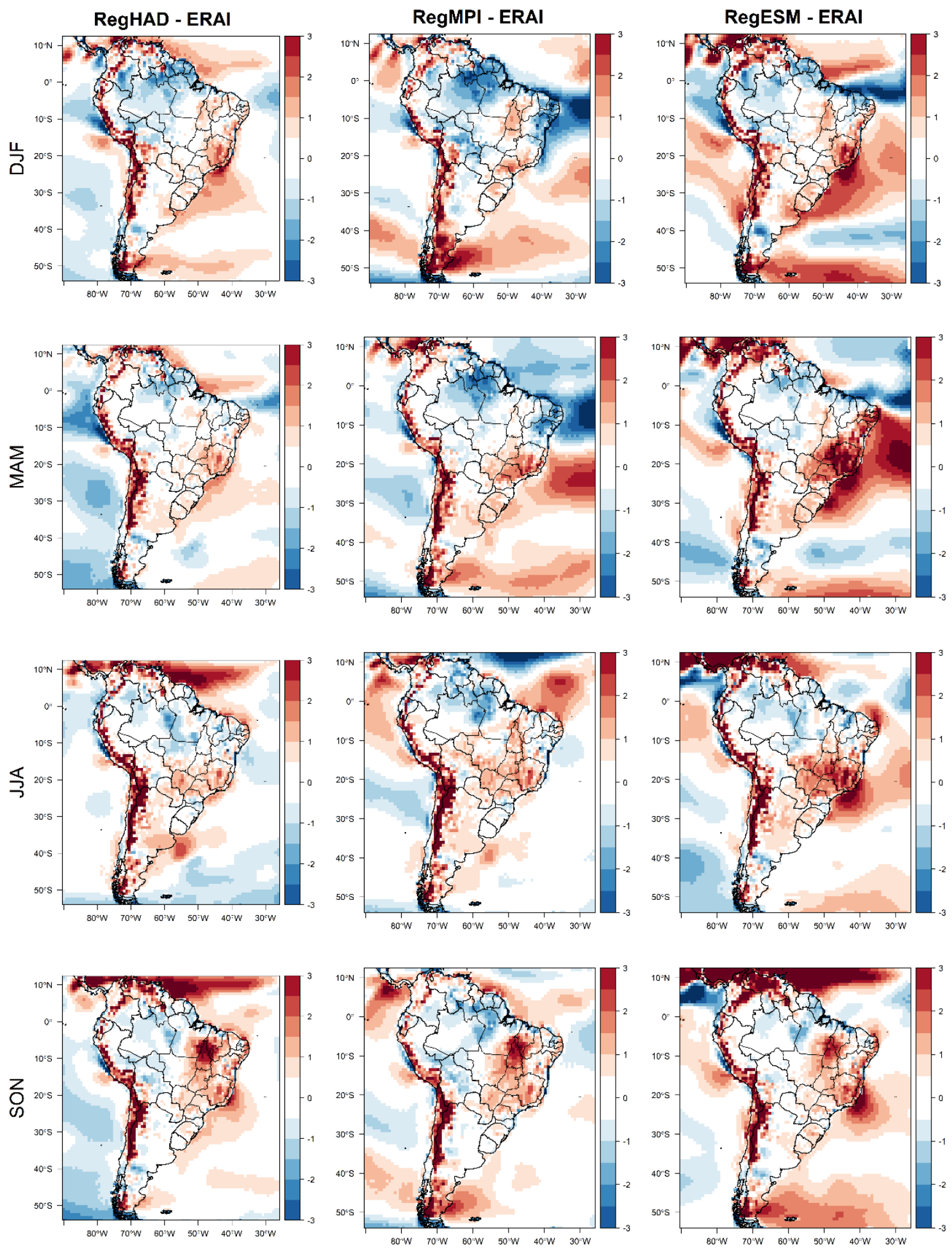

Figura 10 - Bias sazonal do vento a $100 \mathrm{~m}\left(\mathrm{~ms}^{-1}\right)$ no período presente (1985 a 2014) das simulações: RegHAD (esquerda), RegMPI (centro) e RegESM (direita). 

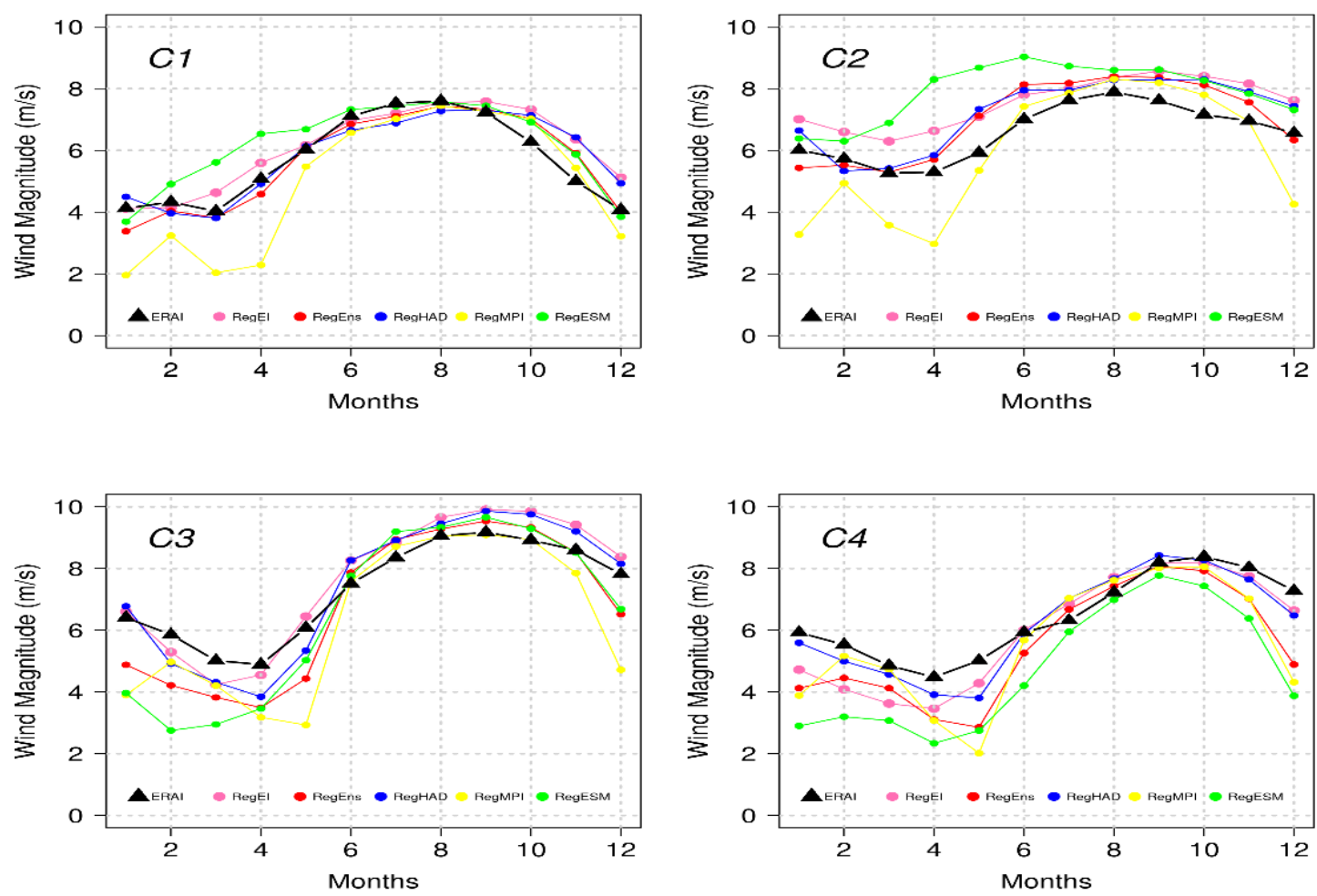

C1

C2
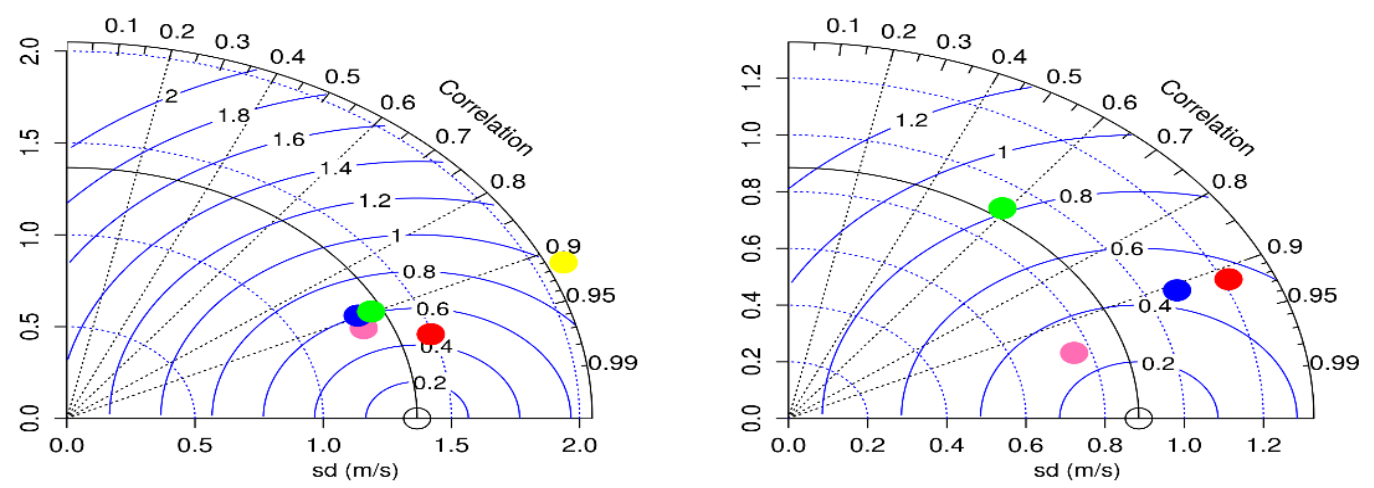

c3

C4
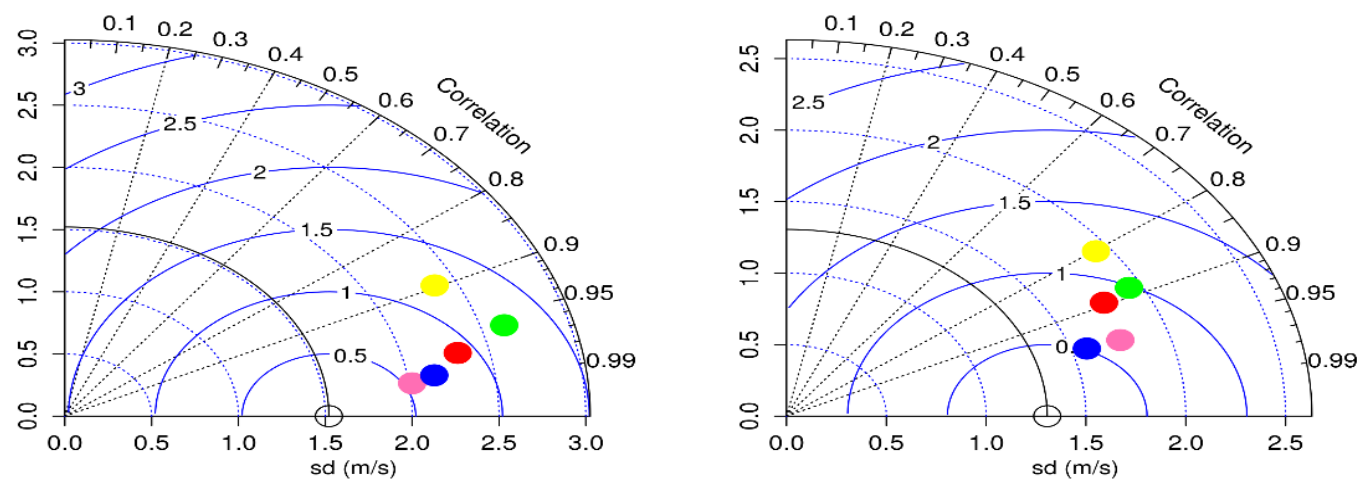

Figura 11 - Painel superior: Ciclo anual da magnitude do vento a $100 \mathrm{~m}$ de altura $\left(\mathrm{ms}^{-1}\right)$ para os quatro subdomínios do NEB simulado pelas simulações individuais (RegHAD, RegMPI e RegESM), ensemble (RegEns), simulação controle (RegEl) e reanálise (ERAl). Painel inferior: Diagrama de Taylor das séries temporais utilizadas no painel superior. 
Dada as proporções continentais da AS e os diversos fatores que influenciam nos regimes dos ventos, pode-se dizer que, em geral, as simulações exibem características comuns, como biases negativos na região Amazônica e positivos no Brasil central e sudeste.

Os biases sazonais nas Figuras 8 e 9 permitem detectar a presença de erros sistemáticos nas simulações. Entretanto, o bias por si só não pode ser utilizado como medida de acurácia do modelo. Assim sendo, os diagramas de Taylor do ciclo anual da magnitude do vento agregam outras estatísticas para avaliação das simulações climáticas. Para os quatro subdomínios do NEB a Figura 11 apresenta os ciclos anuais e os respectivos diagramas de Taylor. Com relação ao ciclo anual da magnitude do vento (Figura 11, superior), nota-se que os subdomínios C3 e C4, localizados na extremidade norte e noroeste do NEB, apresentam maior variabilidade do vento (desvio padrão $\cong 1,5 \mathrm{~ms}^{-1}$ ), com máximos na primavera $\left(>m s^{-1}\right)$ e mínimos no outono $\left(\sim 4.5 \mathrm{~ms}^{-1}\right)$. Essa forte amplitude do ciclo anual da velocidade do vento está associada à migração sazonal da ZCIT (CAVALCANTI, 2016). Comparando os quatro subdomínios que são os mesmos estudados por Brito (2018), verifica-se que a velocidade do vento aqui encontrada é superior. Esse fato pode estar relacionado tanto à baixa resolução como também à assimilação apenas de vento e pressão sobre o oceano da reanálise centenária ERA20C utilizada pelo autor. Ainda referente a C3 e C4, nota-se que o RegHAD e RegEl (RegCM4 forçado pela ERAI) demonstram melhor acurácia em capturar a variabilidade mensal na ERAI observada, seguido pelo RegEns. A fase dos ciclos anuais são bem representadas em todas as simulações, como mostram os valores de correlação acima de 0.9 (C3) e 0.8 (C4).

Também nestes domínios indicam maiores valores de RMSE, acima de 0,5 $m s^{-1}$, o que seria explicado pela maior subestimativa de velocidade do vento de outubro a junho. Em C1 e C2 os valores de RMSE são menores, e os modelos tendem a simular ciclos anuais de velocidade dos ventos mais semelhantes aos da ERAI, especialmente em C1. Nestas regiões o RegEns mostra-se mais acurado, sendo a melhor simulação em C1 (correlação de 0.95 ) e a segunda melhor em C2, seguido do RegEl. A região C2, que compreende a porção leste do NEB, demonstra menor variabilidade do vento (desvio padrão $\cong 0,9 \mathrm{~ms}^{-1}$ ), com velocidades médias acima dos $6 \mathrm{~ms}^{-1}$ (ideais para geração eólica) em quase todos os meses do ano. Isto ocorre devido à forte influência dos alísios de sudeste oriundos do setor norte do ASAS, que persiste de verão a verão. Nesta região, o aumento abrupto da velocidade do vento a 
partir de fevereiro resulta em maior RMSE e menor correlação na simulação RegESM, enquanto nas demais apresentam menores erros de fase e amplitude do ciclo anual. No subdomínio $\mathrm{C} 1$, os ventos são menos intensos devido a maior influência da rugosidade da superfície atuando na desaceleração dos ventos, e somente nos meses de inverno e primavera ultrapassam os $6 \mathrm{~ms}^{-1}$.

\subsubsection{Bias Correction (Correção de viés)}

Conforme evidenciam os mapas de biases sazonais (Figuras 8 e 9), o RegCM4 exibe certas dificuldades em simular a magnitude observada dos ventos, especialmente nas regiões sudeste e centro-oeste do Brasil, na extremidade sul da AS e em partes do Atlântico (entre $20^{\circ}$ S e $30^{\circ} \mathrm{S}$ ). Dessa forma, antes de investigar as projeções futuras de velocidade do vento e WPD, aplicou-se um bias correction na magnitude média mensal do vento nas simulações individuais em cada ponto de grade. De acordo com Reboita et al. (2018) esta técnica minimiza os erros produzidos pelo modelo e proporciona maior confiabilidade às estimativas de WPD. A eficácia da aplicação do bias correction é ilustrada nas Figura 12 e 13 que mostram as séries mensais de magnitude do vento a $100 \mathrm{~m}$ dos quatro subdomínios do NEB antes e após a correção em comparação com a ERAl, e seus respectivos boxplots.

A Figura 13 mostra, de maneira geral, que nos subdomínios do NEB o RegEns simula maior dispersão da magnitude do vento a $100 \mathrm{~m}$ do que a ERAl antes da aplicação do bias correction. Dentre os subdomínios, o RegEns aproxima-se mais da reanálise em $\mathrm{C} 1$. Ainda assim, neste subdomínio, nota-se uma tendência de superestimativa dos mínimos de velocidade do vento a $100 \mathrm{~m}$, refletindo em um menor quartil inferior, o que é corrigido após a aplicação do bias correction. Em C1 e C2, o RegEns simula maior mediana, o que sugere que a distribuição das medidas de vento a 100 m está levemente deslocada para a esquerda. Em C2, entretanto, o RegEns superestima o quartil superior, especialmente no início da série temporal, claramente observado na Figura 12. Em C3 e C4, o RegEns simula menor mediana, oposto ao que acontece em $\mathrm{C} 1$ e C2. No subdomínio C3, o modelo tende a amplificar a variabilidade indicada na ERAl, principalmente para os mínimos de velocidade. Notase que após aplicação do bias correction a diferença entre o RegEns e reanálise diminui drasticamente. Por fim, em C4, verifica-se uma tendência geral de 
subestimativa pelo RegEns da velocidade da ERAI, mais evidente na última década da série temporal (Figura 12).

b) Before bias correction

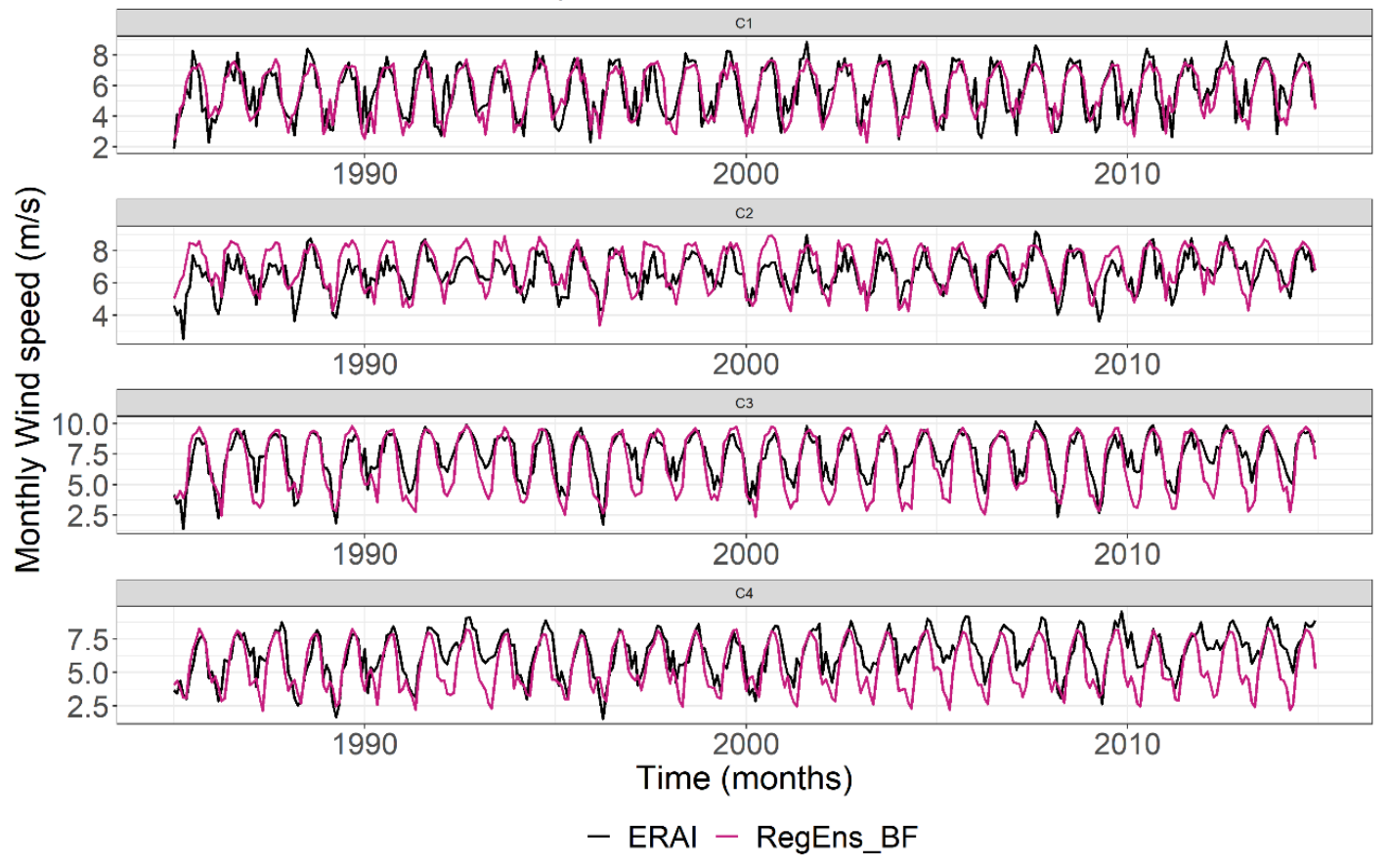

b) After bias correction

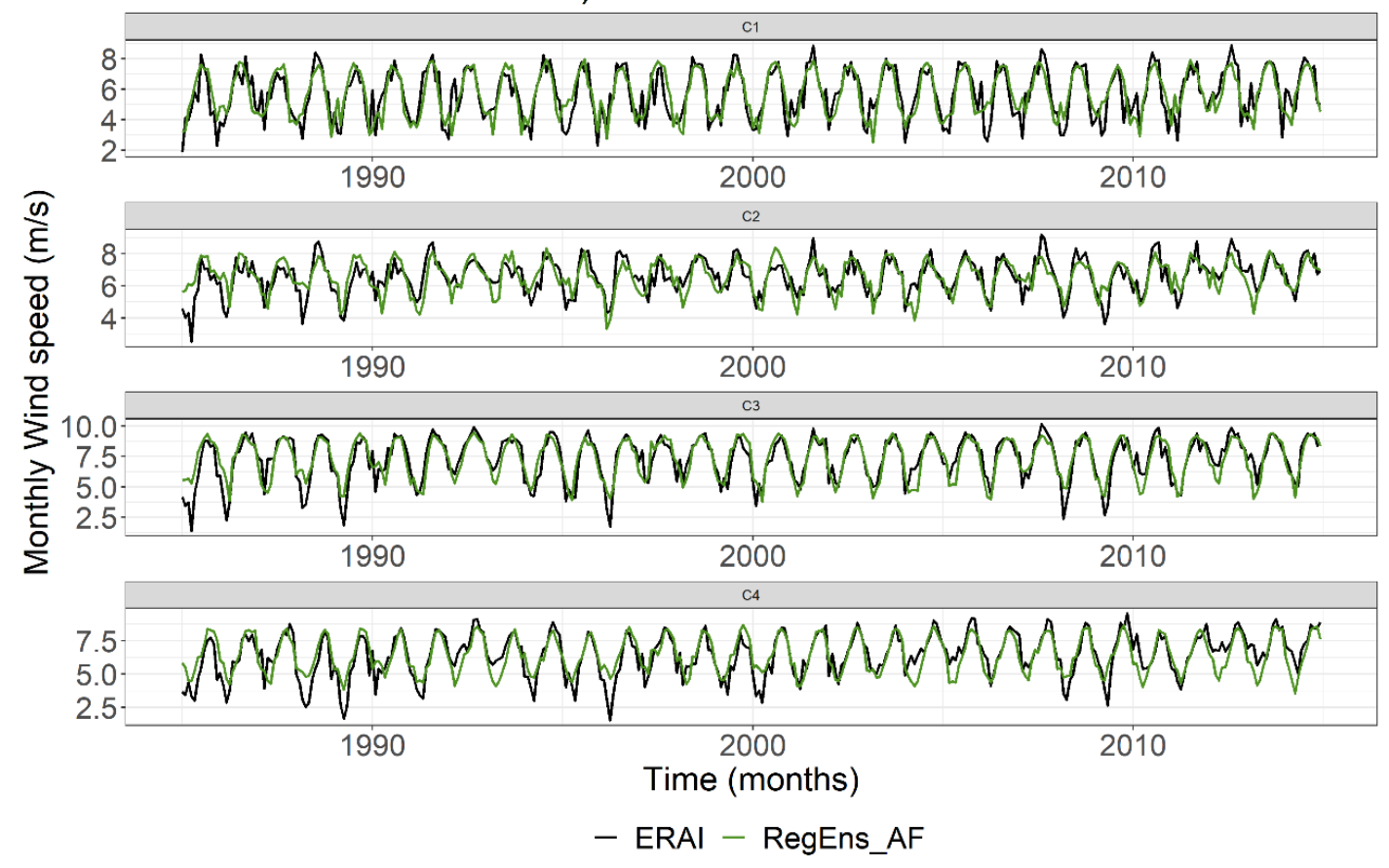

Figura 12 - Séries temporais de magnitude do vento a $100 \mathrm{~m}$ de altura $\left(\mathrm{ms}^{-1}\right)$ do RegEns para as quatro sub-regiões analisadas no NEB (C1, C2, C3 e C4) no período presente (1985 a 2014). O painel superior a) contém as séries temporais antes aplicação do bias correction, e o painel b) após. 


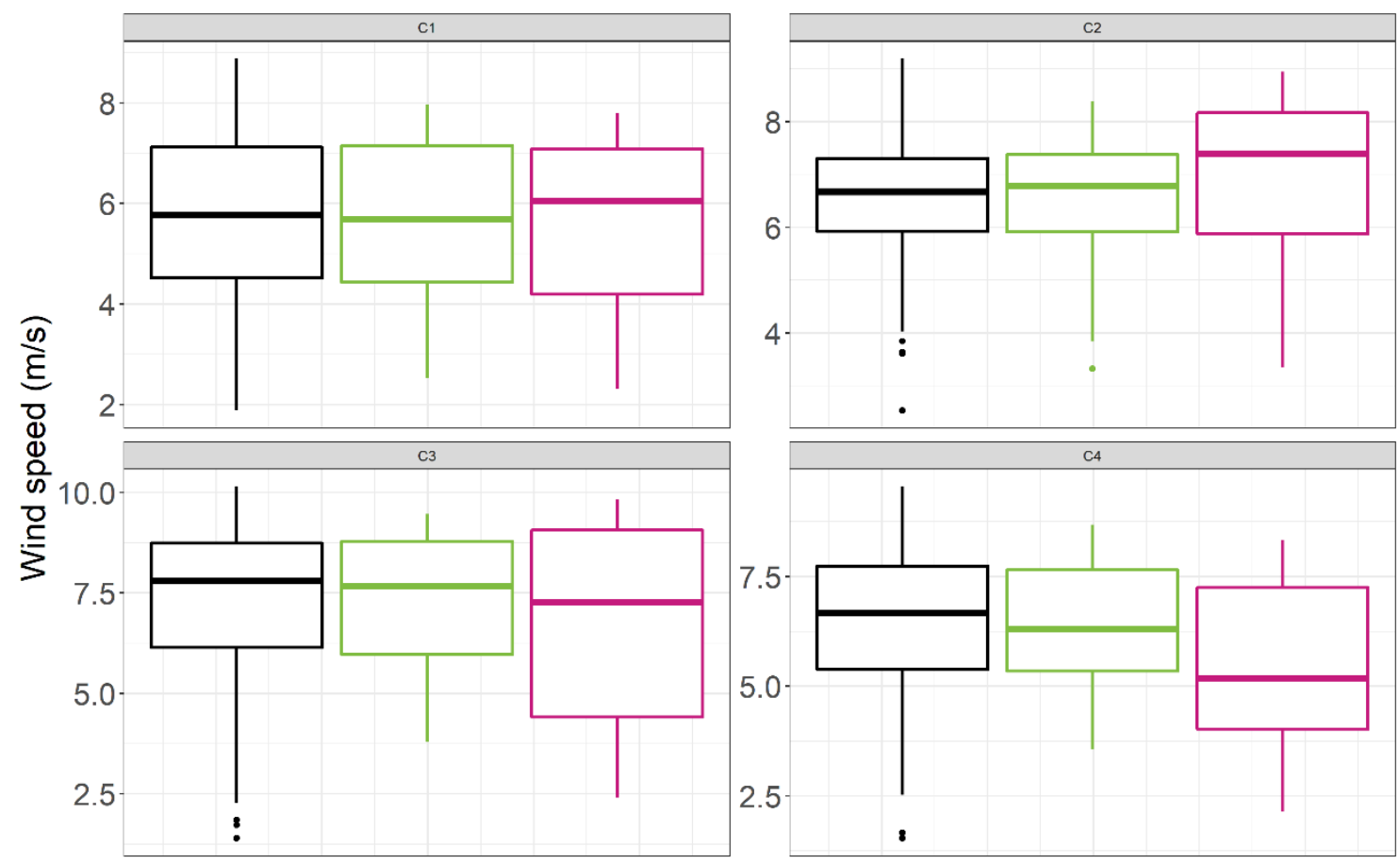

白 ERAI 白 RegEns_AF 白 RegEns_BF

Figura 13 - Boxplot das séries temporais de magnitude do vento a $100 \mathrm{~m}$ do RegEns para os quatro subdomínios analisados no NEB (C1, C2, C3 e C4) no período presente (1985 a 2014).

\subsection{Projeções climáticas do vento e WPD}

\subsubsection{Domínio América do Sul}

As mudanças no comportamento dos ventos no clima futuro da AS foram inicialmente investigadas por meio de mapas de diferença (futuro menos presente) sazonal da magnitude do vento a 100 m (Figura 14) e a WPD associada (Figura 15). Conforme descrito na metodologia, removeu-se o viés climatológico (bias correction) da velocidade do vento de cada modelo antes de calcular tanto a WPD como a tendência (futuro menos presente). $\pm 0,5 \mathrm{~ms}^{-1}$.

As tendências, no cenário RCP8.5, indicam que o aumento drástico das concentrações de gases estufa na atmosfera deverão impactar a intensidade dos ventos sobre a AS, especialmente no futuro distante (2070-2099). No futuro próximo, as alterações mostram-se pequenas e não ultrapassam $\pm 0,5 \mathrm{~ms}^{-1}$ (Figura 14, esquerda). No que se refere ao futuro distante (Figura 14, direita), nota-se uma ampla região de intensificação dos ventos que se inicia no norte da AS e Venezuela, e se estende em direção ao Brasil central. No primeiro semestre do ano o aumento de 
velocidade é da ordem de $1 \mathrm{~ms}^{-1}$, comparado ao clima presente. Já no outono e primavera, a região de intensificação dos ventos torna-se mais abrangente, englobando praticamente todo o Brasil com valores acima de $1 \mathrm{~ms}^{-1}$, e atinge em alguns pontos até $2 \mathrm{~ms}^{-1}$. Ventos mais intensos ao longo de todo ano também são projetados para o norte da Argentina e região sul do Brasil, principalmente nas estações de verão e primavera. Esse padrão de intensificação dos ventos sobre o continente assemelha-se ao encontrado por Reboita et al. (2018) e Lucena et al. (2010) em projeções para o fim do século 21. Ainda assim, algumas diferenças existem em relação às projeções da Figura 14 (direita). No outono, por exemplo, as projeções analisadas por Reboita et al. (2018) indicam intensificação dos ventos (> 1 $m s^{-1}$ ) na costa leste do NEB, o que não ocorre nas projeções deste estudo. Além disso, as projeções climáticas para o extremo norte da AS e Venezuela divergem quanto ao sinal da mudança. No Inverno as projeções da Figura 14 (direita) também discordam sobre a região Amazônica, onde Reboita et al. (2018) mostraram um padrão de dipolo, com ventos mais intensos à nordeste e ventos mais fracos à leste. Enquanto os ventos no norte e nordeste da AS aumentam de velocidade nas projeções climáticas, o extremo sul da AS deve experimentar ventos mais fracos no final deste século, especialmente no sul da Argentina. Este enfraquecimento é notado para as projeções em todas as estações do ano, sendo mais acentuado no verão (< $1,5 \mathrm{~ms}^{-1}$ ). De maneira similar, no centro-oeste da AS e sul da Amazônia também as projeções indicam que os ventos irão ficar mais fracos no primeiro semestre do ano.

Sobre os oceanos, as projeções mostram um padrão sequencial que intercala ventos mais fracos e intensos a cada $20^{\circ}$ de latitude durante todo o ano (Figura 14, direita). Nas latitudes equatoriais do Oceano Pacífico, por exemplo, o RegEns projeta uma redução na magnitude dos ventos a $100 \mathrm{~m}$ no futuro distante, seguido ao sul por uma ampla área de intensificação dos ventos que se estende até 30-40ㅇ. Resultado semelhante foi encontrado por Garreaud e Falvey (2009) com o Providing Regional Climate for Impact Studies (PRECIS) sob o cenário A2. Segundo os autores, o fortalecimento dos ventos na porção centro-leste da ASPS está relacionado ao aumento da pressão em superfície em latitudes médias, que por sua vez intensifica 0 gradiente meridional de pressão. Ademais, as projeções climáticas analisadas por Seth et al. (2010) e Reboita et al. (2018) também apontaram para um alargamento dos anticiclones subtropicais do Hemisfério Sul. 
No cinturão latitudinal de $35-50^{\circ}-S$ os ventos voltam a enfraquecer nas projeções, especialmente no verão $\left(-0,5\right.$ a $\left.-1,5 m^{-1}\right)$ e inverno $\left(-0,5\right.$ a $\left.-1,0 m s^{-1}\right)$, numa banda que se prolonga do Pacífico ao Atlântico e é persistente ao longo de todo $\circ$ ano. A projeção futura para o Atlântico sugere uma tendência geral de enfraquecimento dos ventos alísios ao norte do equador, em concordância com os estudos prévios de Marengo et al. (2010) e Reboita et al. (2018). Para Marengo et al. (2010), o enfraquecimento dos alísios sobre o Atlântico norte tropical seria uma das principais causas da redução da precipitação na Amazônia em cenários futuros. Todavia, uma pequena área que envolve a extremidade nordeste do NEB deve experimentar ventos mais fortes no futuro distante, principalmente durante o outono (> 1,5 $\mathrm{ms}^{-1}$ ). Carvalho Silva (2019), em um estudo sobre o potencial eólico offshore brasileiro, mostraram que a região costeira que se estende do estado do Maranhão ao Rio Grande do Norte detém condições favoráveis para geração eólica. Dessa forma, as projeções aqui analisadas servem de incentivo para a expansão deste mercado ao longo do século 21.

Com relação às projeções climáticas de WPD a 100 m de altura (Figura 15), expresso em termos de diferenças relativas percentuais, nota-se, como não poderia deixar de ser, um padrão semelhante às projeções de magnitude do vento a $100 \mathrm{~m}$. Além disso, nota-se que o impacto das mudanças climáticas sobre as variações de WPD são mais intensas no futuro distante (Figura 14, direita), o que concorda com os resultados prévios de Pereira et al. (2013) e Reboita et al. (2018). No período distante (2070-2099) as projeções do RegEns indicam um aumento na WPD no norte de AS (> 50\%), nordeste da Amazônia (> 100\%), região sul do Brasil e norte da Argentina. Este padrão espacial de intensificação é encontrado nas projeções em todas as estações do ano, sendo a primavera com maiores diferenças positivas. Por outro lado, a região que compreende o sudeste da Amazônia, o Peru e a Bolívia devem experimentar uma redução na WPD no primeiro semestre do ano, em especial no verão $(<-40 \%)$. Ainda correspondente ao verão, nota-se também uma projeção de redução de WPS sobre o NEB (- 20\%) e Minas Gerais (-30\%). Tal resultado difere de Pereira et al. (2013), que encontraram aumento na WPD para o NEB em todas as estações do ano, porém concorda com Reboita et al. (2018). O oposto acontece na região sul do Brasil. Enquanto os resultados deste trabalho projetam um aumento na WPD em todas as estações do ano, em especial no segundo semestre, Pereira et al. (2013) encontraram uma redução na WPD no verão e Reboita et al. (2018) no inverno. 

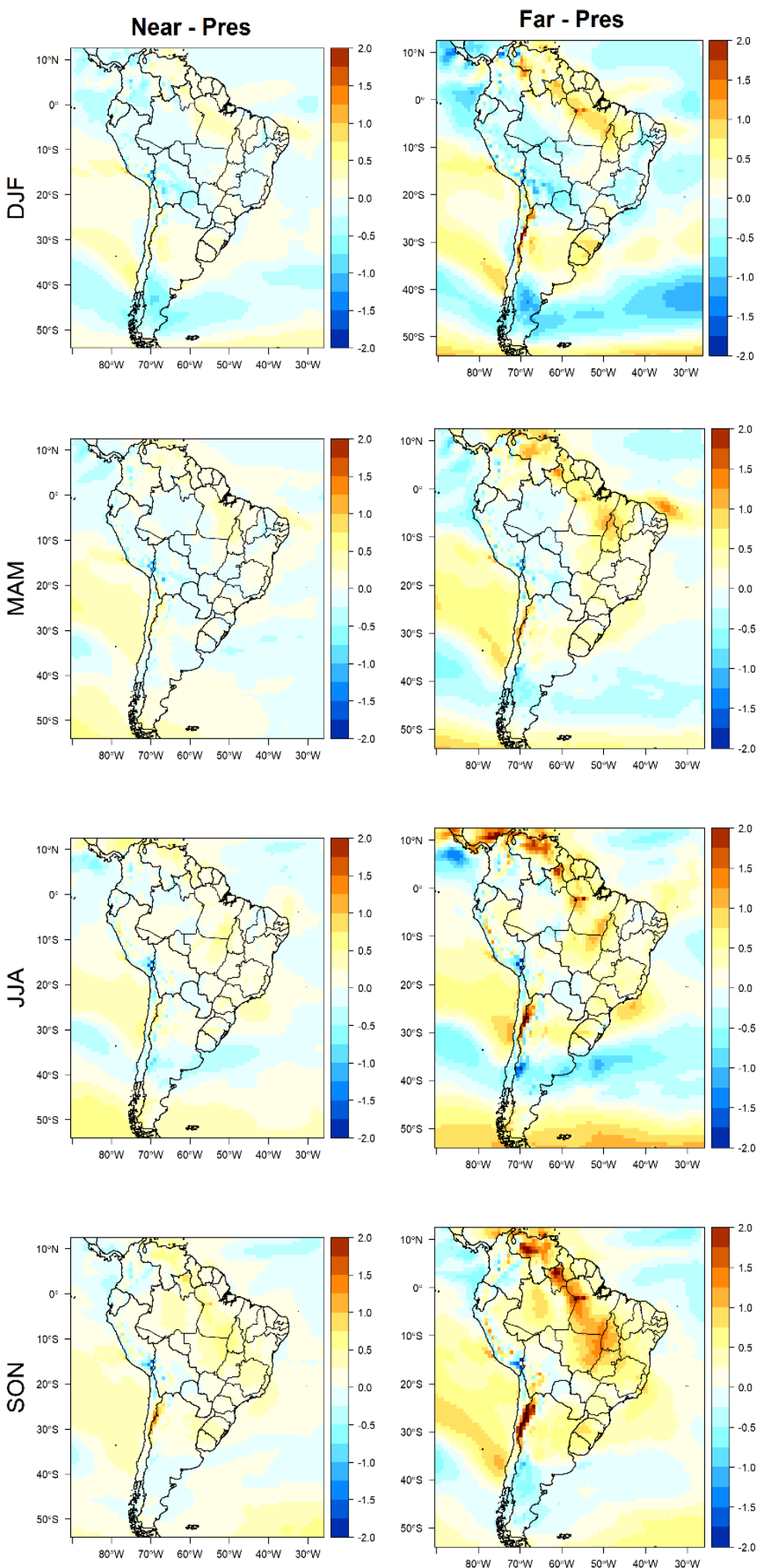

Figura 14 - Tendências (futuro menos presente) sazonais da magnitude do vento $\left(\mathrm{ms}^{-1}\right)$ a $100 \mathrm{~m}$ de altura. Na coluna da esquerda são apresentadas as tendências no futuro próximo (2031-2060) e a da direita as tendências no futuro distante (2070-2099). 

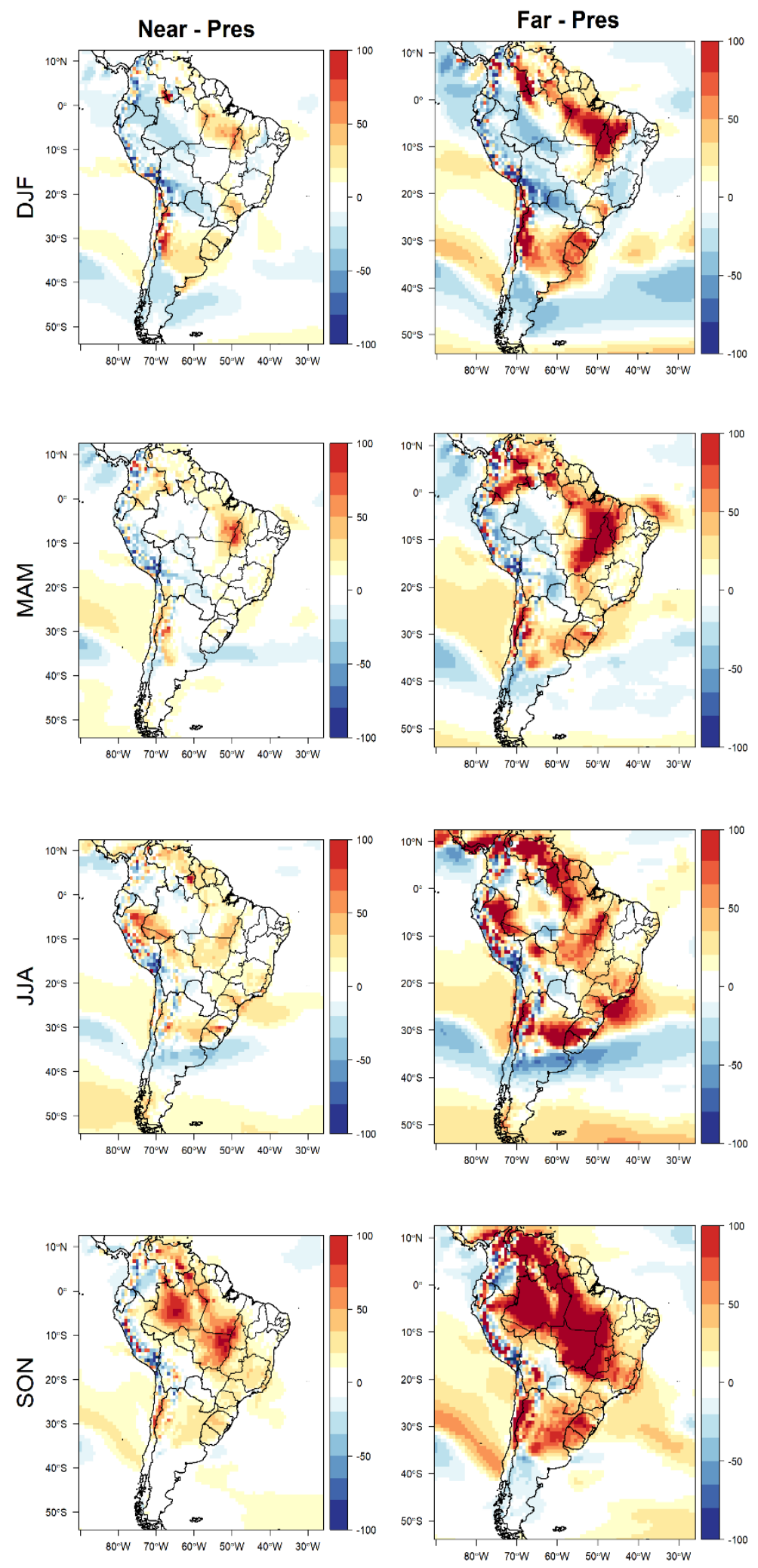

Figura 15 - Idem a Figura 14, mas para a WPD. Neste caso, são tendências relativas expressas em porcentagem (\%). 
Deve-se ressaltar que as diferenças nas projeções de WPD podem estar associadas aos diferentes modelos globais forçantes, período analisado, cenário de emissões utilizados e à resolução horizontal utilizada na regionalização que é de 25 $\mathrm{km}$ no presente estudo e $50 \mathrm{~km}$ em Reboita et al. (2018). Sobre os oceanos, no futuro distante, as projeções indicam o mesmo padrão sequencial sobre o Pacífico, intercalando áreas de aumento e redução de WPD a cada 20-30 de latitude. Destacase a região de intensificação de WPD entre $10^{\circ}$ S e $30^{\circ}$ S. Nessa faixa latitudinal 0 aumento é constante ao longo de todo o ano no oceano Pacífico, podendo chegar a $50 \%$ e, sobre o Atlântico, durante o inverno e primavera. Nos meses de inverno notase uma região de aumento intenso (> $100 \%$ ) próximo à costa da região sul do Brasil, também detectado nas projeções de Pereira et al. (2013) e Reboita et al. (2018). A sul de $30^{\circ} S$ e ao norte do equador voltam a ser projetadas reduções na WPD em comparação ao período presente.

\subsubsection{Domínio Nordeste}

A Figura 16 mostra a tendência sazonal de WPD a $100 \mathrm{~m}$ de altura com foco no Nordeste do Brasil. Diferentemente da Figura 15, a Figura 16 utiliza uma escala reduzida, possibilitando uma melhor caracterização das projeções. Novamente, destaca-se que o impacto das mudanças climáticas na WPD aumenta no futuro distante (2071-2099). Neste período, nota-se que o RegEns projeta um aumento na WPD na porção oeste do NEB (Maranhão e Piauí) em todas as estações do ano. No verão e outono, o aumento na WPD supera os $50 \%$. Na primavera a intensificação na WPD também se mostra significativa, porém, é necessário ressaltar que os modelos superestimaram a velocidade do vento nesta região no clima presente. Já costa leste do NEB e no estado da Bahia notam-se aumentos consideráveis na WPD, variando de 15 a $25 \%$. Outra região que também deve experimentar um aumento na WPD, segundo as projeções do RegEns, é a costa norte e nordeste do NEB, associado à ampla região de intensificação do vento sobre o oceano durante o outono austral. Redução na WPD é projetada somente durante o verão no interior da região Nordeste, chegando a $-20 \%$.

A análise sazonal das tendências de WPD é uma das técnicas mais utilizadas em estudos de projeção climática, sendo muito útil para caracterizar o sinal da mudança nas projeções. Entretanto, para analisar outros aspectos dos ventos e WPD 
no clima futuro é necessário analisar as tendências mensais. Assim, a próxima seção investiga mudanças no ciclo anual da WPD nos quatro subdomínios do NEB (Figura 7, direita) e seus impactos para a complementaridade hídrico-eólica.
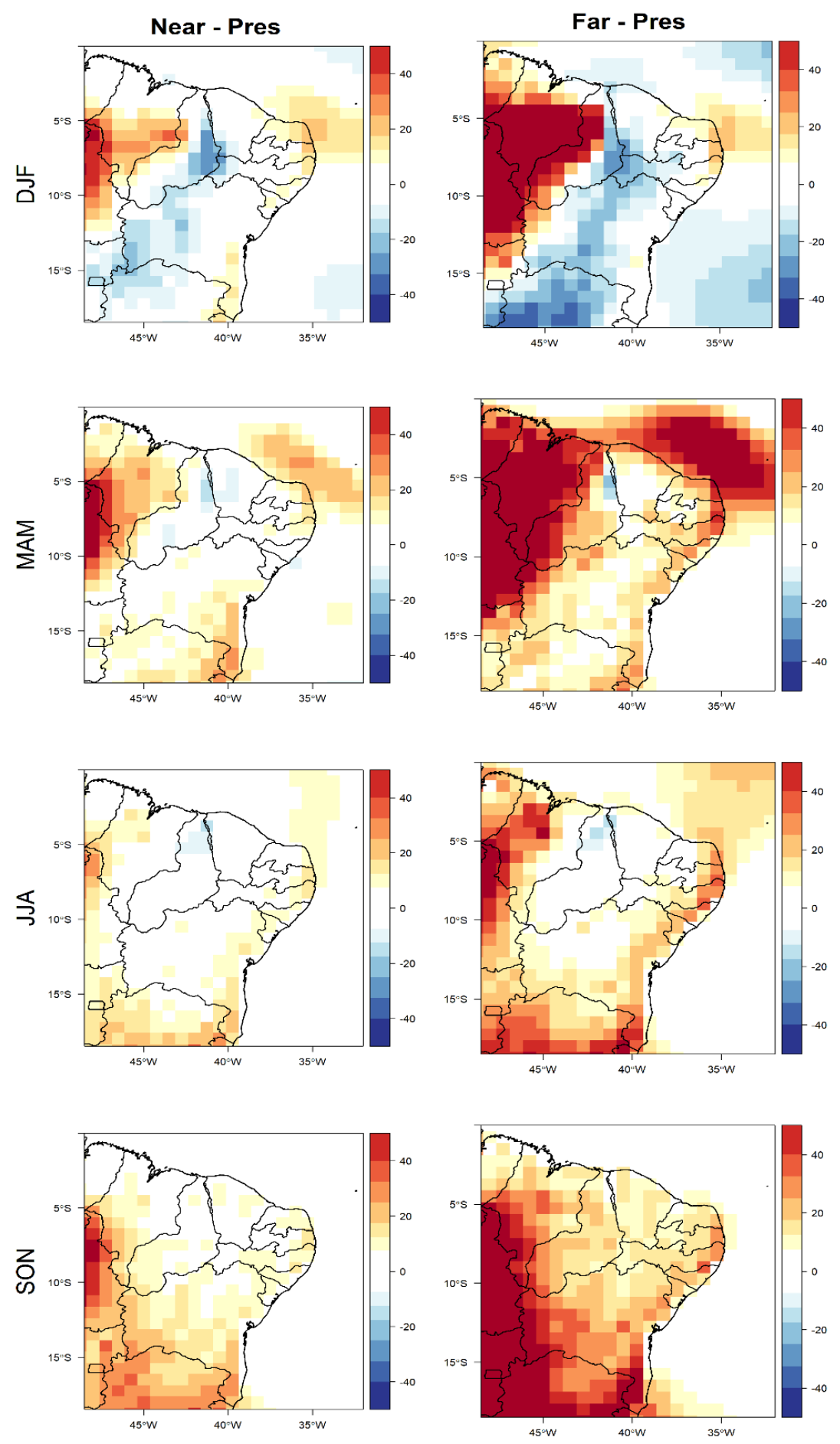

Figura 16 - Idem a Figura 15, mas para o domínio NEB. (*Neste domínio a escala percentual varia de 50 a $50 \%)$. 


\subsubsection{Complementaridade hídrico-eólica no NEB}

As variações de WPD para os quatro subdomínios estudados no Nordeste do Brasil foram avaliadas considerando diferenças mensais percentuais entre os períodos futuro e presente. A Figura 17 mostra as diferenças mensais de WPD para os cenários futuro próximo e distante e as significâncias estatísticas dessas mudanças. Nota-se, para ambos os períodos, uma tendência geral de aumento na WPD em todos os subdomínios do NEB. No futuro próximo as mudanças são menores e, em geral, não apresentam significância estatística (indicada por asterisco). Por outro lado, as comparações entre futuro distante e presente revelam um aumento mais expressivo de WPD e estatisticamente significativo na grande maioria dos meses do ano. No futuro distante, para os subdomínios costeiros C2, C3 e C4 as projeções indicam um comportamento semelhante: a partir de fevereiro as diferenças relativas começam a crescer positivamente $(>10 \%)$ e durante o outono atingem valores máximos (tendência de aumento médio durante o outono: C2 = 22,84\%, C3 = 35,34\% e C4 $=28,20 \%$. Estes resultados, previamente mostrados nos mapas espaciais e reportados na literatura, novamente evidenciam cenário futuro promissor na exploração eólica no nordeste do Brasil. Após o outono, as diferenças diminuem, mas, permanecem positivas até novembro. Por outro lado, no subdomínio $\mathrm{C} 1$, localizado no interior do NEB, as projeções com o RegCM4 mostram um padrão diferente: redução da WPD para o verão, principalmente em fevereiro (-28\%), seguido por um aumento gradual até o mês de novembro, quando a tendência atinge $+29 \%$.

As projeções do RegCM4 para o período seco (junho a novembro, AMARANTE et al., 2000) indicam condições mais favoráveis de WPD para os quatro subdomínios no NEB. Comparativamente, projeta-se no futuro distante um aumento 2 vezes maior comparado ao futuro próximo, sendo $C 1(+8,07 \%)$ e $C 2(+9,35 \%)$ as regiões mais beneficiadas. Como já se sabe, neste período do ano os ventos atingem máxima intensidade no NEB (SANTOS; SANTOS E SILVA, 2013) e, em função disso, a oferta sazonal de energia é balanceada entre as componentes hidráulica e eólica. Dessa forma, os resultados aqui encontrados sugerem, do ponto de vista eólico, que o caráter complementar entre estas duas fontes de energia renovável seguirão viáveis em cenários futuros do clima. Além do mais, em vista da redução nos totais pluviométricos previstos para o NEB ao longo do século XXI (AMBRIZZI et al., 2019), é possível esperar que o setor eólico se torne o principal fornecedor de energia para a região. 

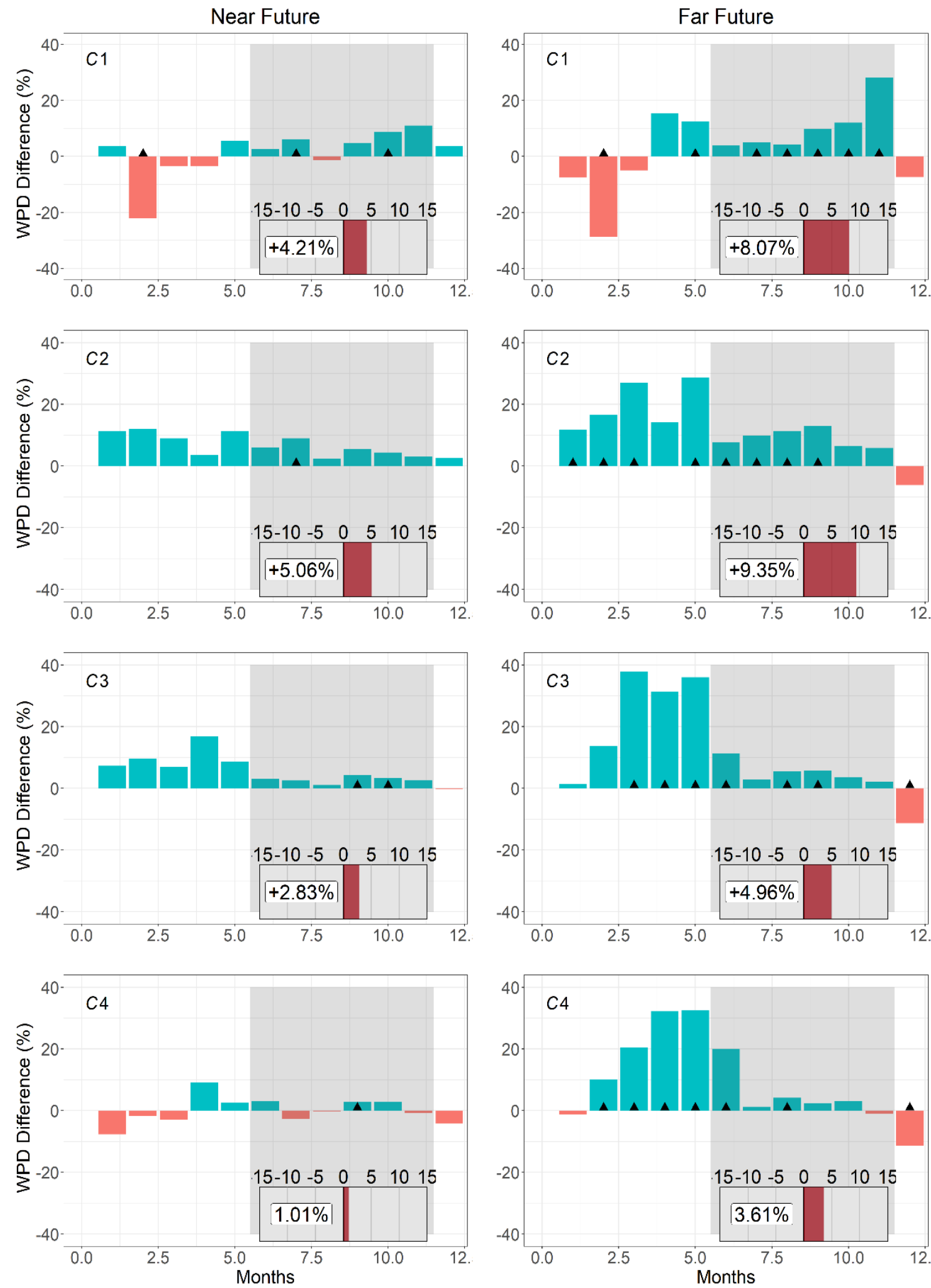

Figura 17 - Tendências mensais relativas (\%) de WPD nos quatro subdomínios ( $C 1, C 2, C 3$ e $C 4)$ do NEB para o futuro próximo (coluna esquerda) e futuro distante (coluna direita). O triângulo preto indica os meses em que a mudança é estaticamente significativa ao nível de $95 \%$. As caixas horizontais exibem a tendência projetada para o período seco, realçado pelo sombreado cinza. 
De fato, isso já vem acontecendo nos últimos anos. Em 2019, por exemplo, 88\% de toda energia consumida no Nordeste veio dos ventos (MME, 2020).

Em relação à tendência de diminuição da precipitação, uma das possíveis causas seria o enfraquecimento dos ventos alísios ao norte do Atlântico equatorial, conforme ilustra a Figura 14. Neste local, as projeções indicam enfraquecimento dos ventos em todas as estações do ano, principalmente no verão e outono. Como a estação chuvosa do NEB é, em grande parte, modulada pela migração da ZCIT para sul entre o verão e outono, o enfraquecimento dos alísios (de nordeste) contribuiria para manter a ZCIT mais ao norte, desfavorecendo as chuvas na região. Neste contexto, o aumento da WPD nas projeções do RegCM4 sobre o NEB (especialmente em C2, C3 e C4) de fevereiro a maio indicaria uma condição essencial para suprir a crescente demanda energética. De fato, embora os ventos no outono sejam relativamente mais fracos comparados ao período seco, eles superam, na média, 5 $m s^{-1}$. Assim, o aumento de velocidade indicado pelas projeções para o futuro distante resultaria em ventos muito próximos da velocidade mínima de operação $\left(6 \mathrm{~ms}^{-1}\right)$ dos aerogeradores, conforme mostram os dados da Tabela 1. Entretanto, outros fatores como a constância e variabilidade, bem como frequência de episódios de ventos extremos devem ser considerados nas estimativas do potencial eólico de uma região. Neste contexto, as próximas seções discutem com maior detalhamento os principais aspectos das projeções de vento, como tendências, extremos e distribuição estatística, destacando os impactos das tendências climáticas em cada subdomínio.

Tabela 1 - Média da velocidade do vento $\left(\mathrm{ms}^{-1}\right)$ a $100 \mathrm{~m}$ de altura durante os meses de outono nos três períodos analisados: presente (1985-2014), futuro próximo (2031-2060) e futuro distante (20702099). Em negrito estão destacados os subdomínios cuja velocidade se aproximará da mínima operável, e o asterisco $\left(^{*}\right)$ indica os locais que sofrerão maior aumento na velocidade em relação ao período presente.

\begin{tabular}{|c|c|c|c|}
\hline & Presente & Futuro Próximo & Futuro Distante \\
\hline $\mathrm{C} 1$ & 5,04 & $5,01(-0,03)$ & $5,21(+0,17)$ \\
\hline $\mathrm{C} 2$ & 5,49 & $5,61(+0,13)$ & $5,81(+0,32)$ \\
\hline C3 & 5,32 & $5,42(+0,09)$ & $5,80(+0,48)$ * \\
\hline $\mathrm{C} 4$ & 4,78 & $4,87(+0,09)$ & $5,33(+0,55)$ * \\
\hline
\end{tabular}




\subsection{Tendências e extremos de vento no NEB}

A evolução temporal entre 1985 e 2099 da velocidade do vento a $100 \mathrm{~m}$ de altura nos quatros subdomínios (C1, C2, C3 e C4) do NEB é mostrada na Figura 18. Ambas as séries temporais apresentam o ensemble do RegCM4 após a correção do bias de cada membro individualmente. A Figura 18 oferece um panorama geral das séries temporais, exibindo a tendência projetada para dois períodos do ano: seco (linha vermelha) e o outono (linha azul). O principal padrão mostrado é o aumento gradual da velocidade do vento ao longo do século XXI nos quatro subdomínios, conforme indicado pela inclinação positiva da reta ajustada. Nota-se que a velocidade do vento é menor no outono e, mais variável, o que corrobora os resultados de Brito (2018) que analisou séries da reanálise ERA20C. Nesta estação, C2 e C3 exibem maior variabilidade.

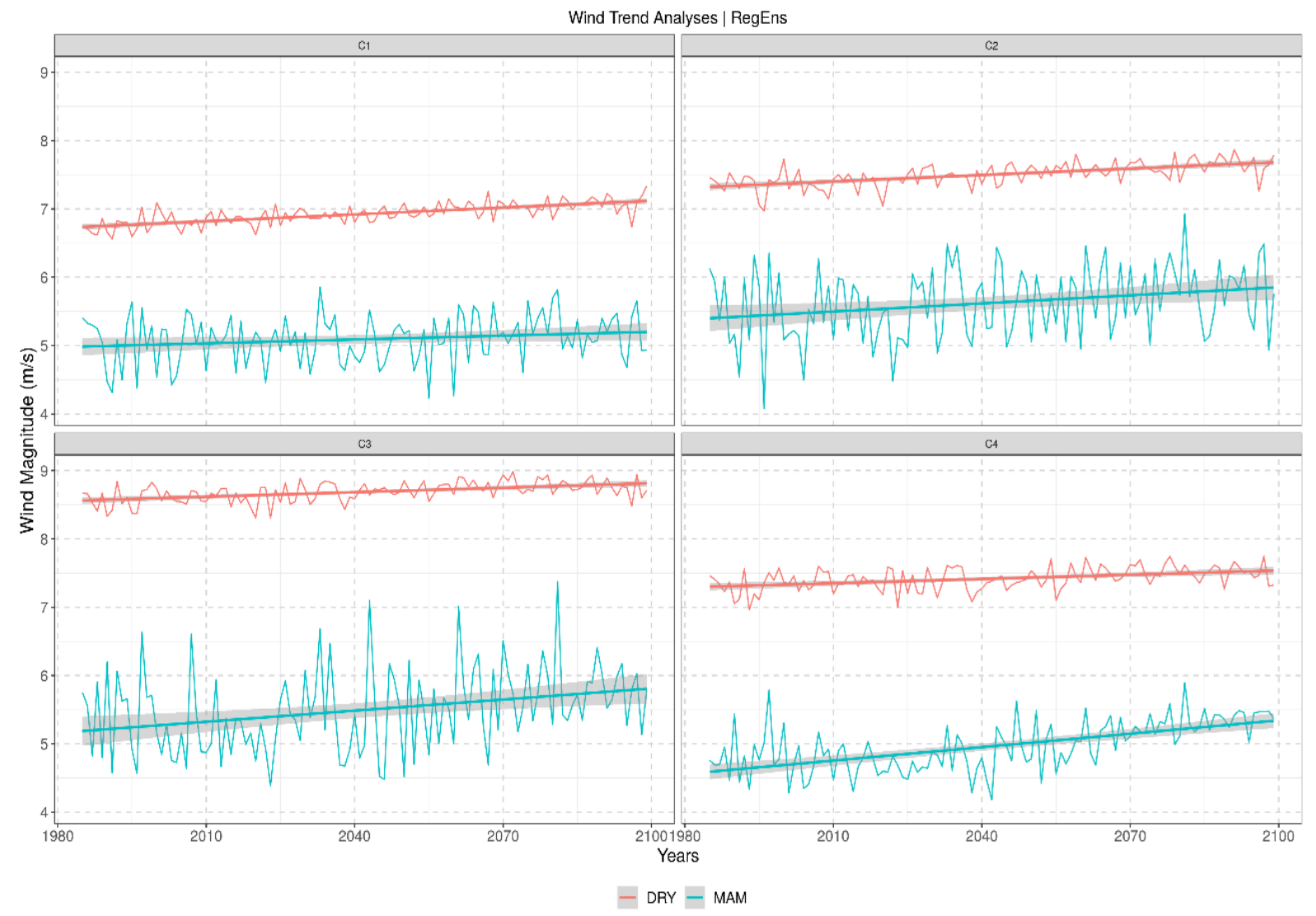

Figura 18 - Séries temporais da velocidade do vento $\left(\mathrm{ms}^{-1}\right)$ a $100 \mathrm{~m}$ de altura da projeção climática no RCP8.5 do ensemble do RegCM4 para o período seco (vermelho) e outono (azul). A reta representa o ajuste linear das séries temporais. 
C1

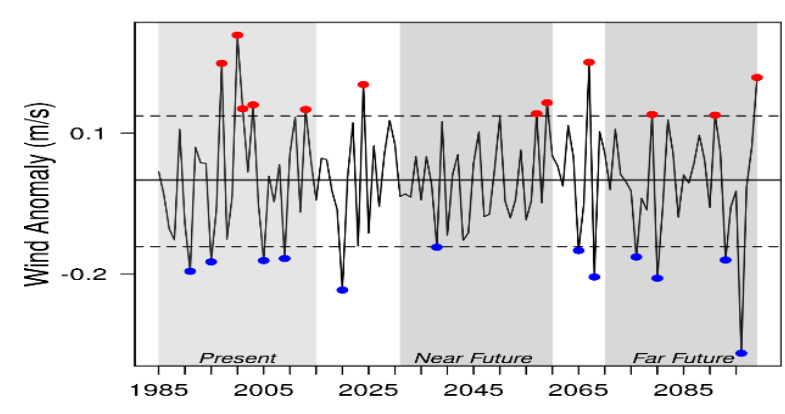

c3

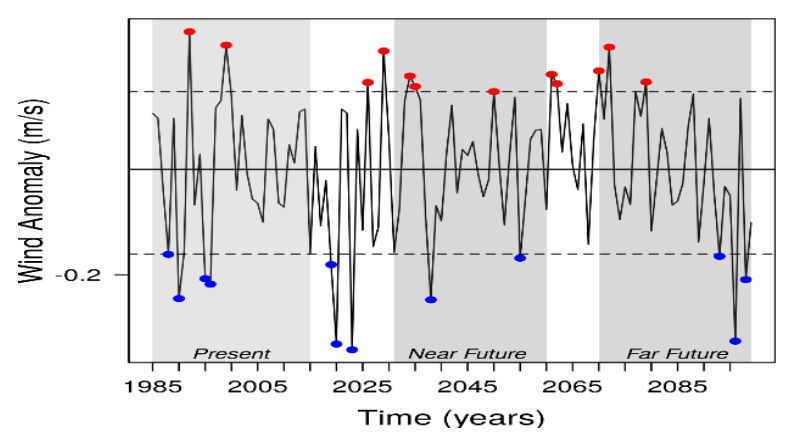

$\mathrm{C2}$

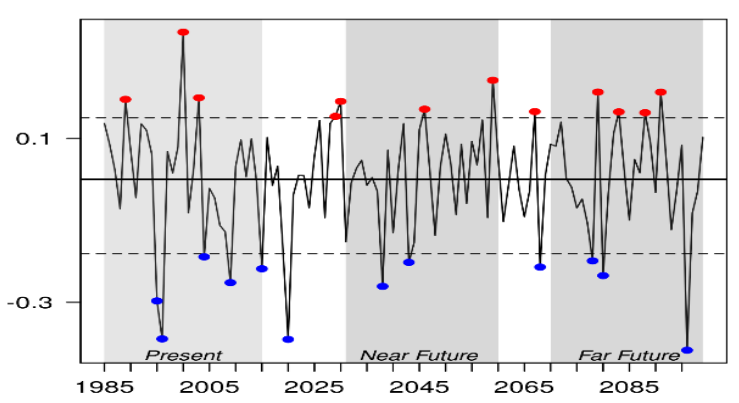

$c 4$

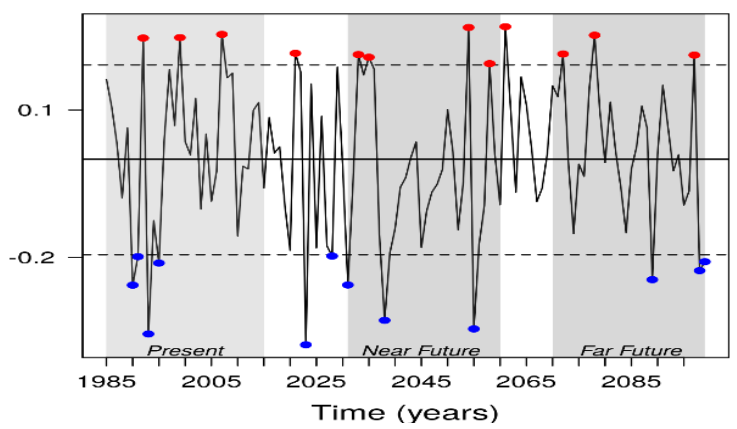

Figura 19 - Séries temporais (1985 a 2099) de anomalias da velocidade do vento a $100 \mathrm{~m}$ (sem tendência e sem a média anual) no período seco das projeções do RegCM4 ensemble. Em cada caixa, a linha horizontal tracejada superior (inferior) representa o limiar do percentil $90 \%(10 \%)$. Os pontos vermelhos (azuis) indicam os anos em que a anomalia de velocidade do vento esteve acima (abaixo) deste limiar.
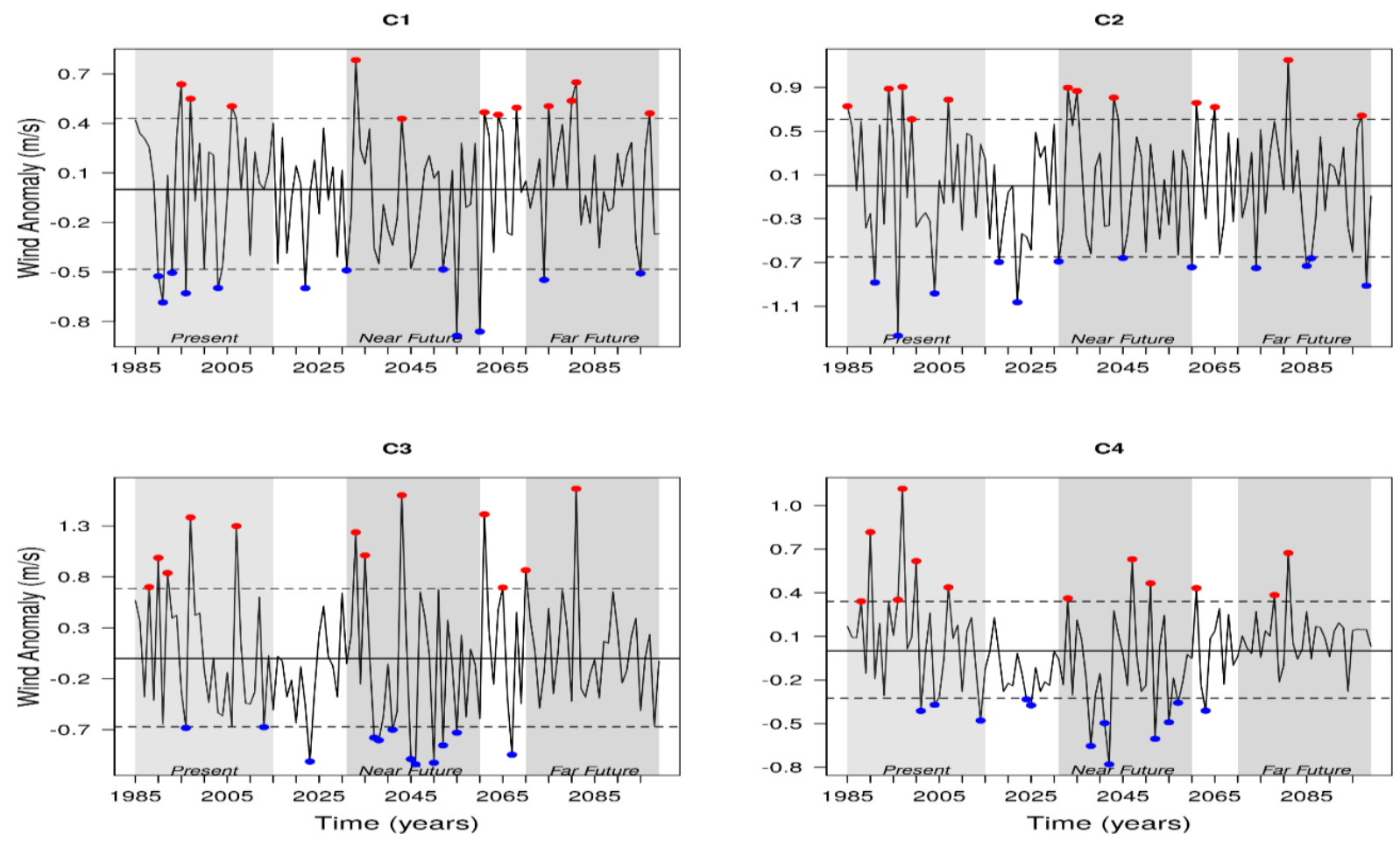

Figura 20 - Idem a Figura 19, mas para o outono. 
As Figuras 19 e 20 mostram a evolução temporal da anomalia do vento a 100 m para os eventos extremos de velocidade do vento no período seco e do outono, respectivamente. Os extremos foram calculados a partir das anomalias mensais da velocidade do vento, ou seja, após remoção do ciclo anual médio e da tendência linear. Semelhante a Brito (2018) os extremos foram identificados utilizando os percentis de $90 \%$ e 10\%. Desta forma, um episódio foi caracterizado como extremo positivo (negativo) quando na média anual em cada um dos períodos analisados (seco e chuvoso) for superior (inferior) ao percentil 90\% (10\%).

No clima presente (1985-2014), durante o outono (Figura 20), o RegCM4 ensemble simula praticamente a mesma quantidade de eventos extremos ( 8 eventos) de velocidade do vento a $100 \mathrm{~m}$ em todos os subdomínios. No geral, há uma predominância de extremos positivos nos subdomínios costeiros (C2, C3 e C4) e extremos negativos no subdomínio C1, localizado no interior do NEB (Tabela 3). O oposto é observado no período seco (Figura 19), ou seja, predominância de extremos negativos em C1, C2 e C4 e extremos positivos em C1. No período seco, C1 registra o maior número de eventos de vento extremo a 100 m (9) e C3 o menor (6) (Tabela 2). No decorrer do século $X X I$, nota-se que os extremos negativos de velocidade do vento do outono se tornam menos frequentes em $\mathrm{C} 1$ e mais intercalados no tempo. No futuro distante, por exemplo, as projeções indicam apenas 2 episódios, comparado com os 5 no presente (Tabela 3). Em C2, por outro lado, os extremos negativos mantêm no futuro regularidade similar à do clima presente, porém diminuem de amplitude durante esta estação. Já as séries temporais de C3 e C4 destacam-se por apresentar caráter oscilatório (Figura 20), de modo que extremos positivos prevalecem em certos períodos (início da série temporal) e negativos em outros (2035 a 2065). Como se sabe, C3 e C4 incluem a extremidade norte do NEB, cujo clima é mais fortemente influenciado por fenômenos como o ENSO e o GRADM (BRITO, 2018; OLIVEIRA; COSTA, 2011). Na análise de extremos de velocidade do vento a $10 \mathrm{~m}$ conduzidas por Brito (2018) também foi constatado a presença de variações decadais durante o período de 1900 a 2010. Segundo o autor, os episódios em que a velocidade média anual do vento esteve acima (abaixo) do percentil 90\% (10\%) estiveram associados à fase positiva (negativa) tanto do GRADM como do ENSO. Assim, é plausível supor que a intensidade e frequência dos eventos extremos de velocidade do vento projetados para o NEB ao longo do século XXI estariam também diretamente relacionados com a evolução destes fenômenos (e outros: MJO, NAO, 
AMO, PDO etc.) em cenários de mudanças climáticas. Para Cai et al. (2020), embora projeções de fenômenos como o ENSO seja uma tarefa difícil, tudo indica que ficarão mais intensos. Ainda sobre as regiões C3 e C4, durante o outono, deve-se ressaltar a projeção de redução na ocorrência de extremos positivos de velocidade no futuro, que em C3 projeta-se com aumento da amplitude e C4 com redução. De fato, é possível notar que a variabilidade interanual da velocidade do vento diminui no futuro distante. Para o subdomínio C1 no outono projeta-se um aumento de extremos positivos a partir de 2060.

Tabela 2 - Número de episódios extremos de vento a $100 \mathrm{~m}$ de altura do RegEns para o período presente (1985 a 2014), futuro próximo (Próximo, 2031-2060) e futuro distante (Distante, 2070 a 2099) nos quatro subdomínios do NEB. Extremos positivos estão representados pelo símbolo + e os negativos pelo símbolo -.

\begin{tabular}{c|cccc}
\hline \multicolumn{1}{|c|}{ Seco } & Extremo & Presente & Próximo & Distante \\
\hline \multirow{2}{*}{ C1 } & + & 5 & 2 & 3 \\
\cline { 2 - 5 } & - & 4 & 1 & 4 \\
\hline \multirow{2}{*}{ C2 } & + & 3 & 2 & 4 \\
\cline { 2 - 5 } & - & 3 & 3 & 4 \\
\hline \multirow{2}{*}{ C3 } & + & 5 & 3 & 2 \\
\cline { 2 - 5 } & - & 2 & 8 & 0 \\
\hline \multirow{2}{*}{ C4 } & + & 4 & 3 & 2 \\
\cline { 2 - 5 } & - & 3 & 6 & 0 \\
\hline
\end{tabular}

Tabela 3 - Semelhante a Tabela 2, mas para o outono.

\begin{tabular}{c|cccc}
\hline Outono & Extremo & Presente & Próximo & Distante \\
\hline \multirow{2}{*}{ C1 } & + & 3 & 2 & 4 \\
& - & 5 & 4 & 2 \\
\hline \multirow{2}{*}{ C2 } & + & 5 & 3 & 2 \\
\cline { 2 - 5 } & - & 3 & 3 & 4 \\
\hline \multirow{2}{*}{ C3 } & + & 5 & 3 & 2 \\
\cline { 2 - 5 } & - & 2 & 8 & 0 \\
\hline \multirow{2}{*}{ C4 } & + & 4 & 3 & 2 \\
& - & 3 & 6 & 0 \\
\hline
\end{tabular}


Com relação à estação seca (Figura 19), os padrões projetados pelo RegCM4 ensemble diferem, em alguns subdomínios, daqueles para o outono. Em C1 por exemplo, enquanto os extremos positivos de velocidade do vento aumentam em frequência e intensidade no outono, diminuem na estação seca. Em C2, pelo contrário, os extremos positivos apresentam tendência de serem mais frequentes no período seco. C3 também deve experimentar uma maior ocorrência de extremos positivos até aproximadamente 2085, porém com menor amplitude. Já em C4, a regularidade de extremos positivos de velocidade deve ser mantida no futuro. Quanto aos extremos negativos de velocidade do vento a $100 \mathrm{~m}$ do período seco, nota-se um padrão geral de redução de ocorrência desses eventos em todos os subdomínios, especialmente no futuro próximo. Já a amplitude dos extremos negativos exibe uma redução no futuro em $\mathrm{C} 1$ e $\mathrm{C} 2$, seguida de um aumento no futuro distante. O oposto é observado nos subdomínios C3 e C4. Nota-se que as projeções dos extremos de vento a $100 \mathrm{~m}$ em C3 e C4 no período seco diferente daquele para o outono, onde os extremos negativos tendem a se agrupar em períodos específicos devido à presença de oscilações de mais baixa frequência, como por exemplo, decenal (ou decadal). Isto vai de encontro às discussões de Brito (2018) de que nos meses de outono o NEB sofre maior influência de fenômenos de baixa frequência.

Em suma, esta análise permitiu avaliar como a frequência e amplitude de episódios de velocidade do vento a $100 \mathrm{~m}$ extrema no NEB poderão ser afetadas pelas mudanças climáticas, expondo suas principais características nos dois períodos do ano de maior interesse do setor eólico: estação seca e outono. Uma alternativa complementar e mais robusta na abordagem deste tema envolve a utilização do modelo estatístico de Weibull, que será discutido na próxima seção.

\subsubsection{Análise de Weibull}

As Figura 21 e 22 mostram as distribuições de probabilidade de Weibull (PDFw) de velocidade do vento a $100 \mathrm{~m}$ de altura da ERAl e RegEns nos quatro subdomínios do NEB no clima presente (1985 a 2014) (PDFw das projeções no Apêndice). O ajuste da PDFw às medidas está representado pela linha vermelha, sendo que cada Figura contém ainda os valores de $\mathrm{R}^{2}$ e os parâmetros $\mathrm{k}$ (forma) e c (escala) das PDFw. Diferente da seção anterior, optou-se por analisar a série temporal para todo o ano, ou seja, sem distinção entre para estações seca e outono. 


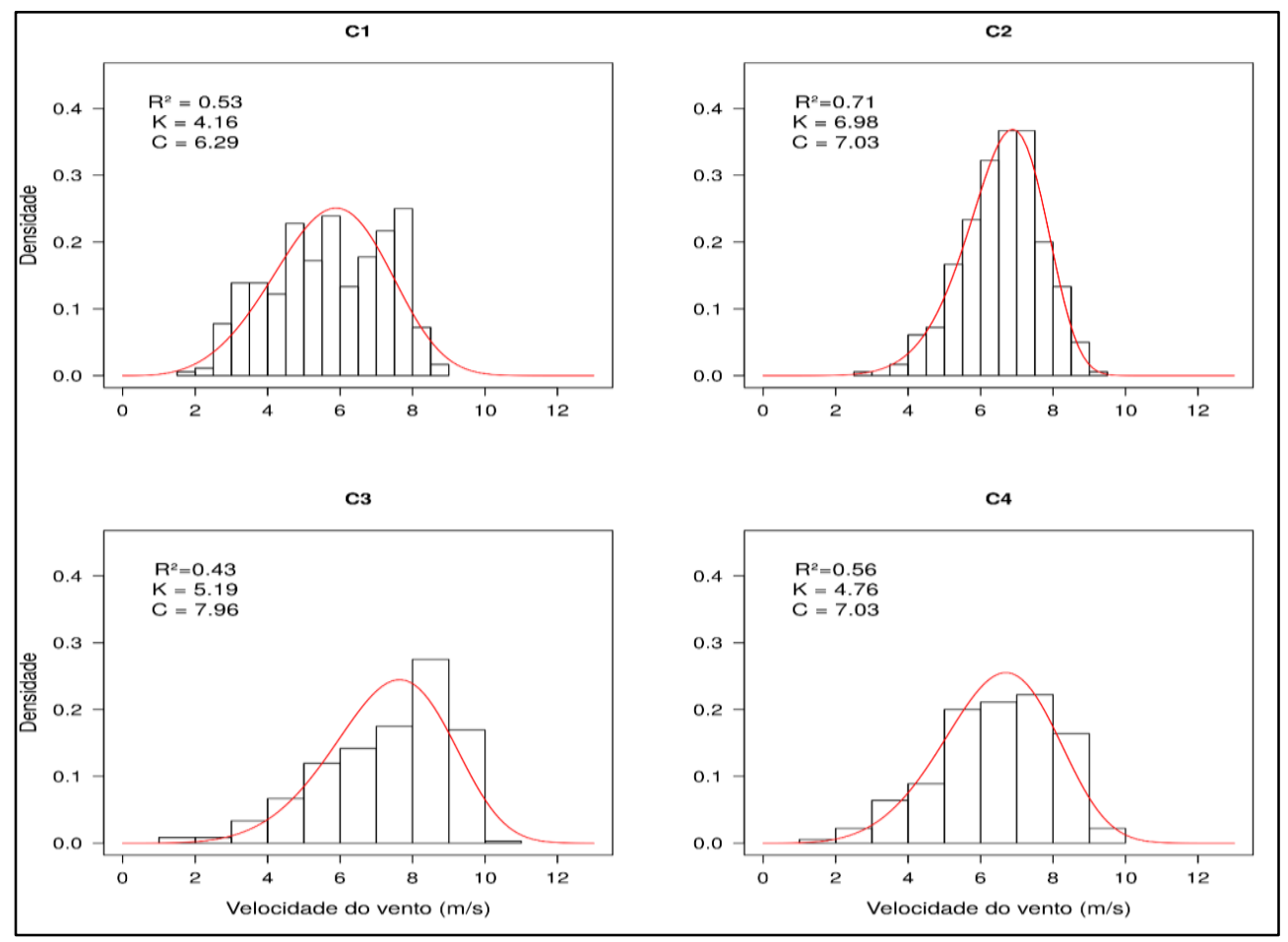

Figura 21 - Distribuição de probabilidade dos valores mensais de velocidade do vento a $100 \mathrm{~m}$ de altura da ERA-Interim no período 1985 a 2014 para os subdomínios C1, C2, C3 e C4. O ajuste da PDFw às medidas de vento está representado pela curva em vermelho e as estatísticas ( $R^{2}$, parâmetros de forma $k$ e de escala $c$ ) do ajuste sumarizados no canto esquerdo superior.

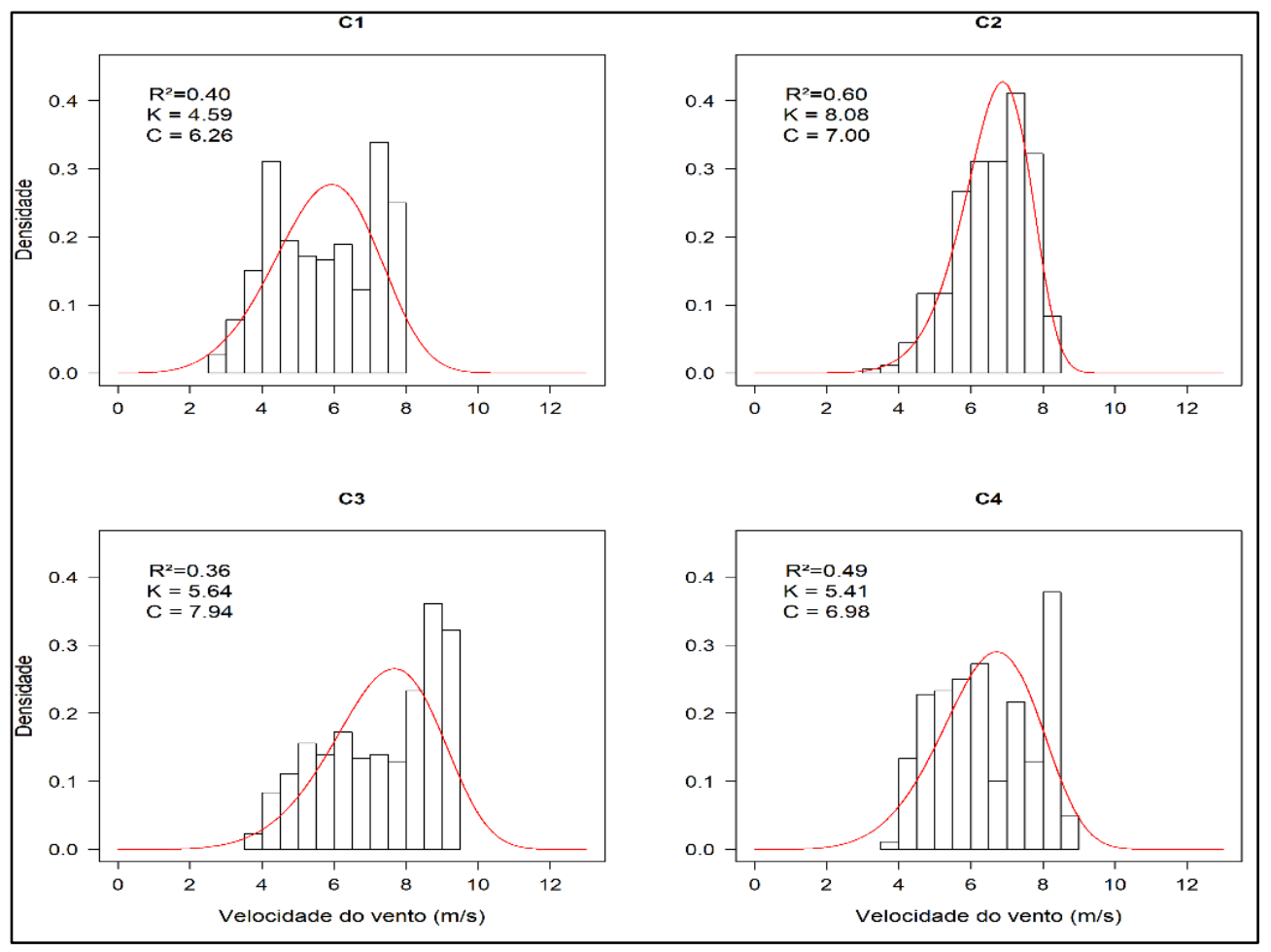

Figura 22 - Idem a Figura 21, mas para o RegEns. 
Assim, é possível identificar a tendência anual projetada pelo RegCM para cada subdomínio e ranquear qual região seria mais ou menos favorecida, do ponto de vista eólico, pelas mudanças climáticas no cenário RCP8.5. A princípio, destacam-se os baixos valores de $\mathrm{R}^{2}$ (Tabela 4) principalmente nas PDFw do RegEns, que podem ser explicados pela frequência temporal dos dados (i,e mensal) e o caráter bimodal de algumas distribuições, como C1. Costa Rocha et al. (2012) também constataram a presença de dois picos de maior frequência nas séries temporais de velocidade do vento no município de Camocim, no Ceará. Entretanto, devido ao fato de usarem dados horários os autores obtiveram altos índices de $\mathrm{R}^{2}$.

Em ambos, ERAI (Figura 21) e RegEns (Figura 22), o subdomínio C2 apresenta maior valor do coeficiente de determinação no período presente, de 0,71 e 0.60, respectivamente. Neste subdomínio, as velocidades estão mais concentradas em torno de um valor médio, semelhante a uma distribuição normal. Este caráter simétrico e de baixa variabilidade se deve, muito provavelmente, aos alísios de sudeste que são persistentes ao longo de todo o ano na região. De fato, $\mathrm{C} 2$ apresentou o menor desvio padrão $\left(0,88 \mathrm{~ms}^{-1}\right)$ dentre os diagramas de Taylor analisados (Figura 11, inferior). Em contrapartida, nos subdomínios C1 e C3 o modelo estatístico de Weibull apresentou maior dificuldade em representar as velocidades do vento, tanto nas séries temporais da ERAI quanto no RegEns. Os demais valores do coeficiente de determinação para as projeções são sumarizados na Tabela 4.

Quanto aos parâmetros derivados da PDFw, nota-se que os valores de k variam de 4 a 7 na ERAI (Tabela 5), sendo maiores no RegEns (4 a 8). Estes valores são maiores do que os encontrados no atlas nacional (entre 2 e 4) e por Costa Rocha (2012) que encontrou valores em geral menores do que 6 para k. Porém, isso pode estar associado ao fato destes estudos utilizarem medidas de velocidade do vento em alturas inferiores a $100 \mathrm{~m}$. Com relação ao parâmetro de escala, nota-se que os valores simulados pelo RegCM4 são muito próximos aos da ERA-Interim no clima presente. Na ERAI, por exemplo, os valores de c concentram-se entre 6 e $8 \mathrm{~ms}^{-1}$, sendo maior no subdomínio C3 $(7,96)$, iguais em C4 e C2 $\left(7,04 \mathrm{~ms}^{-1}\right)$ e menor em C1 (6.29 $\mathrm{ms}^{-1}$ ), enquanto no RegEns são ligeiramente menores. Estes valores, por sua vez, são menores do que os encontrados por Costa Rocha et al. (2012), de 7 a 11 $m s^{-1}$, e por Oliveira e Costa (2011), $\sim 11 \mathrm{~ms}^{-1}$.

Conforme discutido na metodologia (seção 3.3.1), altos valores de k estão associados à regime de velocidades do vento mais constantes e com menor 
variabilidade temporal (distribuições mais simétricas), como é o caso de C2 (Figuras 21 e 22). Em C1, pelo contrário, nota-se maior dispersão das velocidades, o que se reflete em um valor $\mathrm{k}$ relativamente mais baixo (Tabela 5). Em C3 e C4, k é ligeiramente maior do que em $\mathrm{C} 1$, sendo possível notar um centro de maior ocorrência de velocidades, entre 7 e $10 \mathrm{~ms}^{-1}$ em C3 e entre 5 e $8 \mathrm{~ms}^{-1}$ em C4. Entretanto, a comparação entre os subdomínios deve ser feita com cautela, pois os valores de c são diferentes. No subdomínio C3, por exemplo, onde c assume o maior valor $(7,96)$, o centro de massa da distribuição na ERA-Interim está levemente deslocado para direita, sugerindo maior ocorrência de ventos intensos (Figura 21). Já a cauda da distribuição tende a ser mais ampla, dada a ocorrência, em menor frequência, de velocidades do vento muito intensas ou muito fracos.

Tabela 4 - Valores de $\mathrm{R}^{2}$ obtidos com a ERAl e o RegEns para os três períodos analisados: presente (1985 a 2014), futuro próximo (Próximo, 2031 a 2060) e futuro distante (Distante, 2071 a 2099).

\begin{tabular}{cc|ccc}
\hline & ERAI & Presente & Próximo & Distante \\
\hline C1 & 0,53 & 0,41 & 0,37 & 0,38 \\
\hline C2 & 0,72 & 0,60 & 0,61 & 0,70 \\
\hline C3 & 0,43 & 0,37 & 0,38 & 0,42 \\
\hline C4 & 0,58 & 0,49 & 0,50 & 0,57 \\
\hline
\end{tabular}

Os valores dos parâmetros de forma e escala projetados pelo RegCM4 ensemble para os futuros próximo e distante são sumarizados na Tabela 5. De acordo com as projeções do RegCM4, todos os subdomínios exibem um aumento gradual do parâmetro de escala. Isto indica que as velocidades do vento apresentam tendência de serem mais extremas e intensas nestes locais. Dentre os subdomínios, o aumento mais significativo ocorre em C2 no futuro distante $\left(+0.25 \mathrm{~ms}^{-1}\right)$.

Quanto ao parâmetro de forma, as projeções apontam para uma redução em $\mathrm{C} 1$, em resposta ao aumento da variabilidade na velocidade do vento (Tabela 5). Isto concorda com a análise de extremos, que indicam maior frequência de episódios de vento extremo (positivos no outono, negativos na estação seca) no final do século (Tabelas 2 e 3). Dessa maneira, as mudanças projetadas para $\mathrm{C} 1$ no cenário futuro analisado podem ser desfavoráveis ao aproveitamento eólico. Em C2, o parâmetro de forma aumenta no futuro próximo e diminui levemente no futuro distante, mas ainda se mantém superior ao do clima presente (Tabela 5). Recordando a análise de 
extremos de velocidade, a amplitude e frequência dos episódios que estiveram acima ou abaixo dos percentis 90 e 10\% decrescem notoriamente em C2 durante a metade do século XXI (Figura 19 e 20). De fato, é clara a redução da variabilidade da série neste período, em concordância com o aumento de k. Nos anos subsequentes os extremos de velocidade tendem novamente a aumentar à medida que $\mathrm{k}$ diminui. Em C3 para o parâmetro de forma projeta-se também aumento no futuro próximo, porém, diferentemente de C2, segue aumentando no futuro distante (Tabela 5). Esta condição sugere ventos mais constantes no futuro distante. Contudo, deve-se ressaltar que em C3 e demais subdomínios o parâmetro de escala deverá aumentar (indicando velocidades mais variáveis e extremas), o que deve sempre ser levado em conta. Por fim, em C4, $\mathrm{k}$ tende a diminuir no futuro próximo, mas aumenta intensamente no futuro distante (Tabela 5).

Em conclusão, as análises de tendência, extremos e de distribuição de probabilidade de Weibull oferecem perspectivas diferentes sobre a evolução dos ventos no Nordeste do Brasil. Estas informações, se utilizadas conjuntamente, podem proporcionar um melhor planejamento eólico energético diante das mudanças projetadas no cenário de mudanças climáticas RCP8.5.

Tabela 5 - Valores dos parâmetros de forma $(k)$ e de escala (c) obtidos da ERA-Interim (ERAI) e com o RegEns nos três períodos analisados: presente (pres), futuro próximo (Próx) e futuro distante (Dist). Valores entre parênteses indicam diferença entre climas futuro e presente do RegEns.

\begin{tabular}{|c|c|c|c|c|c|c|c|c|}
\hline & \multicolumn{4}{|c|}{$K$} & \multicolumn{4}{|c|}{$\mathrm{C}\left(m s^{-1}\right)$} \\
\hline & ERAI & Pres & Próx & Dist & ERAI & Pres & Próx & Dist \\
\hline $\mathrm{C} 1$ & 4,16 & 4,59 & $4,44(-0,15)$ & $4,37(-0,22)$ & 6,29 & 6,26 & $6,32(\mathbf{0 , 0 6})$ & $6,40(\mathbf{0 , 1 4})$ \\
\hline $\mathrm{C} 2$ & 6,98 & 8,08 & $8,29(\mathbf{0 , 2 1})$ & $7,95(-\mathbf{0 , 1 3})$ & 7,04 & 7,00 & $7,15(\mathbf{0 , 1 5})$ & $7,25(\mathbf{0 , 2 5})$ \\
\hline C3 & 5,19 & 5,64 & $5,72(0,08)$ & $6,04(0,40)$ & 7,96 & 7,94 & $8,04(\mathbf{0 , 1 0})$ & $8,12(\mathbf{0 , 1 8})$ \\
\hline $\mathrm{C} 4$ & 4,77 & 5,41 & $5,37(-0,04)$ & $6,18(0,77)$ & 7,04 & 6,98 & $7,02(\mathbf{0 , 0 4})$ & $7,17(\mathbf{0 , 1 9 )}$ \\
\hline
\end{tabular}




\subsection{Estimativas do potencial eólico do NEB: AEP e CF}

Nesta sessão, o potencial eólico do Nordeste do Brasil é avaliado sob uma perspectiva energética. O principal objetivo aqui é traduzir os resultados das projeções realizadas com o RegCM4 para o âmbito eólico e, assim, torná-los mais abrangentes e compreensíveis. Para isso, são estimadas duas variáveis comumente utilizadas em atlas de energia eólica: a produção anual de energia (AEP) e o fator de capacidade (CF). A AEP, conforme já discutido (seção 3.3.2), é dada pelo produto entre as frequências de velocidades (divididas em intervalos de $1 \mathrm{~ms}^{-1}$ ) derivadas da PDFw e a potência associada, obtida da curva de potência do aerogerador em questão. Ao multiplicar esse resultado por 365 tem-se a geração anual de energia. Como se pode notar, a AEP depende de dois fatores principais: 1) distribuição de velocidade dos ventos; 2) design do aerogerador. Como neste trabalho são usados dados mensais, diferentemente da maioria dos estudos na área, a distribuição de ocorrência de velocidades é mais compacta, uma vez que variabilidade diária não está presente nos valores mensais. Consequentemente, as estimativas de AEP e CF, podem, de certa forma, omitir parte do potencial eólico da região. Dito isto, os valores encontrados de AEP e CF, considerando o aerogerador de $2 \mathrm{MW}$ da Enercon E82 2MW, são exibidos na Tabela 6.

Referente ao clima presente, C3 destaca-se como o subdomínio que registra a maior produção anual de energia, com cerca de 3918,20 MWh (Tabela 6). Em termos de abastecimento residencial, esta quantidade de energia seria suficiente para suprir a demanda de 372 residências americanas, assumindo consumo mensal de $877 \mathrm{KWh}$ (EIA, 2020). Em C2 e C4 a produção anual foi menor, totalizando 2606,42 MWh e 2556,38 MWh, respectivamente. Valor este muito próximo do encontrado por Oliveira e Costa (2011) utilizando um aerogerador de 1,5 MW de potência a $70 \mathrm{~m}$ de altura no NEB. Durante o período analisado (agosto de 1982 a maio de 1983) os autores obtiveram uma produção total de 2540 MWh. O subdomínio C1, como já era esperado, apresenta menor valor de AEP, 1716,84 MWh. Quanto ao fator de capacidade, notase que os valores refletem a mesma hierarquia obtida para AEP (Tabela 6). O CF, que é dado pela razão entre a AEP estimada e AEP teórica, funciona como um índice,

geralmente expresso em termos percentuais, do output energético de um dado aerogerador. Dessa forma, conclui-se que a estimativa do aproveitamento energético do aerogerador da Enercon no RegCM4 ensemble no clima presente é superior em 
C3, aproximando-se dos 30\%, seguido por C2 e C4 ( 19\%.) e C1 ( 13,0\%). Em geral, valores de CF acima dos $20 \%$ são considerados razoáveis para o aproveitamento eólico de uma região. Com relação aos períodos futuros, as projeções indicam um aumento gradual em todos os subdomínios, tanto da AEP quanto do CF. $O$ ranqueamento dos subdomínios, segundo estes índices, permanecerá no futuro o mesmo do período presente, isto é: C3 segue como a região com maior potencial de aproveitamento eólico, seguido de C2, C4 e, em último, C1. Em suma, os aumentos projetados pelo RegCM4 reportados nos índices de AEP e CF são otimistas para o setor eólico. Entretanto, estas estimativas futuras devem ser utilizadas juntamente com as análises conduzidas anteriormente a fim de se obter um melhor planejamento energético.

Tabela 6 - Estimativas de AEP e CF, considerando o aerogerador de 2 MW de potência da Enercon, realizadas com o RegCM4 ensemble nos três períodos estudados: presente (1985-2014), futuro próximo (2031-2060) e futuro distante (2070-2099).

\begin{tabular}{cccc|ccc}
\hline & \multicolumn{3}{c}{ AEP (MWh) } & \multicolumn{3}{c}{ CF (\%) } \\
\cline { 2 - 7 } & Pres & Próx & Dist & Pres & Próx & Dist \\
\hline C1 & $1.716,84$ & $1.791,59$ & $1.894,92$ & 13,06 & 13,63 & 14,41 \\
\hline C2 & $2.606,42$ & $2.811,53$ & $2.943,69$ & 19,82 & 21,38 & 22,39 \\
\hline C3 & $3.918,20$ & $4.072,88$ & $4.205,17$ & 29,8 & 30,97 & 31,98 \\
\hline C4 & $2.556,38$ & $2.597,21$ & $2.801,50$ & 19,44 & 19,75 & 21,31 \\
\hline
\end{tabular}




\section{CONCLUSÕES}

Este estudo abordou o potencial eólico do Nordeste do Brasil (NEB) diante de um cenário de mudanças climáticas a fim de obter subsídios para um melhor planejamento energético no futuro. Para isso, foi utilizado um conjunto composto de três simulações climáticas de alta resolução $(25 \mathrm{~km})$ obtido com o modelo regional RegCM4. Considerando o cenário RCP8.5, as projeções com o RegCM4 foram forçadas por três GCMs do CMIP5 (HadGEM2-ES, MPI-ES e Nor-ESM) no contexto do CORDEX-CORE (GUTOWSKI et al., 2016) para o domínio da América do Sul no período de 1970-2100. As análises focaram em quatro subdomínios sobre o NEB (C1 - interior da Bahia, C2 - leste do NEB, C3 - norte do Ceará e C4 - norte do Maranhão e Piauí) e em três subperíodos principais: clima presente (1985-2014), futuro próximo (2031-2060) e futuro distante (2070-2099).

Inicialmente, foi realizada um estudo de validação, cujo objetivo foi avaliar o desempenho das simulações de vento a $100 \mathrm{~m}$ de altura no clima presente (19852015). Para isto, cada simulação foi comparada com a reanálise ERA-Interim. Os resultados mostraram que o RegCM4 tende a superestimar a velocidade dos ventos na porção leste do Brasil ao longo de todo o ano, especialmente na região sudeste (bias de até $+3 \mathrm{~ms}^{-1}$ ). Superestimativas também foram encontradas sobre a Argentina, oeste do NEB (primavera) e em toda a cordilheira Andina. Estas subestimativas são semelhantes às encontradas por Reboita et al. (2018). Em contrapartida, no noroeste da AS e partes da Amazônia, o RegCM4 simula ventos mais fracos do que a ERA-Interim. Nas demais áreas continentais as diferenças entre simulação e reanálise foram menores $\left( \pm 0,5 \mathrm{~ms}^{-1}\right)$. Sobre os oceanos, as maiores diferenças ocorrem no outono e primavera na faixa latitudinal entre $30^{\circ} \mathrm{S}$ e $50^{\circ} \mathrm{S}$. Com relação ao desempenho individual de cada simulação, notou-se que a simulação RegHAD apresenta menores erros, sendo superior às demais (RegESM e RegMPI) em todos os subdomínios do NEB. Além disso, os índices estatísticos revelaram que em $\mathrm{C} 1$, que corresponde ao interior do NEB, é a região onde o conjunto de simulações apresenta maior destreza em reproduzir o ciclo anual, isto é, desvio padrão mais próximo ao da ERA-Interim, correlação alta e menor raiz quadrada do erro médio quadrático. De forma geral, as simulações no clima presente reproduzem as principais características do vento a $100 \mathrm{~m}$ de altura presentes na reanálise ERA-Interim, mas apresentam bias de intensidade. Portanto, foi aplicada uma correção do viés (bias 
correction) em cada simulação individual, obtendo-se a seguir o RegCM4 ensemble (média dos três membros) corrigido para o período 1985-2099.

Após a avaliação, foram analisadas as projeções climáticas de velocidade do vento a 100 m e WPD, buscando caracterizar as principais mudanças no potencial eólico no NEB no cenário de emissões RCP8.5. Estas análises utilizaram o RegCM4 ensemble corrigido e a tendência foi calculada como diferenças sazonais entre os climas futuros e o presente. As tendências encontradas apontam para um aumento da velocidade dos ventos e de WPD em diversas partes do Brasil, especialmente no futuro distante, como também encontrado em estudos anteriores (LUCENA et al. 2010, OLIVEIRA et al. 2013, REBOITA et al. 2018). As projeções do RegCM4 para este período (2070 a 2099) mostraram que locais como o Brasil central, nordeste da Amazônia, sul do Brasil e o norte da Argentina deverão experimentar um aumento na WPD, podendo chegar a $100 \%$ dependendo da época do ano. Em contrapartida, o potencial eólico de locais como o sudeste da Amazônia, e de países como o Peru e Bolívia, devem sofrer uma redução durante o primeiro semestre do ano, principalmente no verão.

Quanto aos subdomínios do NEB, as projeções de WPD apresentaram uma tendência geral de aumento em relação ao período presente. Isto significa que as mudanças climáticas irão favorecer o potencial eólico destas regiões. Entretanto, por meio da análise de significância estatística, foi possível concluir que as mudanças previstas para o futuro próximo fazem parte das flutuações naturais do clima. Já as previsões para o futuro distante mostraram-se mais expressivas e estatisticamente significativas. As variações mensais de WPD para este período indicaram que o maior aumento deverá ocorrer durante os meses de outono nos subdomínios costeiros, com destaque para C3, onde aumento pode chegar a $+35,34 \%$. À vista das projeções de precipitação para o NEB apontadas por diversos estudos, a intensificação dos ventos nesta época do ano pode ser crucial para suprir a demanda energética da região e, também, salvaguardar o volume de águas dos reservatórios das hidroelétricas. Similarmente ao outono, as diferenças mensais de WPD durante o período seco (junho a novembro) também foram positivas, porém menores. Dentre os subdomínios, C2 e C3 deverão experimentar maior aumento em relação ao período presente, $+9,35 \%$ e 8,07\%, respectivamente. Em termos de complementaridade hídrico-eólica, este cenário sugere que a componente eólica seguirá ativa durante os meses de maior demanda (estação seca) podendo, inclusive, sofrer aumento. 
Com relação aos episódios de velocidade do vento extremo durante outono e a estação seca, as Tabelas 7 e 8 sumarizam as principais mudanças projetadas pelo RegCM4. Estas tabelas indicam as tendências tanto na frequência de ocorrência como na amplitude dos extremos nos futuros próximo e distante.

Tabela 7 - Tendência (futuro menos presente) da frequência de ocorrência e amplitude dos eventos extremos de velocidade do vento a $100 \mathrm{~m}$ de altura. Os extremos positivos e negativos representam, respectivamente, os percentis de $90 \%$ e $10 \%$. Simbologia: -, redução; +, aumento; =, semelhante ao presente.

\begin{tabular}{ccccccc}
\hline \multirow{2}{*}{ OUTONO } & \multicolumn{2}{c}{ Futuro Próximo } & \multicolumn{2}{c}{ Futuro Distante } \\
\cline { 2 - 6 } & & Frequência & Amplitude & Frequência & Amplitude \\
\hline C1 & Positivo & - & + & + & - \\
\cline { 2 - 6 } & Negativo & - & + & - & - \\
\hline C2 & Positivo & - & + & + & + \\
\cline { 2 - 6 } & Negativo & + & + & - & + \\
\hline C3 & Positivo & - & + & - & - \\
\cline { 2 - 6 } & Negativo & + & - & - & - \\
\hline C4 & Positivo & - & + & - & + \\
\cline { 2 - 6 }
\end{tabular}

Tabela 8 - Semelhante à Tabela 7, porém para a estação seca.

\begin{tabular}{ccccccc}
\hline \multirow{2}{*}{ ESTAÇÃO SECA } & \multicolumn{2}{c}{ Futuro Próximo } & \multicolumn{2}{c}{ Futuro Distante } \\
\cline { 3 - 6 } & & Frequência & Amplitude & Frequência & Amplitude \\
\hline \multirow{2}{*}{ C1 } & Positivo & - & - & - & - \\
\cline { 2 - 6 } C2 & Negativo & - & - & + & + \\
\cline { 2 - 6 } & Positivo & + & - & + & - \\
\hline \multirow{2}{*}{ C3 } & Pegativo & - & - & - & + \\
\cline { 2 - 6 } & Positivo & + & - & + & + \\
\hline C4 & Negativo & - & - & - & + \\
\cline { 2 - 6 } & Positivo & + & + & - & - \\
\hline
\end{tabular}


Apesar das diferenças projetadas para ambos os períodos (seco e outono) nota-se um padrão geral de redução na frequência de ocorrência e amplitude dos episódios de vento extremo a $100 \mathrm{~m}$. Para o outono do futuro distante, por exemplo, nota-se apenas 2 aumentos na frequência de ocorrência (positivo, C1 e negativo, C2) e na amplitude (positivo, C2 e positivo, C3). Por outro lado, o RegEns projeta um aumento na amplitude dos extremos de vento a $100 \mathrm{~m}$ para o outono no futuro próximo em grande parte dos subdomínios. O oposto é projetado para o futuro próximo da estação seca, ou seja, redução da amplitude dos episódios extremos. Além disso, destaca-se nesta estação o aumento da amplitude dos extremos negativos para 0 futuro distante, previstos para $\mathrm{C} 1, \mathrm{C} 2$ e C3.

De maneira complementar, a constância e variabilidade dos ventos foram investigadas utilizando o modelo estatístico de Weibull (PDFw). Na maior parte dos subdomínios, o modelo de Weibull representa razoavelmente a distribuição de probabilidade da velocidade dos ventos da ERA-Interim. Os valores de $\mathrm{R}^{2}$ foram relativamente baixos, especialmente em C3 $(0,43)$ e $C 1(0,53)$, o que pode estar associado à utilização de dados com frequência mensal. Para o RegCM4 ensemble, no clima presente e em cada um dos quatro subdomínios $\mathrm{R}^{2}$ é ligeiramente menor do que na ERA-Interim, indicando menor habilidade do modelo de Weibull em representar as velocidades simuladas. Quanto aos parâmetros derivados da PDFw no clima presente, notou-se que para a ERA-Interim os valores de $k$ variaram de 4 a 7 , sendo maior em C2 $(k=6,98)$. Os valores de $k$ são ligeiramente maiores (entre 4,5 e 8) no RegCM4 ensemble no clima presente, mas assim como na ERA-Interim o maior valor é obtido em C2 $(8,08)$. Em termos de variabilidade, este resultado indica que C2 apresenta um regime de ventos de maior constância; para o futuro, as projeções indicam que a magnitude de $\mathrm{k}$ deverá diminuir gradualmente em $\mathrm{C} 1$, projetando aumento na variabilidade das velocidades dos ventos. Nos demais subdomínios, projeta-se um aumento no $\mathrm{k}$, indicando redução na variabilidade das velocidades. Já os valores do parâmetro de escala (c) concentram-se entre 6 e $8 \mathrm{~ms}^{-1}$ no clima presente tanto na ERA-Interim como no RegCM4 ensemble, sendo maior em C3 $(7,96$ e 7,94) e menor em C1 $(6,29$ e 6,26). De acordo com as projeções, estes valores deverão aumentar gradualmente até o final do século nos quatro subdomínios. Deste ponto de vista, os ventos deverão no futuro aumentar de intensidade e atingirem valores extremos nestes locais. 
Por último, com o intuito de ranquear os subdomínios em termos de projeções do aproveitamento eólico, foram realizadas estimativas da produção anual de energia (AEP) e do fator de capacidade (CF), considerando um aerogerador de $2 \mathrm{MW}$ de potência. No período presente, por exemplo, nas simulações do RegCM4 ensemble o subdomínio C3 exibiu os maiores valores de AEP (3918,20 MWh) e CF (29,8\%) e C1 os menores, $1.716,84 \mathrm{MW}$ e $13,06 \%$, respectivamente. Para os períodos futuros, as projeções indicam que tanto a AEP quanto o CF deverão aumentar em todos os subdomínios, o que representaria um cenário otimista para o setor eólico, considerando o cenário RCP8.5. 


\section{PERSPECTIVAS E TRABALHOS FUTUROS}

De acordo com as projeções do RegCM4, os quatro subdomínios do NEB deverão experimentar aumento na intensidade dos ventos a $100 \mathrm{~m}$ de altura. Embora a intensificação dos ventos no NEB em cenários de mudanças climáticas seja um resultado conhecido na literatura, este estudo abordou esta questão de diferentes perspectivas, possibilitando uma visão mais ampla considerando tanto a variabilidade como extremos dos ventos. Ainda assim, inúmeras questões seguem em aberto e novas foram levantadas ao longo desta pesquisa. Neste sentido, sugere-se aos próximos trabalhos:

- Avaliar o comportamento de outras variáveis meteorológicas (pressão e temperatura) a fim de encontrar possíveis explicações do fortalecimento dos ventos.

- Verificar se a intensificação dos ventos ocorre também em outros cenários de emissões, como o RCP4.5.

- Analisar o impacto do aumento da resolução horizontal (comparando as presentes simulações com aquelas em $50 \mathrm{~km}$ disponíveis no CORDEX e temporal (escala diária, por exemplo) nas simulações.

- Ampliar a análise para demais locais com potencial eólico, como o sul do Brasil. 


\section{REFERÊNCIAS}

ABEEÓLICA. Boletin Anual de Geração Eólica: 2019. 2020.

AMARANTE, O. A. DO et al. Wind/Hydro complementary seasonal regimes in Brazil. 2000.

AMARANTE, O. D.; BROWER, M., ZACK, J.; SÁ, A. L. Atlas do potencial eólico brasileiro. Brasília: MME, 2001.

AMBRIZZI, T. et al. The state of the art and fundamental aspects of regional climate modeling in South America. Annals of the New York Academy of Sciences, v. 1436, n. 1, p. 98-120, 2019.

ANTHES, R. A.; HSIE, E.-Y.; KUO, Y.-H. Description of the Penn State NCAR Mesoscale Model Version 4 (MM4)Bolder, CONCAR, , 1987.

ARAUJO, P. H. M. DE; MARINHO, M. H. D. N. Analysis of Hydro - Wind Complementarity in State of Pernambuco, Brazil by means of Weibull Parameters. IEEE Latin America Transactions, v. 17, n. 4, p. 556-563, 2019.

ARCHER, C. L.; JACOBSON, M. Z. Evaluation of global wind power. Journal of Geophysical Research D: Atmospheres, v. 110, n. 12, p. 1-20, 2005.

ARTAXO, P. As três emergências que nossa sociedade enfrenta: saúde, biodiversidade e mudanças climáticas. Estudos Avançados, v. 34, n. 100, p. 53-66, 2020.

ASHOK, K. et al. El Niño Modoki and its possible teleconnection. Journal of Geophysical Research: Oceans, v. 112, n. 11, p. 1-27, 2007.

BARRETO, A. B. Estudo do ciclo diário do vento à superfície no Nordeste do Brasil. 2001.

BENTSEN, M. et al. The Norwegian Earth System Model, NorESM1-M - Part 1: Description and basic evaluation. Geoscientific Model Development Discussions, v. 5, n. 3, p. 2843-2931, 2012.

BLOOM, A.; KOTRONI, V.; LAGOUVARDOS, K. Climate change impact of wind energy availability in the Eastern Mediterranean using the regional climate model PRECIS. Natural Hazards and Earth System Sciences, v. 8, n. 6, p. 1249-1257, 2008.

BOULANGER, J. P.; MARTINEZ, F.; SEGURA, E. C. Projection of future climate change conditions using IPCC simulations, neural networks and Bayesian statistics. Part 1: Temperature mean state and seasonal cycle in South America. Climate Dynamics, v. 27, n. 2-3, p. 233-259, 2006.

BRANDS, S. et al. How well do CMIP5 earth system models simulate present climate conditions in Europe and Africa? Clim Dyn, v. 41, n. 3-4, p. 803-817, 2013. 
BRITO, L. S. Análise do Vento sobre o Nordeste do Brasil na reanálise centenária ERA-20C: Variabilidade Interanual e Extremos. 2018.

BROWER, M. C. et al. A study of wind speed variability using global reanalysis data. AWS Truepower Report, n. May 2013, p. 12, 2013.

CAI, W. et al. Climate impacts of the EI Niño-Southern Oscillation on South America. Nature Reviews Earth \& Environment, v. 1, n. 4, p. 215-231, 2020.

CARVALHO, D. et al. Potential impacts of climate change on European wind energy resource under the CMIP5 future climate projections. Renewable Energy, v. 101, n. 2017, p. 29-40, 2017.

CARVALHO, I. V. DE et al. Densidade de potencial eólico nas diferentes regiões do estado do ceará - litoral, serra, sertão. Revista Geonorte, v. 2, n. 5, p. 1317-1327, 2012.

CARVALHO, L. M. V.; JONES, C.; LIEBMANN, B. The South Atlantic convergence zone: Intensity, form, persistence, and relationships with intraseasonal to interannual activity and extreme rainfall. Journal of Climate, v. 17, n. 1, p. 88-108, 2004.

CARVALHO SILVA, A. J. V. DE. Potencial Eólico Offshore No Brasil: Localização De Áreas Nobres Através De Análise Multicritério. Coppe Ufrj, p. 1-224, 2019.

CAVALCANTI, E. P. et al. Variabilidade da Velocidade do Vento e Influências Oceânicas: Uma Abordagem Para Fins de Geração de Energia Elétrica no Nordeste do Brasil Wind Speed Variability and Ocean Influences: An Approach for Electrical Energy Generation Purposes in Northeastern B. Anuario do Instituto de Geociencias, v. 43, n. 1, p. 273-285, 2020.

CAVALCANTI, I. F. Tempo e clima no Brasil. 2016.

COELHO, C. A. S. et al. The 2014 southeast Brazil austral summer drought: regional scale mechanisms and teleconnections. Climate Dynamics, v. 46, n. 11-12, p. 37373752, 2016.

COSTA, M. A. DE S. et al. Impactos Socioeconômicos, Ambientais e Tecnológicos Causados pela Instalação dos Parques Eólicos no Ceará. Revista Brasileira de Meteorologia, v. 34, n. 3, p. 399-411, 2019.

COSTA ROCHA, P. A. et al. Comparison of seven numerical methods for determining Weibull parameters for wind energy generation in the northeast region of Brazil. Applied Energy, v. 89, n. 1, p. 395-400, 2012.

CRESESB-CEPEL. Tutorial de energia eólica. Disponível em: $<$ www.cresesb.cepel.br>. Acesso em: 25 jan. 2021.

CUSTÓDIO, R. Energia Eólica para a Produção de Energia Elétrica. Eletrobrás, Rio de Janeiro, 2009. 
DA ROCHA, R. P. et al. Interannual variability associated with ENSO: present and future climate projections of RegCM4 for South America-CORDEX domain. Climatic Change, v. 125, n. 1, p. 95-109, 2014.

DAVY, R. et al. Climate change impacts on wind energy potential in the European domain with a focus on the Black Sea. Renewable and Sustainable Energy Reviews, v. 81, n. June 2016, p. 1652-1659, 2018.

DEE, D. P. et al. The ERA-Interim reanalysis: Configuration and performance of the data assimilation system. Quarterly Journal of the Royal Meteorological Society, v. 137, n. 656 , p. 553-597, 2011.

DELIGNETTE-MULLER, M. L.; DUTANG, C. fitdistrplus: An R package for fitting distributions. Journal of statistical software, v. 64, n. 4, p. 1-34, 2015.

EIA. Wind turbine heights and capacities have increased over the past decade. Disponível em: <www.eia.gov>. Acesso em: 27 jan. 2021.

EIA. Average monthly electricity bill for U.S. residential customers declined in 2019. Disponível em: <www.eia.gov>. Acesso em: 27 jan. 2021.

ELGUINDI, N. et al. Regional climate model RegCM user manual. ITCP, Trieste, Italy, n. May, p. 32p, 2011.

ELHADJ SIDI, C. E. B. et al. Performance analysis of the first large-scale (15 MWp) grid-connected photovoltaic plant in Mauritania. Energy Conversion and Management, v. 119, p. 411-421, 2016.

EPE. Balanço Energético Nacional 2020: Ano Base 2019. Disponível em: $<$ chttp://www.epe.gov.br>.

GARREAUD, R. D. et al. Present-day South American climate. Palaeogeography, Palaeoclimatology, Palaeoecology, v. 281, n. 3-4, p. 180-195, 2009.

GIONGO, C. R.; MENDES, J. M. R.; SANTOS, F. K. Desenvolvimento, saúde e meio ambiente: contradições na construção de hidrelétricas Development, health and environment: contradictions in the construction of dams. Serv. Soc. Soc, v. 123, n. 123, p. 501-522, 2015.

GIORGETTA, M. A. et al. Climate and carbon cycle changes from 1850 to 2100 in MPIESM simulations for the Coupled Model Intercomparison Project phase 5. Journal of Advances in Modeling Earth Systems, v. 5, n. 3, p. 572-597, 2013.

GIORGI, F. et al. RegCM4: Model description and preliminary tests over multiple CORDEX domains. Climate Research, v. 52, n. 1, p. 7-29, 2012.

GIORGI, F. Introduction to the special issue: the phase I CORDEX RegCM4 hypermatrix (CREMA) experiment. Clim Change, n. 125, p. 1-5, 2014. 
GIORGI, F.; MARINUCCI, M. R.; BATES, G. T. Development of a second-generation regional climate model (RegCM2). Part I: Boundary-layer and radiative transfer processes. Monthly Weather Review, v. 121, n. 10, p. 2794-2813, 1993.

GIORGI, F.; MEARNS, L. O. Introduction to special section: Regional climate modeling revisited. Journal of Geophysical Research: Atmospheres, v. 104, n. D6, p. 63356352, 1999.

GREENE, J. S. et al. Projected Future Wind Speed and Wind Power Density Trends over the Western US High Plains. Atmospheric and Climate Sciences, v. 02, n. 01, p. 32-40, 2012.

GRIMM, A. M. The El Niño impact on the summer monsoon in Brazil: Regional processes versus remote influences. Journal of Climate, v. 16, n. 2, p. 263-280, 2003.

GRIMM, A. M.; BARROS, V. R.; DOYLE, M. E. Climate variability in southern South America associated with El Nino and La Nina events. Journal of Climate, v. 13, n. 1, p. $35-58,2000$.

GRIMM, A. M.; TEDESCHI, R. G. ENSO and extreme rainfall events in South America. Journal of Climate, v. 22, n. 7, p. 1589-1609, 2009.

GUTOWSKI, J. W. et al. WCRP COordinated Regional Downscaling EXperiment (CORDEX): A diagnostic MIP for CMIP6. Geoscientific Model Development, v. 9, n. 11, p. 4087-4095, 2016.

HALLAK, R.; FILHO, A. J. P. Metodologia para análise de desempenho de simulações de sistemas convectivos na região metropolitana de São Paulo com o modelo Arps: sensibilidade a variações com os esquemas de advecção e assimilação de dados. Revista Brasileira de Meteorologia, v. 26, n. 4, p. 591-608, 2011.

HOFSTAETTER, M. Energia eólica: entre ventos, impactos e vulnerabilidades socioambientais no Rio Grande do Norte. 2016.

HOSKINS, B. J.; KAROLY, D. J. The Steady Linear Response of a Spherical Atmosphere to Thermal and Orographic Forcing. Journal of the Atmospheric Sciences, p. 1179-1196, 1981.

HUEGING, H. et al. Regional changes in wind energy potential over Europe using regional climate model ensemble projections. Journal of Applied Meteorology and Climatology, v. 52, n. 4, p. 903-917, 2013.

IEA. Global energy demand grew by $2.1 \%$ in 2017 , and carbon emissions rose for the first time since 2014. Disponível em: $<$ https://www.iea.org/newsroom/news/2018/march/global-energy-demand-grew-by21-in-2017-and-carbon-emissions-rose-for-the-firs.html>. Acesso em: 21 jan. 2021.

IEA. Renewables Information: Overview. Disponível em: <https://www.iea.org/reports/renewables-information-overview>. Acesso em: 21 jan. 
2021.

IEC, I. 61400-12-1. Wind Turbine Generator Systems - Part 12-1: Power Performance measurements of electricity producing wind turbines. International Standard, $\mathrm{n}$. Geneva, 1998.

IPCC. Climate change 2014: synthesis report. Contribution of Working Groups I, II and III to the fifth assessment report of the Intergovernmental Panel on Climate Change. p. $151,2014$.

ISLAM, M. R.; SAIDUR, R.; RAHIM, N. A. Assessment of wind energy potentiality at Kudat and Labuan, Malaysia using Weibull distribution function. Energy, v. 36, n. 2, p. 985-992, 2011.

JOHNSON, D. L.; ERHARDT, R. J. Projected impacts of climate change on wind energy density in the United States. Renewable Energy, v. 85, p. 66-73, 2016.

JONES, C. D. et al. The HadGEM2-ES implementation of CMIP5 centennial simulations. Geoscientific Model Development, v. 4, n. 3, p. 543-570, 2011.

JUSTUS, C. G.; MIKHAIL, A. Height Variation of Wind Speed and Wind Distributions Statistics. Geophysical Research Letters, v. 3, n. 5, p. 261-264, 1976.

KAIN, J. S.; FRITSCH, J. M. Convective Parameterization for Mesoscale Models: The Kain-Fritsch Scheme. American Meteorological Society, p. 165-170, 1993.

KAISER-WEISS, A. K. et al. Comparison of regional and global reanalysis nearsurface winds with station observations over Germany. Advances in Science and Research, v. 12, n. 1, p. 187-198, 2015.

KIDMO, D. K. et al. Statistical analysis of wind speed distribution based on six Weibull Methods for wind power evaluation in Garoua, Cameroon. Revue des Energies Renouveables, v. 18, n. March, p. 105-125, 2015.

KOIFMAN, S. Geração e transmissão da energia elétrica: impacto sobre os povos indígenas no Brasil. Cadernos de Saúde Pública, v. 17, n. 2, p. 413-423, 2001.

KOUSKY, V. E. Diurnal Rainfall Variation in Northeast Brazil. Monthly Weather Review, v. 108, n. 4, p. 488-498, 1980.

KOUSKY, V. E.; KAGANO, M. T.; CAVALCANTI, I. F. A. The Southern Oscillation: oceanic-atmospheric circulation changes and related rainfall anomalies. Tellus, $p$. 490-504, 1984.

LIMA, F. J. L. DE et al. Avaliaçao do potencial eólico no município de Jaguaruana, litoral cearense. Ciência e Natura, v. 33, n. 1, p. 101-115, 2011.

LIMA, F. J. L. DE; CAVALCANTI, E. P.; SOUZA, E. P. DE. Avalicação do potencial eólico em cinco regiões do estado da Paraíba. Revista de Geografia (Recife), v. 27, n. 1, p. 138-153, 2010. 
LIRA, M. A. T. et al. Caracterização do Regime de Ventos no Piauí Para o Aproveitamento de Energia Eólica. Revista Brasileira de Meteorologia, v. 32, n. 1, p. 77-88, 2017.

LLOPART, M. et al. Climate change impact on precipitation for the Amazon and La Plata basins. Climatic Change, v. 125, n. 1, p. 111-125, 2014.

LLOPART, M.; REBOITA, M. S.; DA ROCHA, R. P. Assessment of multi-model climate projections of water resources over South America CORDEX domain. Climate Dynamics, v. 54, n. 1-2, p. 99-116, 2020.

LUCENA, A. F. P. DE et al. The vulnerability of wind power to climate change in Brazil. Renewable Energy, v. 35, n. 5, p. 904-912, 2010.

MANWELL, J. F.; MCGOWAN, J. G.; ROGERS, A. L. Wind energy explained: theory, design and application. 2010.

MARENGO, J. A. et al. Future change of climate in South America in the late twentyfirst century: Intercomparison of scenarios from three regional climate models. Climate Dynamics, v. 35, n. 6, p. 1089-1113, 2010.

MARENGO, J. A. et al. Development of regional future climate change scenarios in South America using the Eta CPTEC/HadCM3 climate change projections: Climatology and regional analyses for the Amazon, São Francisco and the Paraná River basins. Climate Dynamics, v. 38, n. 9-10, p. 1829-1848, 2012.

MARENGO, J. A.; ALVEZ, L. M. Crise hídrica em São Paulo em 2014: seca e desmatamento. GEOUSP Espaço e Tempo (Online), v. 19, n. 3, p. 485-494, 2015.

MO, K. C.; HIGGINS, R. W. The Pacific-South American modes and tropical convection during the Southern Hemisphere winter. Monthly Weather Review, v. 126, n. 6, p. 1581-1596, 1998.

MOURA, A. D.; SHUKLA, J. On the Dynamics of Droughts in Northeast Brazil: Observations, Theory and Numerical Experiments with a General Circulation Model. American Meteorological Society, v. 38, n. 12, p. 2653-2675, 1981.

NAMIAS, J. Influence of northern hemisphere general circulation on drought in northeast Brazil. Tellus, v. 24, n. 4, p. 336-343, 1972.

OLESON, K.; LAWRENCE, D. NCAR / TN-503 + STR NCAR Technical Note July 2013 Technical Description of version 4.5 of the Community Land Model ( CLM ). n. March 2014, 2013.

OLIVEIRA, J. L.; COSTA, A. A. Estudo de variabilidade do vento em escala sazonal sobre o nordeste brasileiro utilizando o RAMS: os casos de 1973-1974 e 1982-1983. Revista Brasileira de Meteorologia, v. 26, n. 1, p. 53-66, mar. 2011.

PAL., J. S. Regional climate modeling for the developing world: the ICTP RegCM3 and 
RegCNET. Bulletin of the American Meteorological Society, p. 1395- 1410., 2007.

PEIXOTO, J. P.; OORT, A. H. Physics of climate. 1992.

PEREIRA, E. B. et al. The impacts of global climate changes on the wind power density in Brazil. Renewable Energy, v. 49, p. 107-110, 2013.

PEZZI, L. P.; CAVALCANTI, I. F. A. The relative importance of ENSO and tropical Atlantic sea surface temperature anomalies for seasonal precipitation over South America: a numerical study. Climate Dynamics, v. 17, n. 2-3, p. 205-212, 2001.

PHILANDER, S. G. H. El Niño and La Niña. Journal of the Atmospheric Sciences, v. 42 , n. 23, p. 2652-2662, 1985.

PIMENTA, F. M.; ASSIREU, A. T. Simulating reservoir storage for a wind-hydro hydrid system. Renewable Energy, v. 76, p. 757-767, 2015.

REBOITA, M. S. et al. Regimes de precipitação na América do Sul: uma revisão bibliográfica. Revista Brasileira de Meteorologia, v. 25, n. 2, p. 185-204, 2010.

REBOITA, M. S. et al. Climate projections for South America: RegCM3 driven by HadCM3 and ECHAM5. Advances in Meteorology, v. 2014, 2014.

REBOITA, M. S. et al. Extratropical cyclones over the southwestern South Atlantic Ocean: HadGEM2-ES and RegCM4 projections. International Journal of Climatology, v. 38, n. 6, p. 2866-2879, 2018.

REBOITA, M. S. et al. The south atlantic subtropical anticyclone: Present and future climate. Frontiers in Earth Science, v. 7, n. February, p. 1-15, 2019.

REBOITA, M. S.; AMARO, T. R.; DE SOUZA, M. R. Winds: intensity and power density simulated by RegCM4 over South America in present and future climate. Climate Dynamics, v. 51, n. 1-2, p. 187-205, 2018.

ROBALLO, S. T.; FISCH, G. Escoamento atmosférico no Centro de Lançamento de Alcântara (CLA): parte l-aspectos observacionais. Revista Brasileira de Meteorologia, v. 23, n. 4, p. 510-519, 2008.

ROPELEWSKI, C. F.; HALPERT, M. S. Global and regional scale precipitation patterns associated with the EI Niño/Southern Oscillation. Monthly weather review, v. 115, n. 8, p. 1606-1626, 1987.

SANTANA, L. V. R. et al. Análise espacial da distribuição da velocidade do vento no Nordeste brasileiro utilizando a ERA-40. Rev. Bras. Biom, v. 33, n. 3, p. 414-432, 2015.

SANTOS, A. T. S. DOS et al. Assessment of wind resources in two parts of Northeast Brazil with the use of numerical models. Meteorological Applications, v. 23, n. 4, p. 563-573, 2016. 
SANTOS, A. T. S. DOS; SANTOS E SILVA, C. M. Seasonality, interannual variability, and linear tendency of wind speeds in the Northeast Brazil from 1986 to 2011. The Scientific World Journal, v. 2013, 2013.

SAWADOGO, W. et al. Current and future potential of solar and wind energy over Africa using the RegCM4 CORDEX-CORE ensemble. Climate Dynamics, n. 0123456789, p. 1-26, 2020.

SEGURO, J. V.; LAMBERT, T. W. Modern estimation of the parameters of the Weibull wind speed distribution for wind energy analysis. Journal of wind engineering and industrial aerodynamics, v. 85, n. 1, p. 75-84, 2000.

SELAND, Ø. et al. Overview of the Norwegian Earth System Model (NorESM2) and key climate response of CMIP6 DECK, historical, and scenario simulations. Geoscientific Model Development, v. 13, n. 12, p. 6165-6200, 2020.

SETH, A.; ROJAS, M.; RAUSCHER, S. A. CMIP3 projected changes in the annual cycle of the South American Monsoon. Climatic Change, v. 98, n. 3, p. 331-357, 2010.

SILVA, A. R. et al. Complementarity of Brazils hydro and offshore wind power. Renewable and Sustainable Energy Reviews, v. 56, p. 413-427, 2016.

SILVA, B. B. DA et al. Potencial eólico na direção predominante do vento no Nordeste brasileiro. Revista Brasileira de Engenharia Agrícola e Ambiental, v. 6, n. 3, p. 431-439, 2002.

SILVA, G. R. Característica de vento na região Nordeste. 2003.

SILVEIRA, S. R. Geração desentralizada de energia através de fonte alternativa. 2011.

SINES, T. et al. South America CORDEX project using RegCM. Ninth ICTP workshop on the theory and use of regional climate models, 2018.

STEVENS, M. J. M. SMULDERS, P. T. The estimation of the parameters of the Weibull wind speed distribution for wind energy utilization purposes. Wind engineering, $p$. 132-145, 1979.

TABATA, Y. et al. Lower tropospheric horizontal wind over Indonesia: A comparison of wind profiler network observations with global reanalyses. Journal of Atmospheric and Solar-Terrestrial Physics, v. 73, n. 9, p. 986-995, 2011.

TASCHETTO, A. S.; AMBRIZZI, T. Can Indian Ocean SST anomalies influence South American rainfall? Climate Dynamics, v. 38, n. 7-8, p. 1615-1628, 2012.

TAYLOR, K. E. Summarizing multiple aspects of model performance in a single diagram. Journal of Geophysical Research: Atmospheres, v. 106, n. D7, p. 71837192, 2001. 
TEAM, RS. RStudio: integrated development for R. RStudio, Inc., Boston, MA URL http:// www.rstudio. com. v. 42, n. 14, p. 84, 2015.

TIEDTKE, M. A Comprehensive Mass Flux Scheme for Cumulus Parameterization in Large-Scale Models. Monthly weather review, v. 117, n. 8, p. 1779-1800, 1989.

TOBIN, I. et al. Climate change impacts on the power generation potential of a European mid-century wind farms scenario. Environmental Research Letters, v. 11, n. 3, p. 034013, 2016.

UVO, C. B. et al. The relationships between tropical Pacific and Atlantic SST and northeast Brazil monthly precipitation. Journal of Climate, v. 11, n. 4, p. 551-562, 1998.

VAN VUUREN, D. P. et al. The representative concentration pathways: An overview. Climatic Change, v. 109, n. 1, p. 5-31, 2011.

VAREJÃO-SILVA, M. A. Meteorologia e climatologia: versão digital 2. 2006.

VERA, C. et al. Climate change scenarios for seasonal precipitation in South America from IPCC-AR4 models. Geophysical Research Letters, v. 33, n. 13, p. 2-5, 2006.

VERA, C. S.; OSMAN, M. Activity of the Southern Annular Mode during 2015-2016 El Niño event and its impact on Southern Hemisphere climate anomalies. International Journal of Climatology, v. 38, n. January, p. e1288-e1295, 2018.

WALLACE, J. M.; HOBBS, P. V. Atmospheric science: an introductory survey. 2006.

WILKS, D. S. Statistical methods in the atmospheric sciences. Academic press, 2011.

WUEBBLES, D. J.; FAHEY, D. W.; HIBBARD, K. A. Climate science special report: fourth national climate assessment, volume I. . 2017.

ZHANG, Z. S. et al. Pre-industrial and mid-Pliocene simulations with NorESM-L. Geoscientific Model Development Discussions, v. 5, n. 1, p. 119-148, 2012. 


\section{APÊNDICE}

Apêndice A - Lista de figuras complementares aos resultados.
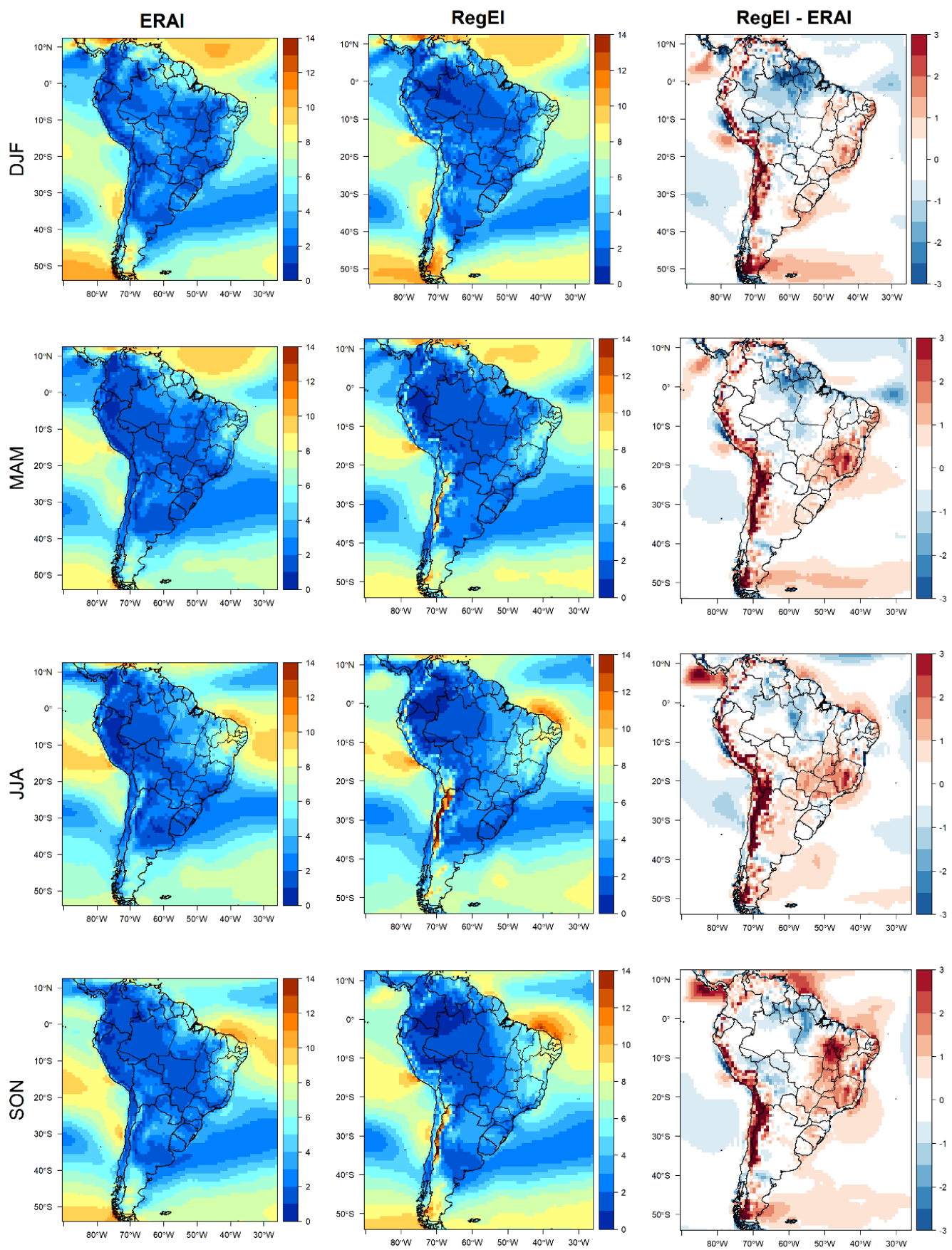

Figura 23 - Climatologia sazonal do vento a $100 \mathrm{~m}$ de altura para o período presente (1985 a 2014), representados pela reanálise ERA-Interim (coluna esquerda), RegEI (coluna central) e diferença entre RegEl e ERAI (coluna direita). 


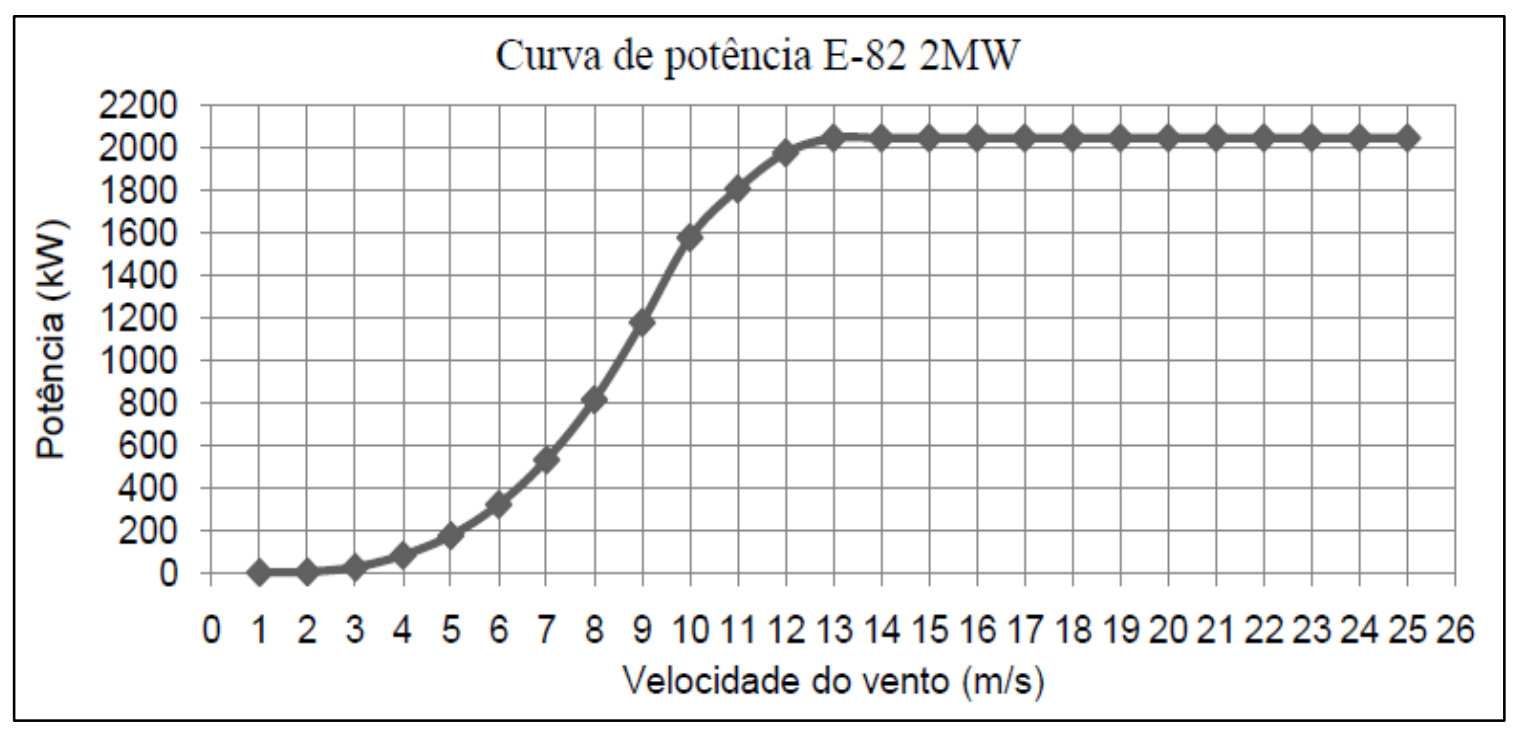

Figura 24 - Curva de potência do aerogerador E-82 2 MW da ENERCON. Fonte: (SILVEIRA, 2011).

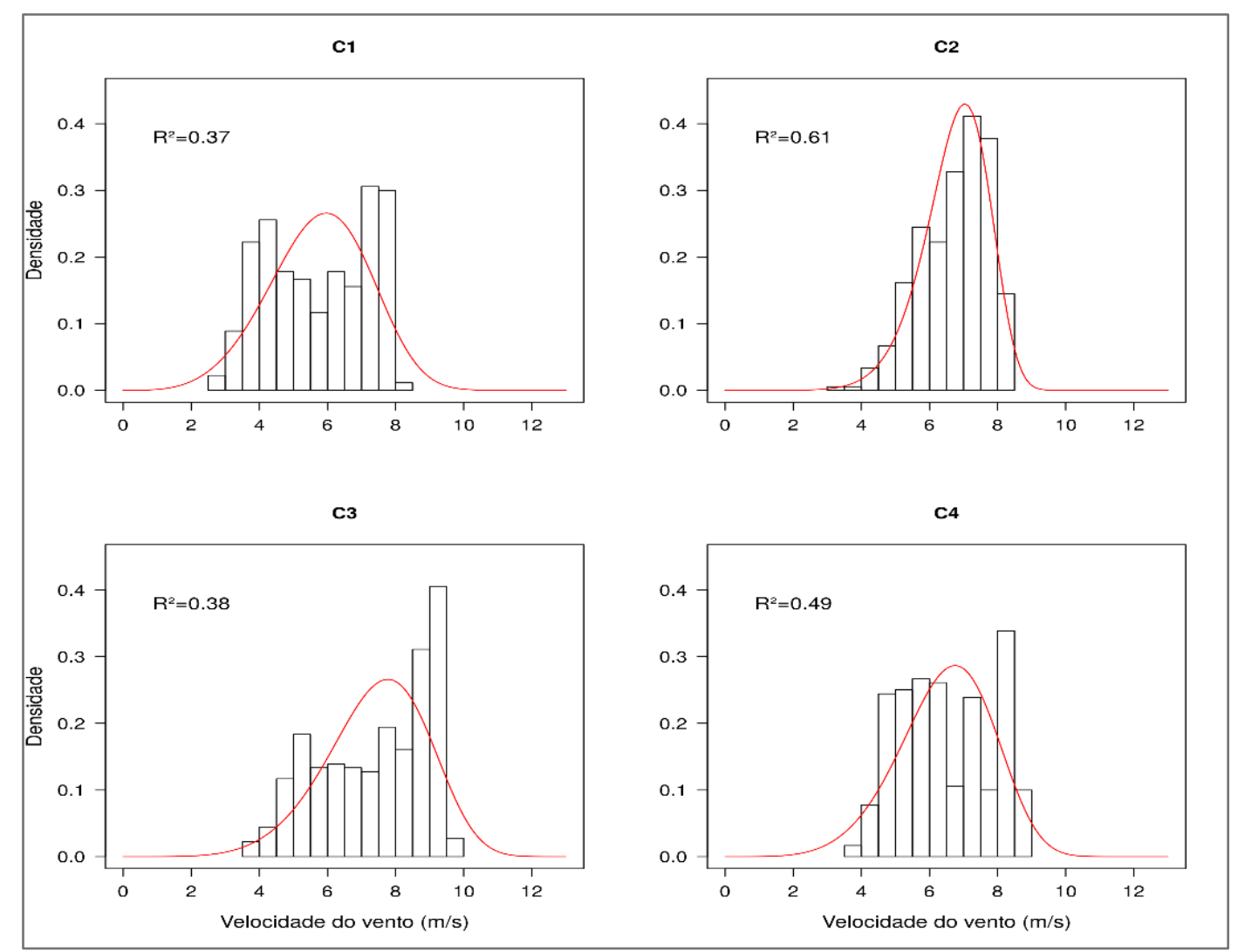

Figura 25 - Distribuição de probabilidade dos valores mensais de velocidade do vento a $100 \mathrm{~m}$ de altura do RegEns para o futuro próximo (2031 a 2060) para os subdomínios C1, C2, C3 e C4. O ajuste da PDFw às medidas de vento está representado pela curva em vermelho e as estatísticas ( $R^{2}$, parâmetros de forma $k$ e de escala c) do ajuste sumarizados no canto esquerdo superior. 


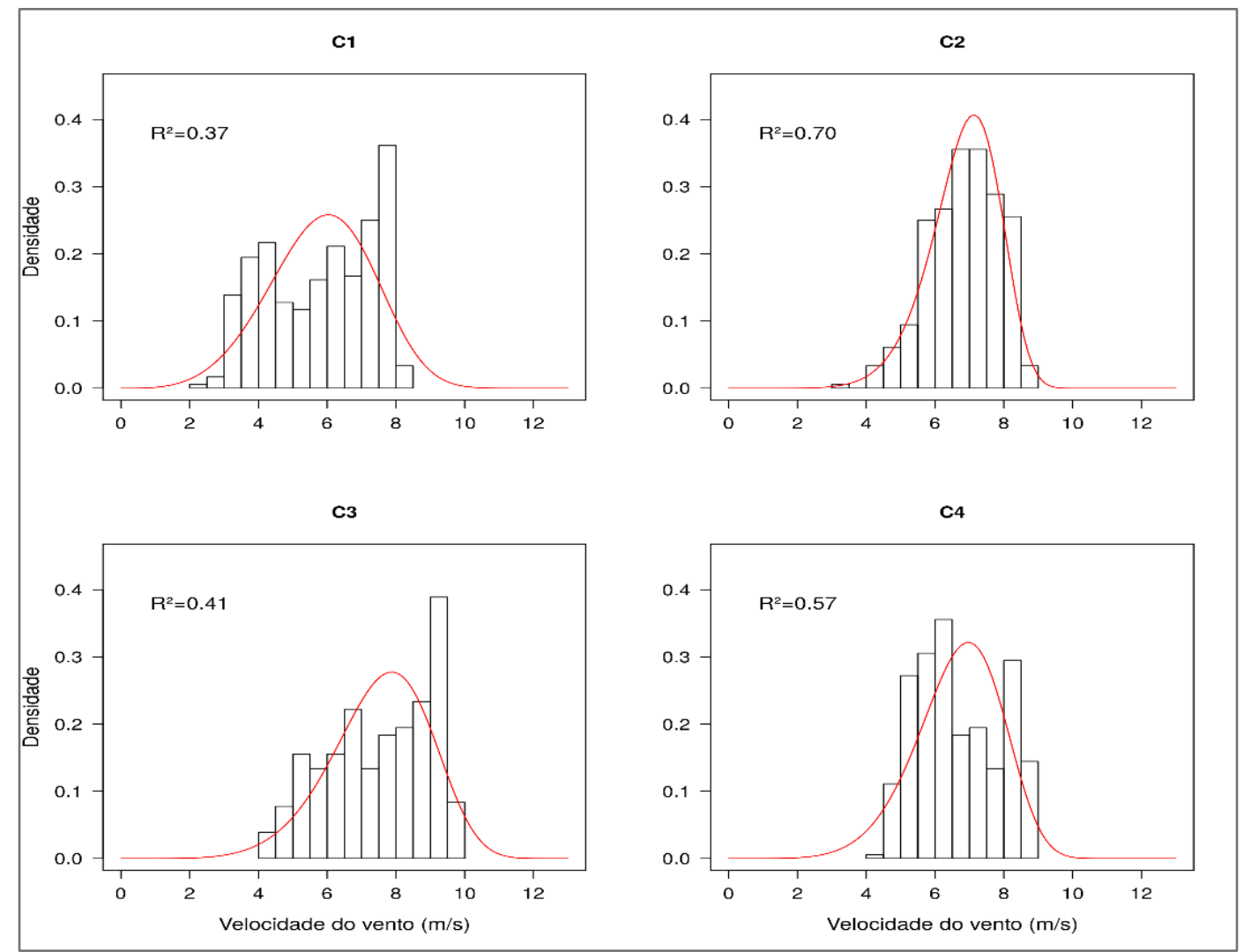

Figura 26 - Idem a Figura 24, mas para o futuro distante. 